\title{
ADDRESSING FORESTRY
} AND AGROFORESTRY IN NATIONAL ADAPTATION PLANS

[ Supplementary guidelines ] 
ADDRESSING FORESTRY ANDAGROFORESTRY IN NATIONALADAPTATIONPLANS

\section{[ Supplementary guidelines ]}

NOVEMBER 2020

By Alexandre Meybeck and Vincent Gitz

CGIAR Research Program on Forests, Trees and Agroforestry

and

Julia Wolf and Theresa Wong

Food and Agriculture Organization of the United Nations

Published by Food and Agriculture Organization of the United Nations and Center for International Forestry Research

Rome, 2020 
Required citation:

Meybeck, A., Gitz, V., Wolf, J. and Wong, T. 2020. Addressing forestry and agroforestry in National Adaptation Plans - Supplementary guidelines. Bogor/Rome. FAO and CIFOR. https://doi.org/10.4060/cb1203en

The designations employed and the presentation of material in this information product do not imply the expression of any opinion whatsoever on the part of the Food and Agriculture Organization of the United Nations (FAO) or the Center for International Forestry Research (CIFOR) concerning the legal or development status of any country, territory, city or area or of its authorities, or concerning the delimitation of its frontiers or boundaries. The mention of specific companies or products of manufacturers, whether or not these have been patented, does not imply that these have been endorsed or recommended by FAO, FTA, CGIAR or CIFOR in preference to others of a similar nature that are not mentioned.

The views expressed in this information product are those of the author(s) and do not necessarily reflect the views or policies of FAO, FTA, CGIAR or CIFOR.

ISBN 978-92-5-133367-9 [FAO]

CFAO, 2020

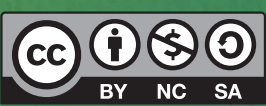

Some rights reserved. This work is made available under the Creative Commons Attribution-NonCommercial-ShareAlike 3.0 IGO licence (CC BY-NC-SA 3.0 IGO; https:// creativecommons.org/licenses/by-nc-sa/3.o/igo).

FAO encourages the use, reproduction and dissemination of material in this information product. Except where otherwise indicated, material may be copied, downloaded and printed for private study, research and teaching purposes, or for use in non-commercial products or services, provided that appropriate acknowledgement of FAO as the source and copyright holders is given and that FAO's endorsement of users' views, products or services is not implied in any way.

All requests for translation and adaptation rights, and for resale and other commercial use rights should be made via www.fao.org/contact-us/licence-request or addressed to copyright@fao.org.

FAO information products are available on the FAO website (www.fao.org/publications) and can be purchased through publications-sales@fao.org. 


\section{Contents}

FOREWORD

ACKNOWLEDGEMENTS

ACRONYMS

1 INTRODUCTION

2 OVERVIEW OF THE NATIONAL ADAPTATION PLAN (NAP) PROCESS

2.1 Guiding principles

2.2 Integrative Framework for National Adaptation Plans and Sustainable Development Goals: the NAP-SDG iFrame

2.3 Relations between NAPs, NDCs, other programmatic documents and national and subnational policies and measures

2.4 Insight on NAP processes in countries

3 WHY AND HOW TO ADDRESS FORESTS, TREES AND AGROFORESTRY IN NAPS?

3.1 Forests and other systems with trees

3.2 Ecosystem services provided by forests and trees

3.3 Impacts of climate change on forests and trees

3.4 Relations between forests and vulnerable systems

4 INSTITUTIONAL ARRANGEMENTS TO ADDRESS FORESTS AND TREES IN NAPS

4.1 Establishing an adaptation process for forests and trees $\mathbf{2 9}$

4.2 Liaise with other agriculture subsectors

4.3 Organize the participation of the forestry sector in the national adaptation planning, including clarifying mandates and engaging stakeholders

\section{LAYING THE GROUNDWORK} AND ADDRESSING GAPS

5.1 Take stock of existing forest sector knowledge and policies and identify gaps

5.2 Assess capacity needs and develop capacities for forest and trees-related adaptation planning

5.3 Assess and identify links between adaptation needs and development goals

41

\section{PREPARATORY ELEMENTS}

6.1 Analyse current and future climate scenarios in relation to forests and forest dependent people

6.2 Identify and assess vulnerabilities of forests, trees and forest dependent people to climate change

6.3 Identify where forests and trees can contribute to strengthen climate change adaptation in identified vulnerable sectors

6.4 Identify adaptation options for forests, tree systems and forest dependent people

6.5 Identify how to improve the enabling environment

6.6 Compile and communicate perspectives about forests and trees

6.7 Review the integration of climate change adaptation in national and subnational forest strategies, programs and plans

\section{IMPLEMENTATION STRATEGIES}

7.1 Ensure appropriate priorities for forests and trees in the NAP

7.2 Putting in place the means to enable transformational change

7.3 Mobilize financial resources 
7.4 Improve capacity for planning and implementing adaptation for forests and tree systems

7.5 Promote coordination and synergy at national and subnational levels

\section{REPORTING, MONITORING AND REVIEW}

8.1 Prepare for monitoring adaptation planning and implementation

8.2 Monitors implementation and update the NAP

8.3 Outreach on the process and report on progress and effectiveness

\section{CONCLUSION}

ANNEXES

Annex 1. Glossary

Annex 2. Check-list of stock-taking elements

86

Annex 3. Knowledge tools

Annex 4. Sub-steps and methodologies to prioritize adaptation optionsg adaptation actions

REFERENCES

\section{TABLES, FIGURES\& BOXES}

\section{TABLES}

1. Correspondence between the NAP technical guidelines and the supplementary guidelines

2. Example of measures to increase forest resilience to various impact of climate change

A. Summary features of key (economic) decision-support methods for choosing climate adaptation actions

B. An example summary table of prioritized adaptation actions according to their benefits and costs

\section{FIGURES}

1. Sample process to formulate and implement NAP

2. Forest and land-use transition curve

3. Potential contributions of forests, trees and agroforestry to the adaptation of other sectors/systems

4. Possible process flow for addressing the agriculture sectors in the formulation and implementation of NAPS

5. Forest managers respond to a wide range of factors

A. A (simplified) decision tree of possible approaches for assessing the costs and benefits of adaptation options

\section{BOXES}

1. Uganda's NAP for Agriculture

2. Adaptation Dialogues for identifying climate risks and actions in Uruguay's NAP-Ag process

3. Definitions used for FAO's forest resources assessments $\mathbf{1 8}$

4. Example questions for assessing forestry institutional capacity for climate change adaptation planning

5. Kenya national drought management authority capacity needs assessment for NAP

6. Extract of Indonesia's NDC

7. Forest dependent people

8. A gender-responsive agriculture NAP progress in Uganda 50

9. Forestry in Uganda's NAP for agricultureg

10. Assessing the financial and economic viability of agroforestry -related adaptation options for Kenyan farmers

11. Fostering linkages between National Adaptation Plans (NAPs) and Nationally Determined Contributions (NDCs) to enhance agriculture sector adaptation planning in Viet Nam

12. The development of an agroforestry policy in Nepala 71

13. Integrating landscape-based approaches in the adaptation planning process in the Philippines

14. The Global Forest Resources Assessment (FRA) 78

15. Assessing sectors' adaptation by steps in Finland 79

A. Examples of generic criteria of importance against which possible adaptation options can be evaluated 


\section{Foreword}

\section{ADDRESSING FORESTRY AND AGROFORESTRY IN NATIONAL ADAPTATION PLANS [ Supplementary guidelines ]}

Forests and trees are greatly impacted by climate change all around the world. Changes in temperature and precipitation, storms, pest outbreaks and the increasing risk of more frequent and intense fires are threatening forests and the livelihoods of the 1.6 billion people who depend on them.

We face a huge challenge, not only to contain global warming but also to cope with the consequences we have already seen and those to come. The COVID-19 pandemic has revealed the vulnerabilities of our societies and food systems, bringing to the forefront the need to build resilience in order to be prepared for new risks.

Acting at the interface between natural resources and human activities, forests, trees and agroforestry provide numerous nature-based solutions to adaptation. For this reason, adaptation will play a major role in the history of climate change and forests. As shown in this publication, forests need to adapt and become more resilient so they can continue to deliver crucial ecosystem services, including those on which other agriculture sectors depend - including crops, livestock, and fisheries. By helping to prevent flooding and erosion for example, forests offer a range of benefits, including to urban areas and cities, and contribute to the adaption of infrastructure, economies and people. However, in order to realize their adaptation potential, forests and trees need visibility on the areas that will stay forests in the future, stability of tenure, as well as long-term investments.
As the importance of adaptation gained increased global recognition, the international community established the National Adaptation Plan (NAP) process for Least Developed Countries (LDCs) and for other developing countries. Indeed NAPs are considered to be a core vehicle for delivering on adaptation priorities as well as countries' nationally determined contributions (NDCs) under the Paris Agreement. The NAP process considers interactions between all sectors - and their implications on planning and implementation - in a coordinated and coherent way, offering considerable opportunities for a more holistic approach to land use and landscapes -

a prerequisite for effective adaptation.

Further to the call for countries to incorporate forests into their NAPs, develop policies for adaptation through forests, take action to improve forest health and to restore degraded forests and landscapes, made by the FAO Committee on Forestry in 2018, FAO and the CGIAR Research Program on Forests, Trees and Agroforestry partnered to prepare these supplementary guidelines specifically on forests, trees and agroforestry.

These new guidelines, developed through a consultative process involving experts from countries, international agencies and research organizations, build upon lessons learned in addressing climate change adaptation related to the agriculture sectors. 
With the adoption of the 2030 Agenda for Sustainable Development and the Paris Agreement, the international community has pledged to ambitious collective objectives. Land use is key to all of these ambitions, especially to the commitments made by countries as set out in their nationally determined contributions. Due to their important role in mitigation, for adaptation, for sustainable management of natural resources and for food security, forests and trees are at the heart of such an integrated approach.
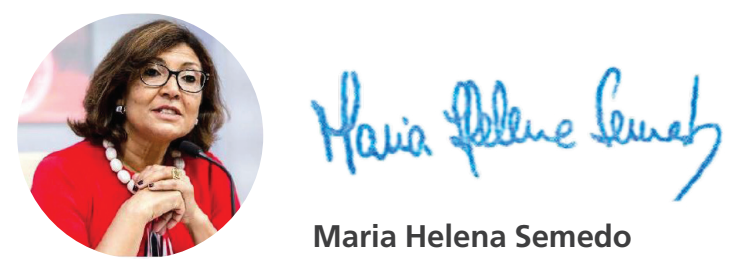

Maria Helena Semedo FAO Deputy Director-General
We hope that this publication will provide support and guidance for countries and other stakeholders to integrate and prioritize these objectives within climate change adaptation and other relevant planning processes.
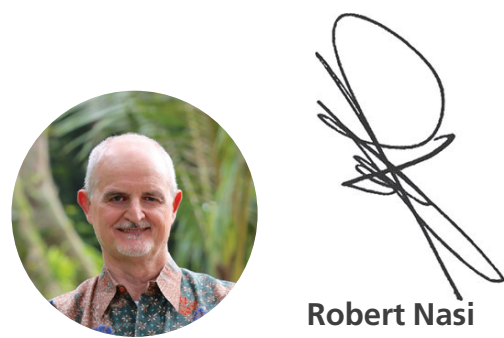

CIFOR Director General 


\section{Acknowledgements}

The authors of the Addressing agriculture, forestry and agroforestry in National Adaptation Plans:

Supplementary guidelines guidelines are Alexandre Meybeck and Vincent Gitz of the CGIAR Research Program on Forests, Trees and Agroforestry (FTA), led by the Center for International Forestry Research (CIFOR) and Julia Wolf and Theresa Wong of the Food and Agriculture Organization of the United Nations (FAO). This publication was prepared and written in collaboration with the FTA and the Forestry department andthe Office of Climate Change, Biodiversity and Environment (OCB) of FAO.

The authors would like to acknowledge the contributions made by the following FAO experts: Simone Borelli, Michela Conigliaro, Rocío CóndorGolec, Krystal Crumpler, Jose Diaz, Elisa Distefano, Claudia Garcia, Cecilia Jones, Paul Maina Guthiga, Willy Kakuru, Daniela Kalikoski, Constance Miller, Peter Moore, Sibyl Nelson, Shanali Pethiyagoda, Simmone Rose, Shiroma Sathyapala, Andrew Taber and Victoire De Wever.

The authors would also like to acknowledge the following researchers from FTA: Christopher Martius (CIFOR), Meine van Noordwijk (ICRAF), Marlene Elias (Bioversity), Houria Djoudi (CIFOR), Roeland Kindt (ICRAF), Beria Leimona (ICRAF),
Lasisa A. Duguma (ICRAF), Bruno Locatelli (CIRAD/ CIFOR), Daniel Murdiyarso (CIFOR), Yves Laumonier (CIRAD/CIFOR), Catherine Muthuri (ICRAF), Eduardo Somarriba (CATIE), Bimbika Sijaparti Basnett (CIFOR), Aster Gebrekirstos (ICRAF), Chris Kettle (Bioversity), Thanglong Trinh (INBAR), Herman Savenije (Tropenbos), Peter Minang (ICRAF), Fergus Sinclair (ICRAF), Ramni Jamnadass (ICRAF) and Pablo Pacheco (CIFOR).

Finally, the authors would like to express their gratitude for the contributions of the experts who participated in the consultations hosted by GIZ on 2 May 2018 in Bonn, Germany, as well as the consultations organized during NAP Expo 2019 in Incheon, Korea.

An earlier version of this publication benefitted from the advice and peer-review of the following experts: Ali Raza Rizvi, Suzan Braatz, Janie Rioux and Michael Huettner. Their precious time is deeply appreciated. The final content remains the sole responsibility of the authors.

We would also like to express our gratitude to Rebecka Ramstedt for advising on the communications for the guidelines and related work, as well as Art\&Design srl for the design and layout. 


\section{Acronyms}

\begin{tabular}{|c|c|}
\hline CBD & Convention on Biological Diversity \\
\hline $\mathrm{COP}$ & Conference of Parties \\
\hline $\mathrm{CSO}$ & Civil society organization \\
\hline DRM & Disaster risk management \\
\hline DRR & Disaster risk reduction \\
\hline EbA & Ecosystem-based adaptation \\
\hline FAO & Food and Agriculture Organization of the United Nations \\
\hline GEF & Global Environment Facility \\
\hline GCF & Green Climate Fund \\
\hline GHG & Greenhouse gas \\
\hline INDC & Intended nationally determined contribution \\
\hline IPCC & Intergovernmental Panel on Climate Change \\
\hline IUCN & International Union for the Conservation of Nature \\
\hline LDC & Least Developed Country \\
\hline LEG & Least Developed Countries Expert Group \\
\hline MAAIF & Ministry of Agriculture, Animal Industry and Fisheries \\
\hline MGAP & Ministry of Livestock, Agriculture and Fisheries \\
\hline MARD & Ministry of Agriculture and Rural Development \\
\hline NAP & National Adaptation Plan \\
\hline NAPA & National Adaptation Programmes of Action \\
\hline NDC & Nationally determined contribution \\
\hline
\end{tabular}




\begin{tabular}{l|l} 
NDMA & $\begin{array}{l}\text { Kenya National Drought Management Authority } \\
\text { nfp }\end{array}$ \\
NGO & National forest programme \\
NWFP & Non-governmental organization \\
REDD+ & Reducing emissions from deforestation and forest degradation \\
SBSTA & Subsidiary Body for Scientific and Technological Advice \\
SDGs & Sustainable Development Goals \\
SFM & Sustainable forest management \\
SIDS & United Nations Convention to Combat Desertification \\
UNCCD & United Nations Development Programme \\
UNDP & United Nations Framework Convention on Climate Change \\
UNFCCC &
\end{tabular}




\section{- Introduction}

Climate change discussions about forests and trees have for a long time focused mainly on their mitigation potential. However, the mitigation potential of forests and trees also depends on their capacity to adapt to a changing climate as well as to increased human pressure. Moreover, forests and trees play a crucial role in the resilience of landscapes and people as well as in their capacity to adapt to climate change. The National Adaptation Plan (NAP) process offers an opportunity to better integrate these roles in national strategies and policies.

The contribution of forests and trees to both adaptation and mitigation is linked to, and depends upon, numerous sector policies that orient land and water use such as those for land planning, water management, energy, building, and agriculture. Due to the fact that it is economy-wide, the NAP process gives the opportunity to examine the interactions between all economic sectors in a coordinated and coherent way. In fact, effective adaptation entails integrating such interactions and draw consequences for planning and implementation. The purpose of this publication is to facilitate the integration of forests, trees and agroforestry in such a process.

This publication Addressing Forestry and Agroforestry in National Adaptation Plans: supplementary guidelines provides technical guidance on the integration of forests, agroforestry and trees in the formulation and implementation of NAPs. It aims to inform policy makers and government officers responsible for NAP planning and processes, as well as forestry stakeholders and other interested actors, on the needs of forestry and agroforestry for adaptation and their potential to support the adaptation of other sectors, subsectors and activities.

These supplementary guidelines therefore aim to:

- show the need for adaptation of forests and trees;

- show the importance of forests and trees for adaptation; show the need to appropriately integrate forest and trees in the NAP process;

PUERTO MALDONADO, MADRE DE DIOS, PERU

A Brazil nut processing. (C)FOR/Marco Simola

- support NAP practitioners in integrating the management of forest and trees in NAPs; 
- support actors in the forestry and agriculture sectors in their engagement and contribution to the process, at national, economy wide level, and both locally and in their sector/value chain; and

- trigger and facilitate a forward-looking intersectoral policy dialogue that fully integrates forests and trees in adaptation planning of all sectors.

This publication has been designed for organizations and individuals involved in national adaptation planning and activities, both from the forestry sector and from other sectors that may benefit from forests and trees for their adaptation, or that have an influence on their capacity to adapt.

This publication complements two other key documents related to national adaptation planning: first, the NAP Technical Guidelines prepared by the Least Developed Countries Expert Group (LEG) of the United Nations Framework Convention on Climate Change (UNFCCC, 2012), and second, the cross-sectoral guidance Addressing agriculture, forestry and fisheries in National Adaptation Plans Supplementary guidelines prepared by FAO (referred to here as "NAP-Ag Guidelines") (Karttunen et al., 2017). It will be complemented by the upcoming Addressing Fisheries and Aquaculture in National Adaptation Plans (FAO, forthcoming).

It mobilizes the existing body of knowledge related to forest management, vulnerability assessments and climate change adaptation, building upon the experience of FAO and the Forests, Trees and Agroforestry research program of the CGIAR (FTA). In order to effectively address the needs of countries, the publication also relies on an analysis of the NAPs already published and comparable documents prepared by developed countries or subnational authorities. The publication has benefitted in particular from the NAP-Ag program and the recommendations of the LEG as well as from consultations involving technical experts and key stakeholders from civil society organizations, non-governmental organizations, the private sector and international organizations.

Given the multiple links of forests, trees and agroforestry with other activities and sectors, the contributions they make to their adaptation as well as to multiple Sustainable Development Goals (SDGs), this publication adopts a systemic approach following the Integrative Framework for National Adaptation Plans and Sustainable Development Goals (NAP-SDG iFrame) recently defined by the LEG. Such an approach helps integrate different assessment approaches into NAPs and allows for more explicit consideration of how to address the SDGs through NAPs.

This publication sets the stage by providing an overview of the NAP process (Chapters 1 and 2) and highlighting the importance of integrating forests and trees in the formulation and implementation of NAPs (Chapter 3). It then provides indicative forests, trees and agroforestry related activities in NAPs, organized in line with the four elements of the UNFCCC NAP Technical Guidelines (see Table 1): (i) element A, laying the groundwork and addressing gaps (Chapters 4 and 5); (ii) element B, preparatory elements (Chapter 6); (iii) element C, implementation strategies (Chapter 7); and (iv) element D, reporting, monitoring and review (Chapter 8).

\section{TABLE 1.}

\section{Correspondence between the NAP technical guidelines and the supplementary guidelines}

\begin{tabular}{|l|l|l|}
\hline UNFCGC NAP TECHNICAL GUIDELINES & & $\begin{array}{l}\text { ADDRESSING FORESTRY AND AGROFORESTRY IN NATIONAL ADAPTATION } \\
\text { PLANS: SUPPLEMENTARY GUIDELINES }\end{array}$ \\
\hline Element A. Lay the groundwork and address gaps & $\rightarrow$ & Chapters 4 and 5 \\
\hline Element B. Preparatory elements & $\rightarrow$ & Chapter 6 \\
\hline Element C. Implementation strategies & $\rightarrow$ & Chapter 7 \\
\hline Element D. Reporting, monitoring and review & $\rightarrow$ & Chapter 8 \\
\hline
\end{tabular}




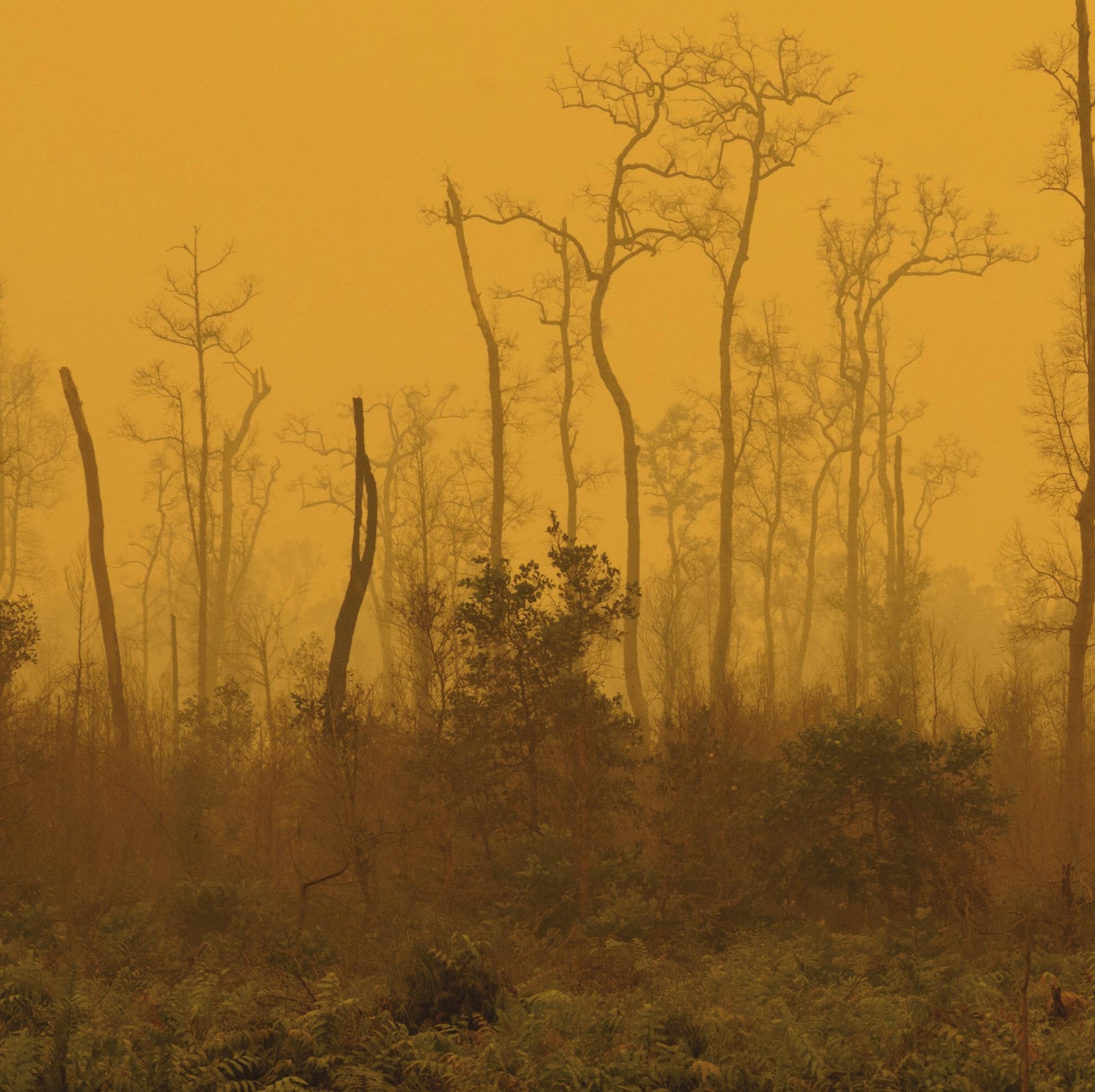




\section{Overview of the National Adaptation Plan (NAP) process}

\author{
The purpose of this \\ chapter is to frame \\ the consideration \\ of forests and \\ trees within the \\ perspective of \\ the NAP process \\ as defined by the \\ UNFCCC and as \\ implemented by \\ countries through \\ specific national \\ processes and \\ orientations.
}

\subsection{Guiding principles}

The NAP process was established under the UNFCCC as part of the Cancún Adaptation framework adopted in 2010 at the sixteenth session of the UNFCCC Conference of the Parties (COP 16). The purpose of the NAP process is for Least Developed Countries (LDCs) and other developing countries to identify medium- and long-term adaptation needs and to develop and implement strategies and programmes to address those needs (Decision 1/CP.16).

The objectives of the NAP process, agreed upon at COP 17 (Decision 5/CP.17) are: i) to reduce vulnerability to the impacts of climate change, by building adaptive capacity and resilience; and ii) to facilitate the integration of climate change adaptation, in a coherent manner, into relevant new and existing policies, programmes and activities, in particular development planning processes and strategies, within all relevant sectors and at different levels, as appropriate.

Decision 5/CP.17 enumerates guiding principles for the NAP process:

- continuous planning process at the national level with iterative updates and outputs;

- country-owned, country-driven;

- not prescriptive, but flexible and based on country needs;

- building on and not duplicating existing adaptation efforts;

- participatory and transparent;

- enhancing coherence of adaptation and development planning;

- supported by comprehensive monitoring and review;

- considering vulnerable groups, communities and ecosystems;

- guided by best available science;

- taking into consideration traditional and indigenous knowledge; and

- gender-sensitive. 
Initial guidelines for the formulation of NAPs are contained in the annex of decision 5/CP.17. They are complemented by the Technical guidelines for the NAP process, which were developed by the LEG in response to decision 5/CP.17 paragraph 15 and are available in multiple languages ${ }^{1}$. These technical guidelines provide the basis for the formulation and implementation of NAPs (see Figure 1).
Supplements to the guidelines have been developed for various sectors and are available on NAP Central $^{2}$. The supplement on the agriculture sectors prepared by FAO as part of the NAP-Ag programme, as well as the Guidelines to Support the Integration of Genetic Diversity into Climate Change Adaptation Planning and NAPs are of particular interest to the forestry sector. Also, the guidelines on biodiversity (CBD, 2014) and those on water (GWP, 2019) are of particular relevance.

\section{FIGURE 1.}

\section{Sample process to formulate and implement NAP}

Element A:

lay the groundwork and address gap

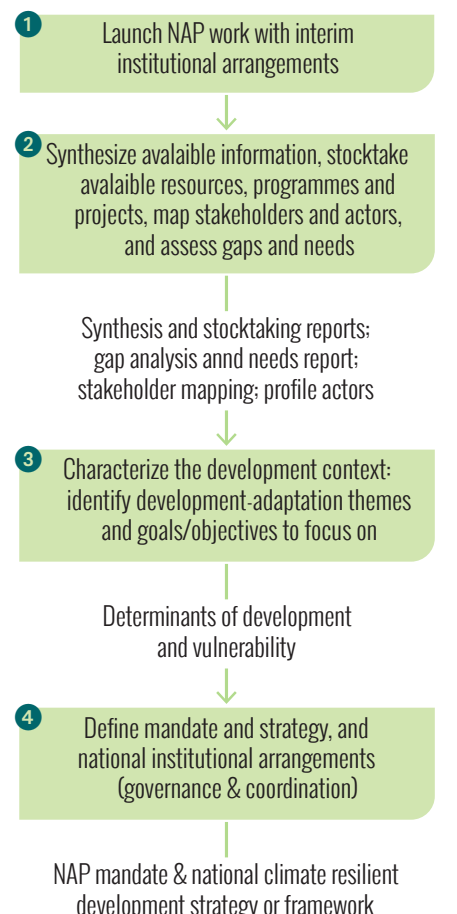

development strategy or framework

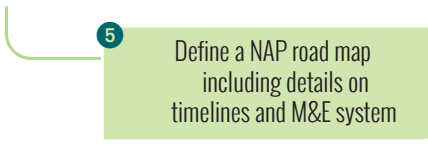

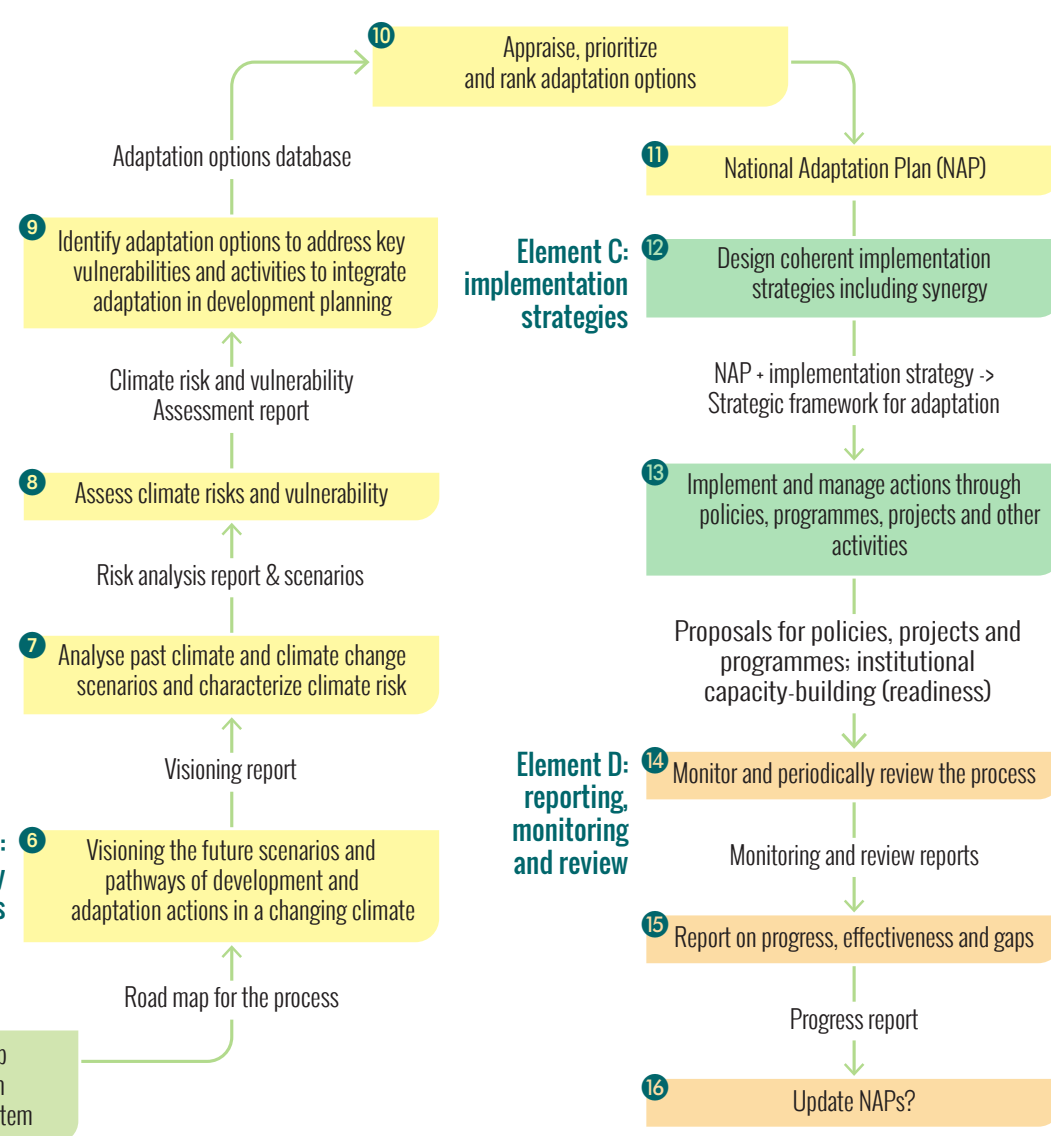

Source: LEG, 2012

1 Access them here: https://www4.unfccc.int/sites/NAPC/Guidelines/Pages/Technical-guidelines.aspx

2 Access them here: https://www4.unfccc.int/sites/NAPC/Guidelines/Pages/Supplements.aspx 
2.2 Integrative Framework for National Adaptation Plans and Sustainable Development Goals: the NAP-SDG iFrame

The Paris Agreement provides a global goal on adaptation in Article 7, which is as follows: enhancing adaptive capacity, strengthening resilience and reducing vulnerability to climate change with a view to contributing to sustainable development, and ensuring an adequate adaptation response in the context of the goal of limiting the average global temperature increase to less than $2^{\circ} \mathrm{C}$.

Therefore, the agreement integrates its contribution to sustainable development as part of the adaptation goal. Most countries that have integrated an adaptation component in their nationally determined contribution ${ }^{3}$ (NDC) have defined a long-term goal or vision to guide it (UNFCCC, 2015). These goals are closely intertwined with development objectives such as poverty eradication, economic development or improvement of living standards, security and human rights; in some cases, mentioning explicitly the Sustainable Development Goals (SDG). Several developing countries mentioned the objective of becoming an emerging country with a middleincome economy by 2030. For instance, the NDC of Ethiopia combines ambitious objectives for development, mitigation and adaptation with a central place given to the agriculture sectors, including protecting and re-establishing forests for their economic and ecosystem services, with a target of more than 7 million hectares afforested or reforested.

Such development objectives and goals are likely to orient the preparation of the corresponding NAPs. In fact, as the NAP is a broad national process oriented towards the future, it needs to take national medium- and long-term objectives into account. Contrary to the National Adaptation Programmes of Action (NAPA) that address the most urgent needs of the LDCs, the NAPs are longterm and therefore need to take into consideration the adaptation of a country that is itself evolving.

For these reasons, considering also the intrinsic links between adaptation and the achievement of the SDGs, the LEG invites countries to adopt an Integrative Framework for National Adaptation Plans and Sustainable Development Goals, the NAP-SDG iFrame, to help integrate approaches and the explicit consideration of how to contribute to addressing the SDGs through NAPs (UNFCCC, 2017).

The LEG notes that integrative systems approaches are helpful in addressing the coherence and synergy of adaptation action at multiple scales and levels, including over time, considering other relevant frameworks such as the SDGs and the Sendai Framework for Disaster Risk Reduction 2015-2030 (UNFCCC, 2018). A systems' approach to adaptation can greatly facilitate and strengthen the integration of forestry in NAPs, leveraging its potential for transformational change. Forests and other tree formations need themselves to be apprehended as systems.

Forests and trees are closely linked to, and often integrated with, other agricultural systems. Through the ecosystem services they provide, forests are also linked to several other broad systems: biodiversity, water, energy production, human settlements, to use the themes identified by countries themselves (see section 3.4).

Due to the depth of interrelations between forests and trees with other systems, adopting a systems' approach to adaptation allows for a more effective consideration of the contributions of forests and trees. Moreover, it facilitates the articulation of the different scales where different sectors/ systems interact, in particular landscapes and even households. Finally, it enables countries to appropriately take into account the institutional, economic and social environment that determines these various relations. This is especially important in order to identify social vulnerabilities, levers of/ constraints to change as well as potential outcomes of adaptation measures. and the distribution of costs and benefits.

3 NDCs embody efforts by each country to reduce national emissions and adapt to the impacts of climate change. The Paris Agreement (Article 4, paragraph 2) requires each Party to prepare, communicate and maintain successive NDCs that it intends to achieve. 
Such an integrated systems approach also facilitates the inclusion in adaptation planning of various objectives and commitments regarding forests and land restoration such as those deriving from the SDGs, Paris Agreement, UN Strategic Plan for Forests 2017-2030 and from the Bonn Challenge on forest landscape restoration.

\subsection{Relations between NAPs, NDCs, other programmatic documents and national and subnational policies and measures}

As previously stated, one of the objectives of the NAP process is to facilitate the integration of climate change adaptation in a coherent manner into relevant new and existing policies, programmes and activities, especially development planning processes and strategies, in all relevant sectors and at different levels, as deemed appropriate. In fact, as indicated by the NAP-SDG iFrame, such an objective can be best served if an integrative systemic approach to sectors and actors, and to adaptation, is adopted.

The NAP is the vehicle for aligning adaptation with other goals and measures, in particular those related to the SDGs, climate change mitigation objectives, as well as broad national development strategies. Countries have expressed their commitment to addressing climate change in their NDC. Implementation will require that countries either modify existing national policies and measures or adopt new ones. In many cases countries have explicitly mentioned the realization of a NAP in their NDC - the NAP can be a major vehicle for the implementation of adaptation commitments (see example of Vietnam in box 11). Many countries have also made in their NDC a commitment to mitigation through forestry and in some cases have explicitly made the link between mitigation and adaptation for forestry.
Other commitments have been made in the NDCs for the restoration of degraded land. All these commitments may also contribute to the achievement of other global objectives.

Because it aims to modify or create policies and measures, often at different levels of government and involving various sectors and categories of actors, the effectiveness of the NAP process depends in fact on its capacity to influence and modify other processes. Of particular importance here is therefore the way the process can facilitate coordination within and between sectors and relevant policies as well as between different levels of government and between actors both inside the sector and with linked ones.

\subsection{Insight on NAP processes in countries}

Most developing countries are in the process of preparing their NAP, in fact, 20 of them have already transmitted a NAP to the UNFCCC secretariat 4 . In addition, numerous developed countries have prepared adaptation plans. These documents provide a first look at the different approaches taken by countries, including how NAPs can be linked to other strategies, how they are prepared and organized by sectors or regions, and how forestry is represented.

NAPs often make an explicit reference to other pre-existing national climate change documents as well as to development strategies and plans. In many cases, and especially for NAPs that have been among the firsts to be completed, the process built on earlier climate change strategies and plans. In such cases the NAP may be part of a broader climate change strategy or plan. For instance, Sri Lanka already had, at the time of finalization of its NAP, a National Climate Change Policy, adopted in 2012, and a National Climate Change Adaptation Strategy (2011-2016). It thus specified that the NAP is a rolling plan with a set of implementable actions. It is focused on practical interventions; the strategies and principles being already stated in previous documents.

4 At 2 June 2020. Available on the NAP portal periodically updated: https://www4.unfccc.int/sites/NAPC/Pages/national-adaptation-plans.aspx 
Several other countries, explicitly or implicitly, articulate broader principles and strategies, that may figure already in another climate change document, and more practical interventions, to be included in the NAP. Such a focus on practical actions may also be linked to the expected possibilities of specific international sources of additional financing.

Within their NAP, countries generally distinguish cross-cutting needs and activities, and sectoral ones. Such a distinction can lead to having a general section (or document) with principles and crosscutting issues and activities and sectoral sections (or documents), which often form the bulk of the NAP. In some countries, such as in Brazil and Chile, these sections constitute separate documents. In other cases such as Palestine and Sudan, the NAP adopts a sub-national (regional) structure. For example, Sudan's NAP starts from an analysis of vulnerabilities with proposed adaptation measures conducted at the state (subnational) level, with the explicit objective to have as a major focus of the plan a better understanding of adaptation challenges at state level. Some countries, like Colombia, adopt both approaches: a national plan and regional plans in the process of being prepared. In addition, most NAPs integrate the possibility of having actions that are subnational, in particular on topics where the competency has been devolved at a subnational level of government (Kenya for instance). Some national adaptation plans are organized to serve as a framework and background for subnational plans (Australia, Canada for instance).

When the NAP is organized by sectors (see example in Box 1), these sectors are generally chosen because of their particular vulnerability to climate change and/or their role in the overall adaptation of the country. The sectors and their precise delineation are generally adapted to correspond to specific line ministries to facilitate preparation and implementation of the plan.

\section{BOX 1.}

\section{Uganda's NAP for Agriculture}

The National Adaptation Plan for the Agricultural Sector in Uganda was launched in November 2018 and is the country's plan for the integration of agricultural sector priorities and concerns into the overall Uganda NAP (MAAIF, 2018). The Plan was initiated in January 2015 by the Climate Change Task Force within the Ministry of Agriculture, Animal Industry and Fisheries (MAAIF) in coordination with the Ministry of Water and the Environment, as well as the Ministry of Finance, Planning and Economic Development. Technical and financial support came from the FAO project Global Climate Change Alliance (FAO and EU) and the NAP-Ag programme.

The plan contains 21 costed, prioritized adaptation options in the following areas: fisheries management climate information; early warning and disaster preparedness; forestry, land and natural resources management; and research and knowledge management. A cost-benefit analysis was used for the prioritization of different actions.

Uganda's NAP for agriculture was formulated in coherence with the NAP Technical Guidelines. First, a draft action framework for the agriculture sector was prepared, followed by guidelines to national and provincial planners for mainstreaming climate change into agriculture sector plans. An effort has been made to learn from the experience of Uganda's NAPA (2007) as well as the overall vision of the National Climate Change Policy. The major steps were: 
stocktaking to identify available information on climate impacts and vulnerability to identify entry points for climate change adaptation in the agriculture sector;

- training on tools for appraising adaptation options for parliamentarians, youth groups, planners at the central and district levels, and non-state actors to enhance capacity for appraising adaptation options, gender analysis and mainstreaming of gender in plans and adaptation; and

- stakeholder consultations to collect information on present and expected economic and social impacts of climate change.

\section{Key features of the Plan}

1. Consultation and inclusivity - From the beginning, a participatory and inclusive process was prioritized. Consultations were conducted among government officials at national and local levels from different sectors such as agriculture, environment, water, gender and youth; the private sector; development partners and civil society representatives. Participants from 6 districts of the central cattle corridor (Sembabule, Mubende, Kiboga, Luwero, Nakasongola and Nakaseke) were also included. The following activities were conducted:

- local government consultations identified agriculture sector priorities for consideration in the NAP, gathered experiences on NAPA implementation and good practices;

- visits to NAPA pilot projects generated lessons learnt from the implementation of adaptation technologies and NAPA projects initiated in 2007 to inform the NAP-Ag process; and

- consultative workshops (3-days) involving local governments and participants from the cattle corridor were used to share impacts and existing priority interventions, approaches and potential partners.

2. Towards a gender-responsive NAP - As gender was one of the eight priority themes, a gender capacity development strategy was formulated through a detailed needs assessment, tailored trainings and field visits so that decision-makers could better understand the challenges faced by male and female farmers (See Box 8).

3. An agro-ecological zone approach capturing lessons learnt. Learning from past adaptation projects the plan took the approach of defining adaptation actions for the different agro-ecological zones. This will guide farmers, technical officers and decision-makers on investments that are cognizant of upstream-downstream impacts of actions.

\section{Next steps}

The next stage is the implementation of the plan. Ongoing and future projects are expected to align their activities with recommendations. Also, new coordination arrangements have been recommended. The NAP for Agriculture proposes that the MAAIF's Climate Change Task force become formalized 
as a functional task force. An Agriculture Climate Change Coordination Unit (ACCU) will be formed to precise functions, implementing both the NAP and the country's Climate Smart Agriculture programme.

The plan will be updated every five years in coherence with the update cycle of the National Development Plan, while the MAAIF's planning cycle will integrate some of the key actions. Guidelines on gender-sensitive mainstreaming of climate change adaptation in local level plans, budgets and policies are being planned to be submitted to Parliament. They will include guides for different subsectors. Resource mobilization efforts are currently underway to leverage domestic and international funding sources to implement the plan and disseminate its findings. The NAP for Agriculture is the first sectoral NAP in Uganda and the lessons learnt during its development and implementation are being fed into the overall NAP process through engagement workshops and mainstreaming into projects.

Source: FAO \& UNDP. 2020a. Integrating Agriculture in National Adaptation Plans Case Study - Uganda, Rome

Forests are often included in the biodiversity/ ecosystem sector of the NAP, generally because in many countries the Ministry of Environment is responsible for forestry. For instance, in the Kenyan NAP one of the measures proposed for the environment sector is to prepare an adaptation plan for forests; another one is to strengthen tree-planting and conservation initiatives. Forests in Chile, for example, are included in the biodiversity plan of the NAP, but planted forests are part of the sylvoagropastoral plan. In most of the published NAPs, agroforestry is covered in the agriculture section of NAPs.

Countries have established specific institutional arrangements to prepare and implement their NAP. These arrangements generally rely on existing institutions, with the addition of dedicated coordination bodies and mechanisms at central level. In some cases, they are complemented by subnational coordination mechanisms.

In line with the objective of mainstreaming climate change adaptation in policies and budgets, countries generally rely on existing line ministries and agencies to handle the adaptation of their respective sectors, rather than on specialized institutions mandated for climate change across the board. For instance, the NAP of Cameroon describes in detail the roles and responsibilities involved in the implementation of the NAP of the various ministries, of the Parliament, of the different levels of the national administration, of local authorities, as well as of the private sector, civil society, traditional and religious authorities, media, research and academia.

The overall coordination of the preparation and implementation of most of the NAPs available when preparing this publication is done by the combination of a line ministry and a collegial body that gathers representatives from different ministries and agencies under the authority of a minister, often the ministry of environment or, in some cases, of the Prime Minister or Head of State. In many cases it is the collegial body that has the overall authority. In others it is the main line ministry, like in Sri Lanka, with the Climate Change Secretariat in the Ministry of Mahaweli Development and Environment, the collegial body having mainly the role of overseeing cross-cutting issues. The main line ministry is generally the one in charge of climate change policies, which is often the ministry of environment, but not always. In Finland, the Ministry of Agriculture and Forestry is responsible for coordinating the implementation of the National Climate Change Adaptation Plan and the various ministries are responsible for the implementation, monitoring and evaluation of the plan within their respective administrative branches. Often, the coordinating organizations are complemented by an advisory body, that can be an expert group or a council that includes representatives of civil society and of the private sector. 
The NAP coordination mechanisms often rely on pre-existing overall climate change coordination mechanisms. It is for instance the case for Sri Lanka with the coordinating role of the Climate Change Secretariat, including for the sectoral plans. It is also the case in Chile, where it is the Council of ministers for sustainability and climate change that approves the NAP, the sectoral plans and their modifications. In Cameroon the overall responsibility for the preparation and implementation of the NAP is exercised by the steering committee of the national process for Reducing Emissions from Deforestation and forest Degradation (REDD+), using existing structures. Such arrangements may facilitate the integration of synergies and trade-offs between mitigation and adaptation which are of particular importance for the agriculture sectors and especially for forestry.

NAPs are often not as detailed on the way the various sectors are organized. Responsibility seems generally to be vested in the line ministry in charge of the sector. In some cases, such as Sri Lanka, a defined role is also explicitly assigned to each sectoral entity by the overall leading entity.

Some NAPs explicitly mention forms of coordination and organization at the subnational level, either under the responsibility of subnational levels of the national administration or delegated to local authorities, depending on the institutional organization of the country. They can also mention explicit forms of coordination between regional and national levels; for instance, in Chile a regional focal point on climate change of the ministry of environment is in charge of the link with the department of climate change of the same ministry, while in Cameroon the regional and provincial coordination structures for adaptation report to the national steering committee.

Although the responsibility for the preparation and implementation of the NAP lies with the government, there are various forms of integration of non-governmental actors, in particular civil society and the private sector. At the central level, there is often an advisory body with representatives of civil society and the private sector. There are also cases of regional consultative councils, such as in Chile. Brazil organized a public consultation on a first draft of the plan and took into consideration the comments made to finalize it. In Uruguay the NAP process included stakeholder dialogues to identify risks and vulnerabilities (see Box 2). In its review of progress, the secretariat of the UNFCCC (2018) notes that even if the forms differ between countries, there is evidence of the engagement of civil society and other stakeholders throughout the process to formulate and implement NAPs. There is also evidence of the use of the knowledge and experience of local communities. A study conducted by Southern Voices on Adaptation (2018) in Cambodia, Kenya, Malawi, Nepal, Sri Lanka and Vietnam highlighted progress in participation and transparency. Participants in the study, while recognising that there are still many challenges to face, noted the positive impact that the decentralization of the process can make on participation and transparency.

\section{BOX 2.}

\section{Adaptation Dialogues for identifying climate risks and actions in Uruguay's NAP-Ag process}

In Uruguay, the National Adaptation Plan to Climate Variability and Change for the Agricultural Sector (NAP-Agro), launched in September 2019, is a strategic instrument that will help the country achieve the national adaptation and mitigation commitments established in its first NDC under the Paris Agreement, as well as contribute to the SDGs (MGAP, 2019). The development of the NAP-Agro involved a three-year stakeholder consultation process within and beyond the agriculture sectors (MGAP, 2019). Known as Adaptation Dialogues, these consultations helped to identify national adaptation priorities, challenges and responses to feed into the Plan. This process was led by the Office of Agricultural Programming and Policy of the Ministry of Livestock, Agriculture and Fisheries, in 
coordination with the National System of Response to Climate Change and Variability. Technical support was provided by UNDP and FAO, under the NAP-Ag programme.

Involving more than 200 people, these dialogues identified impacts of climate variability and change as well as priority adaptation strategies focusing on different productive systems, rural women and family farming. The dialogues held were on forestry, rice production, family farming, dairy system, gender.

The Dairy System Adaptation Dialogue was the first dialogue to be held. Participants identified three main climatic challenges at the farm-level: excess rainfall, water deficit and drought, and heat stress. The dialogue found there was a lack of tools and infrastructure to successfully adapt the dairy production system to climate change and variability. Furthermore, it showed there was a consensus that dairy production needed to adapt to the increased variability in climate and climate change, and that the system should be based on direct grazing in pastures with strategic farmproduced forage reserves used as diet supplements, with minimum out-offarm inputs. This system requires infrastructure for cooling and shading cattle during the summer; in addition, roads and surfaces are needed for channeling excessive rainfall and facilitating the movement of cattle and crops.

The dialogue also emphasized the importance of the social and economic aspects of dairy production. Overall, the shared view was that there was a need to develop production systems that attract younger generations to the farms. This ranged from automated systems that build in time for rest and leisure, to the need to establish financial instruments, climate risk insurance and funds to help soften the effect of price fluctuations, and increased costs of production associated with extreme climate events.

The Forestry Adaptation Dialogue was held with the support of the Uruguayan Association of Forestry Producers (Sociedad de productores forestales). The Dialogue analysed the risks and vulnerabilities associated with different climate events, such as the rise of drought conditions leading to increased temperatures that can result in an increase in plant diseases and pests, production losses, and increased fire risk. Another key risk identified was the excess of water due to abundant rainfall that can cause a combination of economic and productive knock-on effects. Production losses were also identified as being a potential result of plant health problems, soil erosion and logistical difficulties for harvest that may result in a loss of timber quality. It was agreed that global warming and the projections for the increased intensity of weather events in Uruguay would lead to an increase in the risk factors mentioned.

A final Adaptation Dialogue focused on cross-cutting topics that included family farmers from all the production systems. The Family Farming Adaptation Dialogue was organized together with the national section of the Specialized Reunion of Family Farmers (REAF) of the Southern Common Market (MERCOSUR). More than forty farmers, including crop producers, dairy farmers, livestock farmers, fishermen, sheep farmers, as well as fruticulture and horticulture farmers, brought their concerns to the table and contributed to the dialogue, which resulted in the identification of adaptation responses to be prioritized in the NAP-Agro. 
Some broad conclusions of relevance to the integration of forestry and agroforestry in the NAP process can be drawn from these examples. In most countries the preparation and implementation of the NAP is organized by sectors, generally in coherence with line ministries, with the explicit objective of facilitating mainstreaming of adaptation. The overall coordination is made by the combination of a lead administration and a coordinating inter-ministerial body that also play a leading role in the design and implementation of cross cutting activities. Such an organization, while being an indispensable first step and conducive to mainstreaming adaptation inside sectors, might not be able to facilitate cross sectoral cooperation on adaptation measures. In fact, Finland has designed a 5-step graduation of adaptation and includes cross-sectoral cooperation within the criteria for the highest level of adaptation (see Box 14). This is particularly important for forests and trees, given their potential contribution to the adaptation of other sectors and the influence of other sectors on their vulnerability and adaptive capacity. Forestry is often integrated into an ecosystems/biodiversity sector, however, this can detract from the recognition deserved for its contribution to objectives other than biodiversity, such as the economy or livelihoods, especially of the most vulnerable, indigenous peoples, local communities, women and ethnic minorities. As shown by the examples of plans where there is room for a strong subnational component (Sudan, Canada, Australia), it is often at this level that the various contributions of forests and trees to adaptation are the most recognised and strengthened. Exchanges between sectors at the local level, as well as between local and national levels, are thus particularly important to facilitating the integration of forestry and agroforestry in overall adaptation policies design and implementation. 


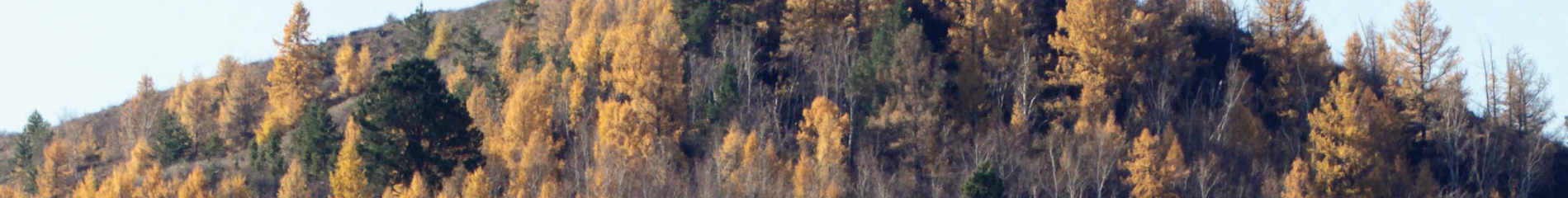

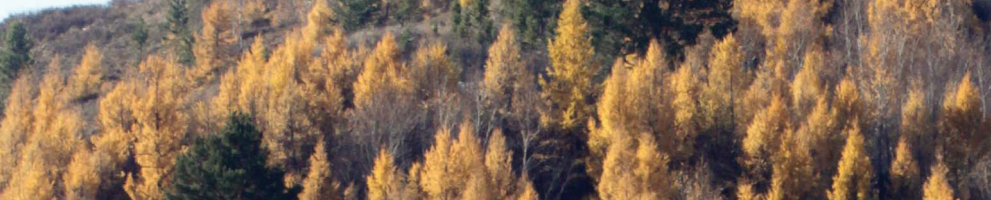

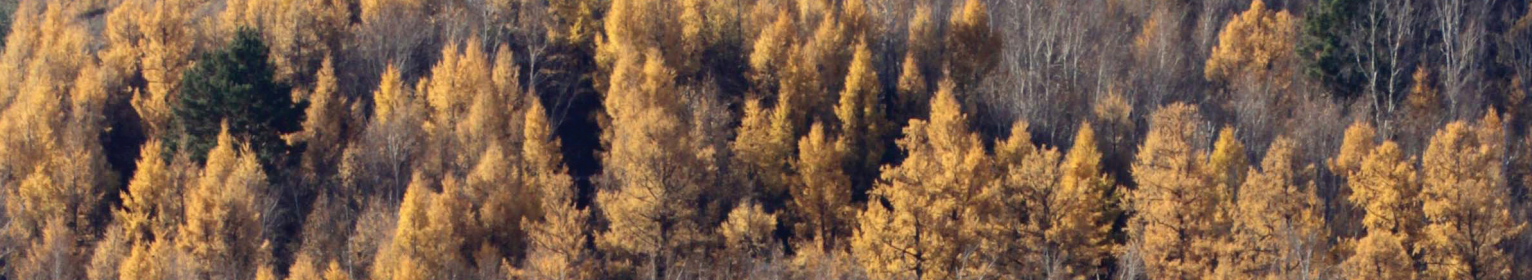
(1) 14
1
1

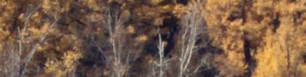

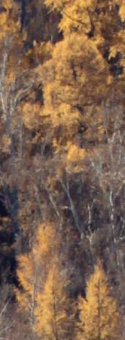

Xe.
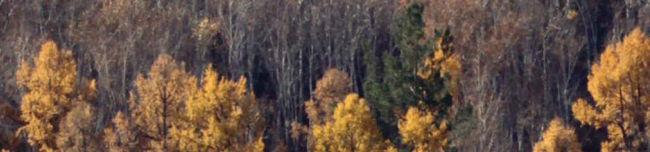

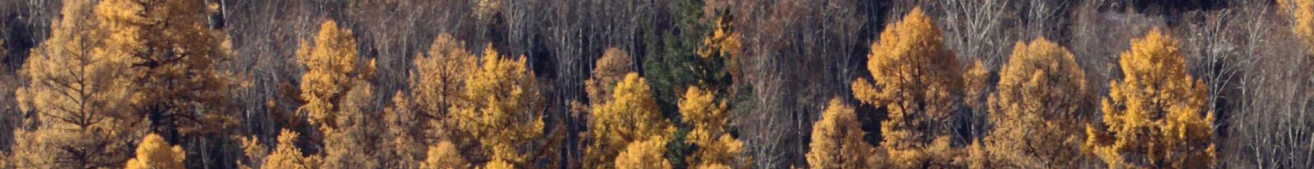

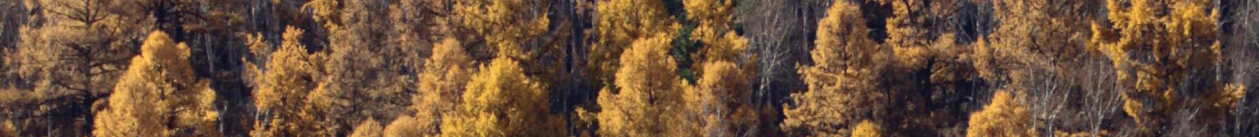

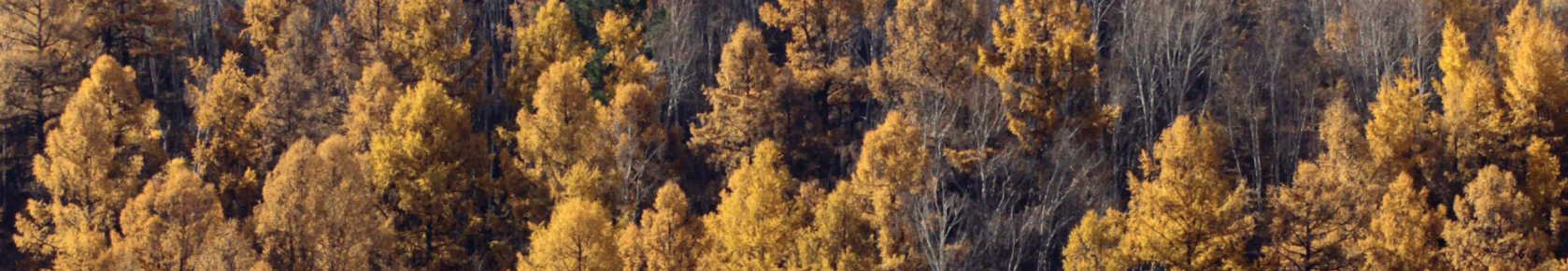

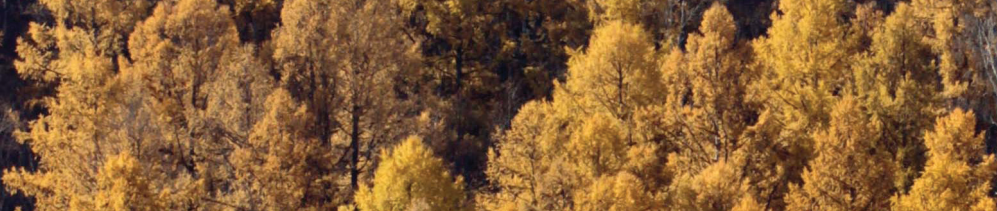

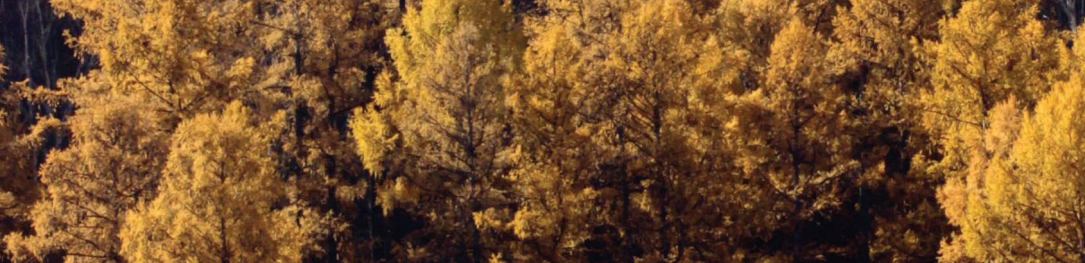

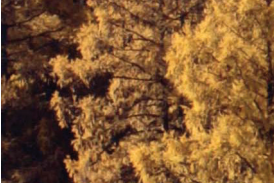

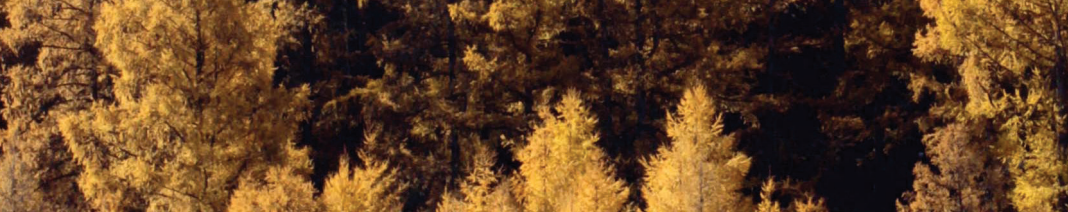

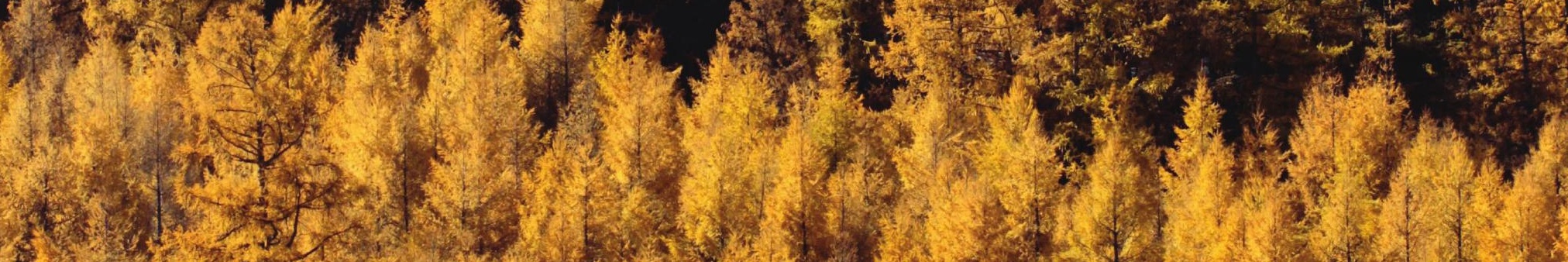

$\sqrt{1}$

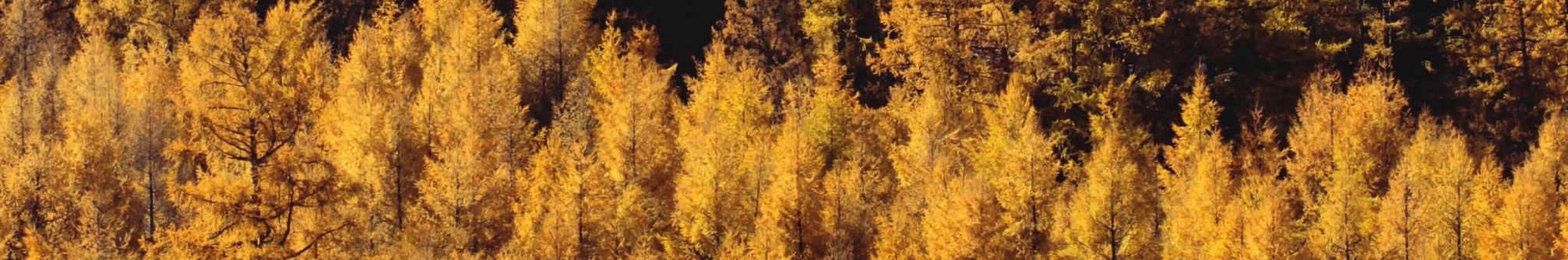

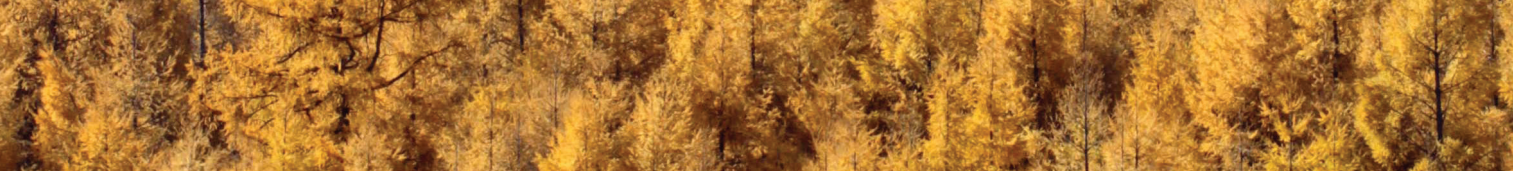

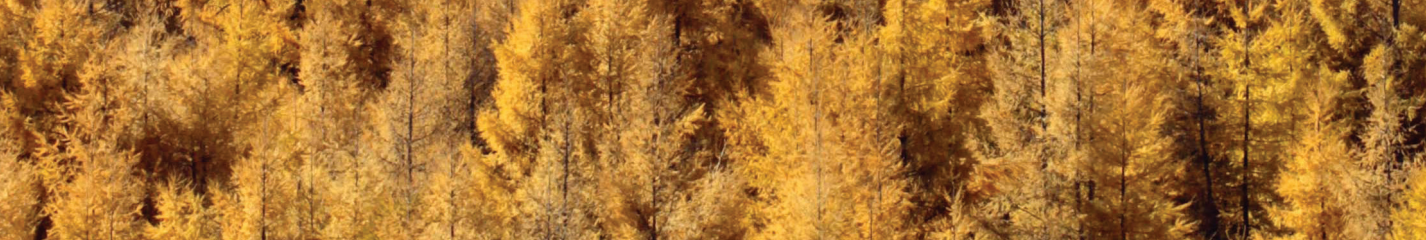

2. 


\section{Why and how to address forests, trees and agroforestry in NAPS?}

\author{
This chapter \\ highlights the main \\ reasons why forests \\ and trees (including \\ agroforestry, \\ orchards, trees \\ outside forests, \\ urban and peri- \\ urban forests) must \\ be appropriately \\ integrated into the \\ formulation and \\ implementation of \\ the NAPs.
}

The first reasons common to all other agricultural subsectors pertain to their particular vulnerability to climate change. A second group of reasons is based on the multiple ecosystem goods and services provided by forests and trees, most of which will be threatened by climate change. The third and often underestimated group of reasons is that forestry and the ecosystem goods and services provided by forests and trees can be called on to play a critical role in the adaptation of most of the other sectors, of systems identified as vulnerable (such as crop, livestock, water systems), and of vulnerable people and populations. This is why forests and trees are an essential component of nature-based solutions (NbS) that are defined as actions that use ecosystems to help societies address a variety of environmental, social and economic challenges in sustainable ways. NbS are explicitly considered as alternatives to human-made technologies, engineering and infrastructures. They integrate conservation and protection of biodiversity as a basic objective. NbS are being increasingly promoted to address climate change and other societal challenges (MacKinnon et al., 2008; IUCN 2009). The role of forests and trees is envisaged and managed best at the landscape level, which calls for a landscape approach to adaptation.

For all these reasons, and in line with the recommendations of the LEG, this chapter adopts a systems approach. It starts from the description of the diversity of forests and systems with trees and their contributions to other sectors/systems at different levels, then examines their main vulnerabilities to climate change, and how they can best contribute to the adaptation of these other sectors/systems.

\subsection{Forests and other systems with trees}

This publication deals with forests as per their FAO definition (see Box 3), with areas described as forests at national level even if not strictly corresponding to the FAO definition, and with other tree systems, including agroforestry, which are very often submitted to the same type of climate related impacts and very often provide 
the same type of ecosystem services. Furthermore, it examines the dynamics between the categories of land-use (including agriculture), as they have a strong influence on their vulnerability to climate change.

\subsubsection{A diversity of forests, and a diversity of perspectives on forests}

Forests are extremely diverse, depending on latitude, elevation, topography, slope, temperature, rainfall patterns, soil composition, plant-animal interactions and historical and current human activities. They are also defined in very different ways, from numerous perspectives, by different actors: as a specific type of ecosystem; as an area producing wood for a commercial concern, as an area producing a diversity of wood and non-wood products in a community forest; as the traditional territory of an indigenous tribe; as a hunting area; a recreational space; a conservation area; etc. This diversity of perspectives on "forests" explains the number and diversity of legal definitions used at national and international levels, often for different purposes.

At global level, the Forest Resources Assessment (FRA) of FAO has contributed to the harmonization of the approaches used to define and categorize forests (see Box 3). The FRA uses an agreed global definition of forest that includes a minimum threshold for the height of trees $(5 \mathrm{~m})$, at least 10 percent canopy cover and a minimum forest area size (0.5 ha). Urban parks, orchards, palm oil plantations, agroforestry and other agricultural tree crops are excluded from the FAO definition (but rubber, cork oak and plantations of Christmas trees are included).

\section{BOX 3.}

\section{Definitions used for FAO's forest resources assessments}

\section{Forest}

"Land spanning more than 0.5 hectares with trees higher than 5 metres and a canopy cover of more than 10 percent, or trees able to reach these thresholds in situ. It does not include land that is predominantly under agricultural or urban land use."

Among forests, FAO distinguishes three categories:

- Primary forest: "Naturally regenerated forest of native species, where there are no clearly visible indications of human activities and the ecological processes are not significantly disturbed."

- Other naturally regenerated forest: "Naturally regenerated forest where there are clearly visible indications of human activities."

- Planted forest: "Forest predominantly composed of trees established through planting and/or deliberate seeding." This category includes "plantations", defined as "Planted Forest that is intensively managed and meets ALL the following criteria at planting and stand maturity: one or two species, even age class, and regular spacing. Specifically excludes: forest planted for protection or ecosystem restoration."

\section{Other wooded land}

"Land not defined as "Forest", spanning more than 0.5 hectares; with trees higher than 5 metres and a canopy cover of 5-10 percent, or trees able to reach these thresholds; or with a combined cover of shrubs, bushes and trees above 10 percent. It does not include land that is predominantly under agricultural or urban land use." 


\section{Other land with tree cover}

"Land considered as "Other land", which is predominantly agricultural or urban land use and has patches of tree cover that span more than 0.5 hectares with a canopy cover of more than 10 percent of trees able to reach a height of 5 metres at maturity. It includes both forest and non-forest tree species."

This subcategory includes groups of trees and scattered trees (e.g. "trees outside forest") in agricultural landscapes and urban areas, respecting the three criteria described above. It includes in particular fruit tree plantations and agroforestry systems, as well as tree plantations established mainly for other purposes than wood production, such as oil palm plantations.

* More details/explanations on the definitions can be found in FAO (2018c, 2018d).

\subsubsection{Other systems with trees}

There are numerous systems with trees that are not covered by the FAO definition of forests, either because of a lower canopy coverage, smaller size, or their classification as an agriculture or urban area. Among these systems figure the "other wooded lands" category that includes the wooded areas that are not considered forests by FAO because, while meeting the criteria of size and height, they do not meet the criteria of canopy cover (see Box 3). Some countries have a broader definition of forests than FAO and part of these systems fall under the national definition of forest. There is also a great variety of systems closely linked to agricultural activities such as diverse agroforestry systems (including silvopastoral systems), mosaic landscapes where forest patches are too small to be considered forest for statistical purposes, as well as agriculture tree plantations such as palm oil, olive trees and orchards (fruit and nuts trees).

Agroforestry is the collective name for landuse systems and technologies where woody perennials (trees, shrubs, palms, bamboos, etc.) are deliberately used on the same land-management units as agricultural crops and/or animals, in some form of spatial arrangement or temporal sequence. In agroforestry systems there are both ecological and economic interactions between the different components (Lundgren and Raintree, 1982). In other words, trees are an integral part of the system, whether they play a predominantly service role (e.g. windbreaks) or provide one of the main commercial products (e.g. intercropping with plantation crops). Proper design and management of agroforestry systems can make them effective carbon sinks with a potentially important role for mitigation. By providing products and services that would otherwise be sourced from forests, agroforestry is also a very valuable strategy for enhancing local livelihoods, while reducing pressure on natural forests. The presence of trees in agricultural landscapes also contributes to reduced vulnerability and increased adaptative capacity to climate change thanks to their biophysical and economic contributions.

Mosaic landscapes with trees and forest fragments provide diverse ecosystem services, including water cycle regulation, pollination and pest control services (Ricketts, 2004; Ricketts et al., 2008; Holzschuch et al., 2010) and, depending on their distribution, can contribute to the connectivity of forest areas, thus reducing the impact of fragmentation that may affect the health of the forest and induce biodiversity loss (Bogaert et al., 2011). In addition, fragmentation and lower connectivity of forest patches affect the ability of pollinators, natural enemies of pests, water and nutrients to move across a landscape (Vira et al., 2015).

Agricultural tree crops plantations (such as palm oil, coffee, cocoa or olive tree plantations, as well as orchards) share many of the characteristics of plantation forests (as defined in Box 3), especially those covering large areas. Small and/or mixed orchards are close to or part of agroforestry systems. Tree systems and individual trees located in urban and peri-urban areas constitute the so-called urban forest of a city. Such systems can play a role 
in compensating - to some extent - the enormous contribution of urban areas to climate change and more importantly, they can make cities more resilient to climate impacts. In fact, a strategic management of forests and trees in and around urban settlements can decrease local temperatures, reduce energy consumption for air conditioning and heating, mitigate floods as well as the impact of stormwater runoff by increasing the permeable urban surface, and also increase water quality and availability.

\subsubsection{Dynamics of forests and other tree systems}

In numerous areas of the world forests and tree systems are evolving rapidly, under the influence of many factors, at local and globallevels: increasing demands on land and forests, abandonment of some agricultural areas and environmental concerns. These factors can profoundly modify the vulnerability of forests and tree systems to climate change, especially when considering medium-term perspectives. In a particular country, forest and tree cover area is often subject to significant change with time. Historically, with time and with economic development and demographic transitions, countries generally experience a decrease of their forested area, followed for some by a subsequent increase, with changes in both type and amount of tree cover in landscapes. Therefore, forests and systems with trees are evolving along time along what has been described as the forest transition curve, which includes deforestation and forest degradation phases, and also the potential for degraded, ex-forested lands to be restored in the form of productive forests and/or agroforests. It is important to understand these actual or potential changes as they will often influence the vulnerability of forests and trees to climate change and other stresses as well as their capacity to contribute to human well-being.

The forest transition curve (see Figure 2) illustrates how a continuum of management intensity, from low to high intensity, cuts across the "evolution" of forest and tree cover loss and recovery (Mather and Needle, 1998).

\section{FIGURE 2.}

\section{Forest and land-use transition curve}

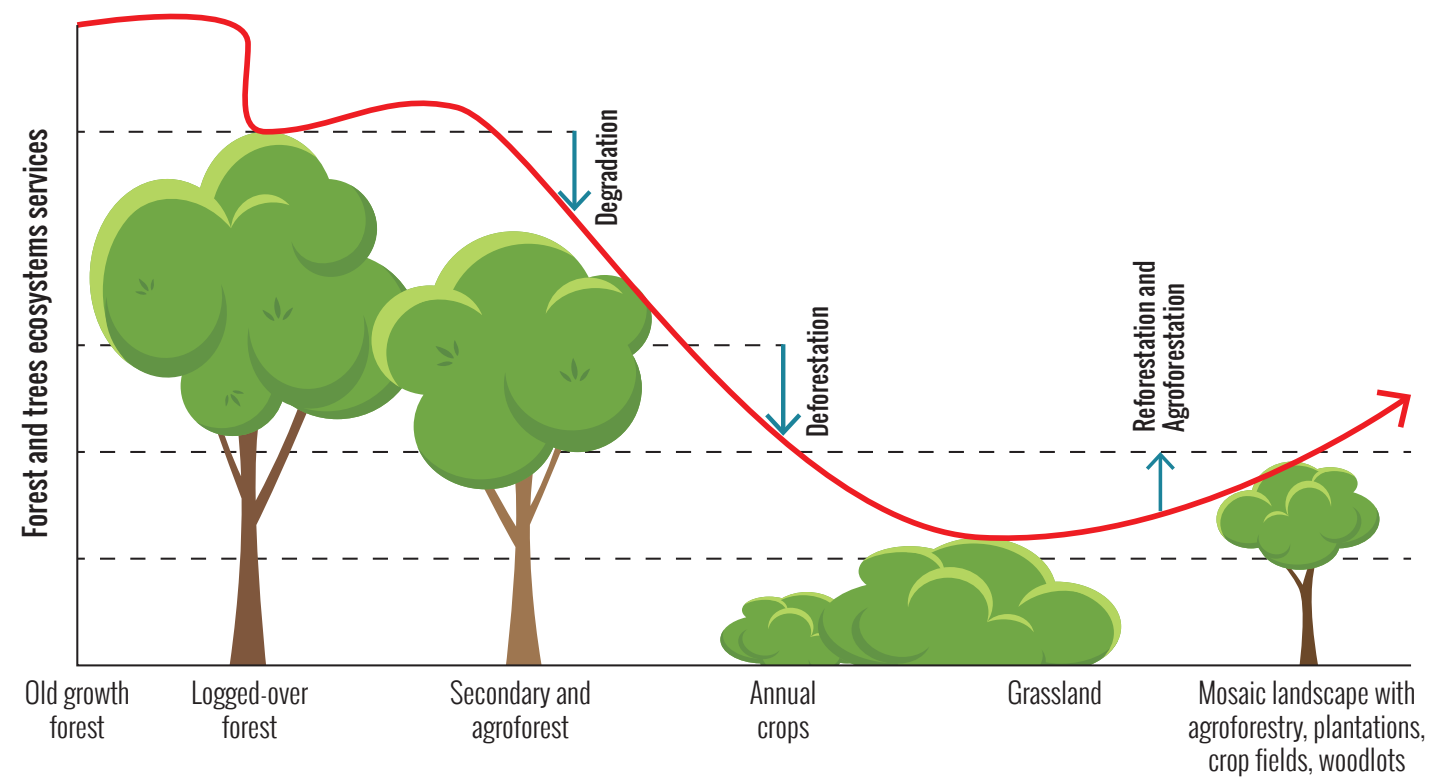




\subsection{Ecosystem services provided by forests and trees}

Forests and trees provide essential services at different scales from field and local communities to national, regional and global levels. These services can contribute to reducing the vulnerability of society to climate change (Locatelli et al., 2008; Meybeck, Rose, and Gitz, 2019). Forests provide food, energy, materials and numerous other ecosystem services on which people depend to various degrees for their livelihoods, food security and nutrition, including regulation of freshwater supply, conservation of biodiversity and climate change mitigation. These contributions are threatened by climate change, with impacts on livelihoods, food security and nutrition. Moreover, forests are often of particular importance for livelihoods in time of crisis, which are themselves likely to multiply and intensify due to climate change.

A great variety of animal and plant forest foods are consumed by people living in forests or nearby (Jamnadass et al., 2015; HLPE, 2017) and can represent an important part of their diet, especially when taking into account the nutrient content. For instance, studies in Gabon (Blaney et al., 2009) and in Tanzania (Powell et al., 2013b) estimated the contribution of wild foods to 20 percent of iron intake and more than 30 percent for vitamin A, two of the nutrients for which there are major deficiencies. Moreover, as underlined by Vira et al. (2015), forests and diversified tree-based systems can provide vitamins all year round thanks to different fruiting phonologies. Bushmeat, fish, and insects are an important source of protein, particularly in some regions, in both tropical, temperate and boreal forests (HLPE, 2017). Forests and trees are also supporting grazing livestock systems in numerous regions.

Fuelwood, both wood and charcoal, is a major source of energy for cooking and boiling water, often the only available in rural areas in developing countries. At the global level it is estimated that 2.4 billion people rely on fuelwood for cooking, including two thirds of African households (FAO, 2017b). Forests and trees also provide numerous materials used for building, furniture, tools, handicraft as well as numerous substances used in both traditional and occidental medicine.

These goods are also traded, at local, regional and even global scales thus determining two categories of beneficiaries: the consumers and all those earning an income from the collection, transformation and distribution of these goods. For example, a study from FAO (2014) estimated that 19 percent of the population of Africa, 15 percent of Asia and Oceania and 8 percent in Latin America were engaged in fuelwood and charcoal production in 2011, mainly on a part-time basis. Many of these activities are informal and not completely covered by national statistics. Many of them are also heavily gender differentiated, calling for a thorough analysis by gender. In addition to the employment and income provided by the collection and trade of goods, forests generate public and private income and employment in the recreational and tourism industry, which can have a very significant impact in some areas.

Besides the provisioning ecosystem services they deliver, forests and trees provide numerous regulating and supporting ecosystem services that are essential to agriculture (Richardson, 2010; Foli et al., 2014), as well as to communities and to humankind.

Forests and trees play a considerable role in the hydrological cycle, regulating surface and groundwater flows while contributing to water quality (Miura et al., 2015; Ellison et al., 2017) and contributing to rainfall, locally and remotely downwind (Ellison et al., 2017). In addition, they facilitate infiltration and can improve groundwater recharge as well as provide important protection against flooding, including far downstream. In coastal areas, mangrove forests protect 18 million people and are critical ecosystems that shield coastal lands and communities from sealevel rise, storms and floods, as well as provide a range of benefits associated with fisheries (Global commission on adaptation, 2019). Forests and trees contribute to soil accumulation (Kimble et al., 2007) and its protection against water and wind erosion as well as to nutrient circulation (Bradshaw et al., 2007), including through their root system.

Forests are host to over half of the world's known terrestrial plant and animal species (Shvidenko et al., 2005; Aerts and Honnay, 2011). These include a number of species that provide beneficial services 
at various spatial scales, such as pollinators and natural enemies to pests (Foli et al., 2014). Pollination is one of the most frequently studied ecosystem services, in fact, numerous studies have shown a link between the proximity to forests and forest patches and the density of wild pollinators that benefit the pollinated crops yields and quality (Garibaldi et al., 2016).

Forests also play a considerable role in climate regulation at various geographical and temporal scales. Locally they act as windbreaks and provide a cooling effect beneficial for crops, animals and humans, including around urban areas. As mentioned above, they play a key role in the distribution of precipitation through "rain recycling" including at regional and continental scales. Moreover, because of their role in the carbon cycle they play a major role in climate change mitigation at the global level.

In addition to these economic and environmental benefits, forests are also carrying social, cultural and religious values that are of critical importance to many communities and groups, especially in the case of indigenous peoples where forests are not only essential to their livelihoods, but also to their culture, traditions, religion, spiritual beliefs and practices (e.g. Widmark, 2009).

The provisioning, regulating, supporting (and even) cultural ecosystem services provided by forests and trees can serve as key assets for landscapes, communities and households in the context of climate change. Climate change is bound to amplify a number of risks affecting farming systems, landscapes, communities and households (e.g. FAO 2016a) for which forests and trees can act as a buffer, reducing the impacts of shocks. This justifies why, in the context of climate change and when devising adaptation plans, forests and trees and the role they play in the resilience of landscapes, communities and households against diverse shocks and risks deserves specific attention. In many ways, they offer no-regret options and a range of safety nets.

For instance, the ecosystem services provided by forests and trees are particularly important for reducing the impacts of climate variability and weather-related shocks, such as floods, droughts, winds and heatwaves on economic activities, infrastructure and people (see examples in section 6.3). In agroforestry systems, trees can contribute to microclimate regulation, increasing productivity and resilience of the food production system (Pramova et al., 2012).

Trees contribute to a diversification of sources of food and income that can help buffer climate change induced economic shocks. Furthermore, diversified systems are likely to provide more resilience to an increased volatility of food supply and prices (Vira et al., 2015), climate-related or not. In many communities, forest foods (including wild game) are used as a safety net during the lean or hungry season or when a crop fails (Blackie et al., 2014; Keller et al., 2006; Shackleton and Shackleton, 2004; Sunderland et al., 2013; Karjalainen et al., 2010; Koffi et al., 2017). For instance, in Tanzania a greater portion of the diet has come from wild foods during periods of food insecurity (Powell et al., 2013b). In a review of 9 studies that included an assessment across seasons, six cases showed higher dependence on wild foods during the lean or food-insecure season, while the other three showed higher wild food use when it was the most available (Powell et al., 2015). In semi-arid regions, like in the Sahel, during the dry season trees and shrubs provide fodder for livestock (Franzel et al., 2014). Also, forests and trees are used as a safety net to address occasional income needs, particularly in times of conflict, natural disaster or economic crisis. The most vulnerable men and women can find a source of income and employment through woodfuel and non-wood forest products (NWFP) collection and sale (Angelsen and Wunder, 2003; Shackleton and Shackleton, 2004; Mulenga et al., 2012).

The recognition of this buffering function of forests and trees in landscapes (van Noordwijk et al., 2011) that shields people from climate related hazards and shocks has led to propose the concept of "climate adaptation services" (Lavorel et al., 2015), defined as: "the benefits to people from increased social ability to respond to change, provided by the capacity of ecosystems to moderate and adapt to climate change and vulnerability".

These buffering functions of forests and trees go well beyond agriculture. They are key to the adaptation of land and water systems through the provision and regulation of water flows, in quantity and quality, locally and remotely, ensuring protection against floods, erosion, landslides, sea level rise. In addition, they represent great potential for the adaptation of cities as they provide a cooling effect that will become even more valuable with the increasingly frequent heat waves in urban areas. 


\subsection{Impacts of climate change on forests and trees}

The risks that climate change and variability pose to forests and trees are well recognized. Climate change can have both direct and indirect impacts on forests and trees. We qualify here as direct impacts those that are directly caused by a modification of physical characteristics such as temperature or precipitation. Indirect effects are those that affect production and or condition through changes in other species such as pollinators, native pests, disease vectors, invasive species (insect pests, pathogens, plants and vertebrates).

Direct effects are easier to predict because they can be more easily simulated and/or modelled. They are now quite well projected for some tree species and simple forest types. Indirect impacts of climate change on forests and trees are much more difficult to model given the high number of interacting factors determining the forest health and condition. In some cases, either a reference to a comparable system under the predicted climate or the observation of the impacts of a comparable climate change on another system can be useful for the prediction of impacts (FAO, 2016a).

Negative impacts are already apparent in many places, often combining with other stresses (Braatz, 2012; Keenan, 2015). Recent evidence suggests that in a wide range of forest systems, warming and changes in precipitation are increasing tree mortality through heat stress, drought stress and pest outbreaks (Allen et al., 2010). Many areas of boreal forests have experienced productivity declines that have been attributed to warming-induced drought (Williams et al., 2013). Warming and drying, coupled with productivity decline, insect disturbance and associated tree mortality, also favour greater fire disturbance (Settele et al., 2014). The overall trend for temperate forests has been until recently an increase in growth rates, due to a combination of increasing growing season length, higher atmospheric $\mathrm{CO} 2$ and nitrogen deposition and forest management (Ciais et al., 2008). However, recent indications point to signs of climate stress with increasing tree mortality, changes in fire regime, insect outbreaks and pathogen attacks (Settele et al., 2014). Have also been noted a significant decrease in tree regeneration after wildfire in the US Rocky Mountain (StevensRuman et al., 2018). Storms and violent winds, inundations and floods as well as landslides and avalanches also affect forests. In coastal areas forests, particularly mangroves, are impacted by saltwater intrusion and sea-level rise, and damage from coastal storms.

Most tree species have a climatic range within which they grow best, are competitive with other plant species, can adapt to environmental change, and respond to increased insect attacks, disease, and adverse environmental conditions and anthropogenic influences. Some species will adapt better than others to changing conditions, which will lead to changes in the composition of forests rather than in geographic shifts in forest types (Breshears et al., 2008). In general, tree species are likely to move to higher latitudes or altitudes due to global warming (Rosenzweig et al., 2007; Breshears et al., 2008). Such shifts can occur over quite short distances along altitudinal gradients (e.g., in mountains), while requiring shifts of hundreds of kms in flat areas. Models predict that the potential climatic space for most tree species will shift poleward and to higher altitudes faster than natural migration. Boreal forests are expected to move north due to climate change while temperate forests will expand to the north and to a greater extent than boreal forests; therefore, the total area of boreal forests will be reduced (Burton et al., 2010). In turn, changes in tree species composition are a main driver of changes of forest productivity under climate change (Morin et al., 2018).

It is expected that the impacts of climate change, land-use change and unsustainable land-use practices will interact with each other (FAO, 2017c). Changes in water availability will be a key factor in the survival and growth of many forest species, although the response to prolonged droughts will vary among species and also among varieties of the same species (Lucier et al., 2009). Climate change will increase the risk of frequent and more intense fires, especially in areas where it leads to lower precipitation or longer dry periods, as in the case of boreal forests (Burton et al., 2010), forests in Mediterranean and subtropical regions (Fischlin et al., 2009), in addition to areas where traditional fire-based land-clearing practices 
are used, such as in the Amazon (Aragão et al., 2008; Nepstad et al., 2008). Moist tropical forests have many species that are vulnerable to drought and fire-induced mortality during extreme dry periods. Forest fire frequency and severity are increasing due to a combination of land-use change and drought, including in the Amazon. Climate change, deforestation, fragmentation, fire and human pressure place virtually all dry tropical forests at risk of replacement or degradation (Miles et al., 2006).

Climate change may increase the impact of pests by allowing them to establish in areas where previously they could not; in fact, the effects of climate change on forest insects have been demonstrated for a number of species and guilds (Pureswaran et al., 2018). Changes in temperature can result in changes in geographic ranges and facilitate overwintering, allowing some species to extend their geographic range towards the pole and to higher altitudes (Porter et al., 2014; Svobodová et al., 2014). For instance, the spread of the mountain pine beetle (Dendroctonus ponderosae) in boreal forests has largely been attributed to the absence of consistently low temperatures over long periods, which has allowed for already existing outbreaks to spread across mountain areas and into colder boreal forests (Burton et al., 2010). Pine processionary moth, Thaumetopea pityocampa, is a model insect indicator of global warming, through its northwards and upwards range expansion (Roques et al.,2015). An increase in infestations of root and bud rots is expected in Finland's coniferous forests due to a virulent fungus, Heterobasidion parviporum, whose spread is favoured by longer harvesting periods, increased storm damage and a longer spore-production season (Burton et al., 2010). In the tropics, increased warming accelerates the life cycle of many insect pests and increased fire damage makes trees more susceptible to insect attacks, which in turn speeds up the life cycle of these pests (Lucier et al., 2009). Climate change may also increase the impact of pests by allowing them to appear earlier in the season due to higher temperatures. Furthermore, studies predict an increased number of generations per year under climate change, such as for the coffee nematode in Brazil (Ghini et al., 2008) and walnut pests in California (Luedeling et al., 2011).

In spite of their diversity, the wide range of forests and tree-based systems share some common challenges with regards to adaptation to climate change. Trees have a life cycle often spanning dozens or hundreds of years, therefore, they must be adapted both to present climate and to future climate in the long term. Given their longevity, they will experience more variability and shocks than other plants, in addition, they need to be more resilient to a more diverse set of conditions. Compared to annual crops, trees are more difficult, and take more time, to domesticate and multiplicate, and this needs to be factored into the evolution of managed and planted forests. Natural forests also tend to be complex systems with multiple interactions between species that can be modified by climate change often in unexpected ways, which makes adaptation to climate change more challenging. Finally, and this may be the more important, adaptation of forests and trees takes time, requires long-term efforts, appropriate policies and secure tenure.

\subsection{Relations between forests and vulnerable systems}

The objective of this section is to consider the sectors identified by countries as the most vulnerable to climate change and to examine how forests and trees can contribute to their resilience and adaptation.

The sectors most frequently identified as vulnerable in NAPAs prepared by the least developed countries (UNFCCC, 2018) were:

- agriculture

- water

food security

- infrastructure (including coastal infrastructure, buildings, transportation and communication)

- ecosystems and biodiversity

- health.

Were also identified:

- vulnerable areas: coastal areas, rural areas, cities, river valleys and oasis; and

- vulnerable populations: rural populations, coastal communities, poor populations and women. 
Most countries that have included an adaptation component in their NDC have identified particularly vulnerable sectors and areas (UNFCCC, 2015). These have been summarized as follows:

- water

- agriculture and forestry

- ecosystems and biodiversity, including wildlife

$\checkmark$ health

- energy, tourism, infrastructure and human settlements

- areas liable to drought and desertification, lowlying coastal areas and small islands

- land-locked countries and mountains

- vulnerable populations

- rural populations

- poorest segments of society

- women, youth, the elderly and the disabled.

These sectors also inform the structure of most of the NAPs, with some modifications in scope that are generally due to national specificities and linked to line ministries' responsibilities. When considering these sectors as systems it appears that, in most cases, forests already contribute significantly to their resilience and their role will become increasingly important with climate change.

The potential of forests and trees to make a contribution to adaptation through the ecosystem services they provide has been amply recognised by the NAPAs. In fact, a screening of the priority projects proposed in the NAPAs has revealed the importance of forestry, not only in itself, but also for support to the adaptation of other sectors (Meybeck et al., 2012). NAPAs include projects directly dealing with forests, for instance, assistance to the implementation of communitybased forest management plans or community- based forest fire management and prevention. Moreover, forestry is very often part of integrated projects for the improvement of watershed management, prevention of soil erosion, landslides and floods. The importance of ecosystem services has been acknowledged in more than 50 percent of the NAPAs, with forests and trees the most often cited (Pramova et al., 2012). Approximately 22 percent of the projects proposed in the NAPAs include ecosystem activities for social well-being or adaptation with most of them in support of other adaptation measures (e.g. infrastructure) (Pramova et al., 2012). Forestry projects are often described as benefitting several sectors, for example, restoration of mangroves in Djibouti is expected to contribute to restocking fisheries and controlling erosion for the enhancement of agriculture, as well as to the adaptation of coastal zones and the water sector by protecting human settlements against storms, controlling salt water intrusion and contributing to groundwater recharge. A project in Burkina Faso for the improvement of the management of natural vegetation and promotion of non-timber forest products is expected to deliver additional food, income and health benefits. The study concludes by inviting to adopt a broader perspective towards ecosystem-based adaptation (EbA).

Forests, trees and agroforestry can play an important role in the adaptation of most of the sectors identified by countries as the most vulnerable. The potential contributions of forests, trees and agroforestry are symbolized by the arrows in Figure 3. Much of this potential and the related actions will need to be implemented in practice at the local level, in the landscape, through EbA; however, it will require that enabling conditions are put in place at the national level. 


\section{FIGURE 3.}

\section{Potential contributions of forests, trees and agroforestry to the adaptation of other sectors/systems}

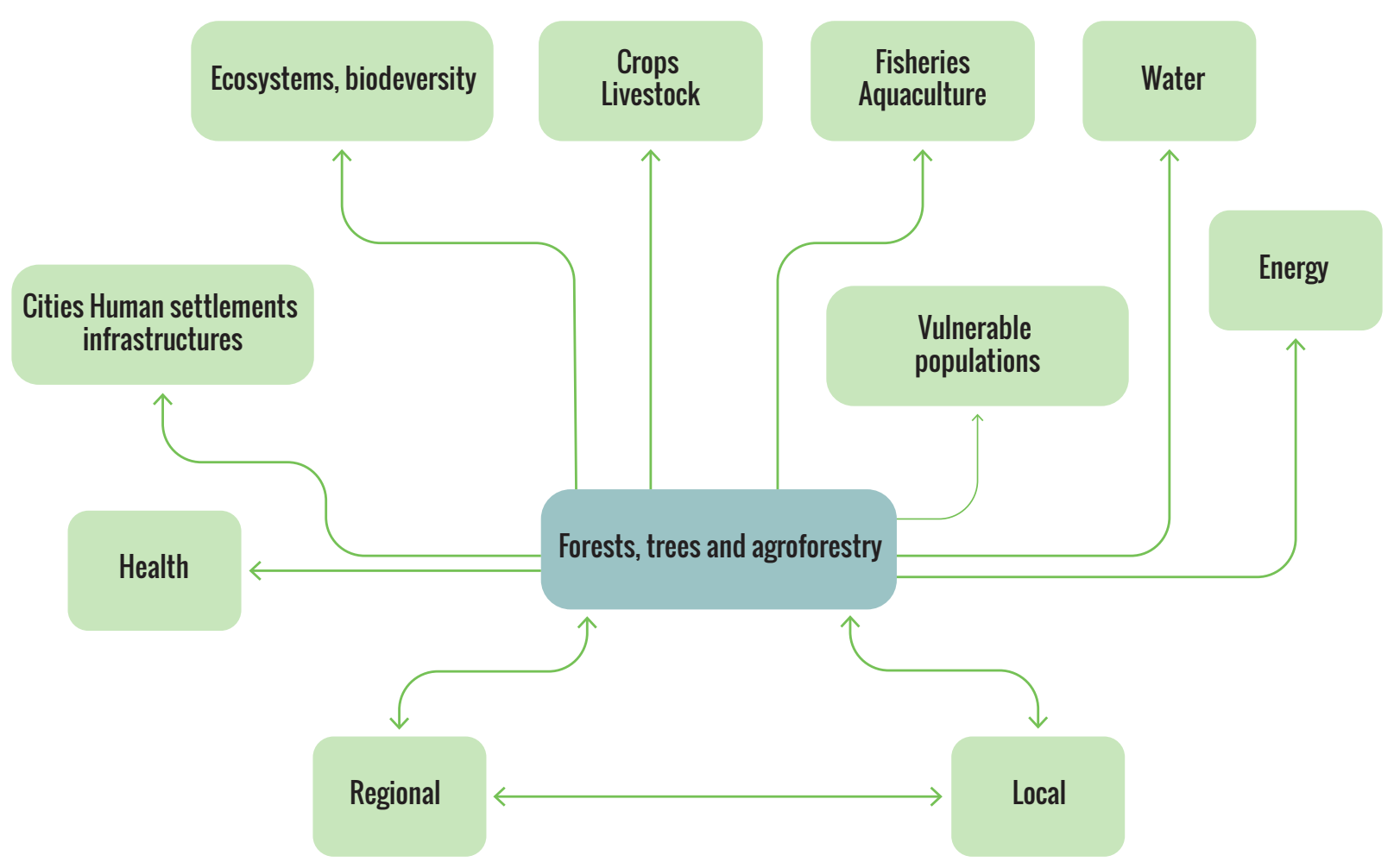

These arrows represent physical, biological and/ or economic contributions. Each sector can also be considered as a system, with its own actors and institutions. As summarized in the figure these sectors generally correspond to the perimeters of line ministries, to which regional and local institutions should be added and can be either emanations of national administrations or of local governments, depending on the countries. In the organizational reading of the figure, the arrows represent links to be constructed between systems, actors and institutions, as part of the NAP, to strengthen potential contributions of forests, trees and agroforestry to the adaptation of other sectors and ultimately of the whole country. 


\section{- Institutional arrangements to address forests and trees in NAPs}

\author{
The objective of this \\ section is to provide \\ recommendations \\ on possible ways \\ for the forestry \\ sector to best \\ engage in the \\ process according \\ to national \\ institutional \\ specificities \\ (building upon \\ section 2.4).
}

The two broad axes identified above, i.e. the potential of forests and tree systems to adapt to the effects of climate change and the contribution of these systems to increased resilience in a number of key sectors particularly vulnerable to the effects of a changing climate, call for two different and complementary institutional set ups: (i) inside the forest sector; and (ii) in relation to other agriculture subsectors as well as with other relevant sectors, including water management, energy, land planning etc.

This dual process should be embedded in the overall NAP process itself and rely as much as possible on existing organizations and mechanisms. It should be led by the forestry focal point for the NAP. Furthermore, it needs to be supported by appropriate communication mechanisms to facilitate the engagement of forest and tree systems actors and to ensure the circulation of information from and towards the various institutions in charge of the NAP.

\subsection{Establishing an adaptation process for forests and trees}

Given the breadth of the impacts of climate change on forests and forest-dependent people (see Box 6) there is a need for a forestsector specific process in order to understand vulnerabilities and potential ways to adapt. This process should be aligned with and integrated into the country's national forestry program (nfp), or the process that provides a framework for implementing sustainable forest management and forest-related contributions to sustainable development (FAO, 2018a).

A process to analyse climate change vulnerabilities and adaptation measures in the forest sector shall take into account the diversity of situations even at the national level, diversity of forests and systems with trees, of people dependent on them, of the relations between people and forests, and diversity of priorities. It should involve all relevant actors and build upon a combination of top down and bottom up approaches to facilitate exchanges between the scientific community and the knowledge, concerns and capacities of local actors. 
This sectoral process should have three main objectives: (i) raise awareness on forests and trees vulnerability to climate change, on the risks associated with a loss or degradation of these resources, as well as on the adaptation strategies that can be put in place for forests and trees to maximize their contribution to the successful implementation of the NAP; (ii) support the steps of the NAP process, providing data, information and knowledge on the sector, on its vulnerabilities, on what is needed to enable its adaptation and its contribution to the adaptation of other sectors; and (iii) follow the preparation and implementation of the plan, assess the potential impacts of its measures on forestry and on other sectors and propose improvements when appropriate. The sectoral process should be well linked to the overall national one and use existing structures and institutions as much as possible to contribute to the mainstreaming of adaptation.

To achieve the objectives mentioned above, the process will need to associate all relevant national actors as well as diverse scientific and technical competencies. It will also need to involve local actors, both for gathering information and facilitating their engagement in local processes. It could for instance rely on a national group, to which provincial or regional focal points could be associated, for instance provincial or regional forest officers, who themselves, as appropriate, could organize a provincial or regional concertation. Depending on the way the NAP process is organized, the sectoral process at local/regional levels will be more or less developed. There is however always the need, for forestry, to have a good link to local levels given the local specificities of the sector and also given that it is at landscape level that its interactions with other sectors can be best understood and measures implemented.

Several points are particularly important for the sector in order to orient the composition of such groups. One of the overarching principles of the NAP process is inclusion and transparency. This calls for a wide range of participation that would include women, indigenous people and all vulnerable and marginalized groups, especially as they are particularly vulnerable and often partially or totally forest dependent (see Box 7). Such a broad participation can also help making more visible the contributions of forests to livelihoods and human well-being that are not accounted for in economic statistics. In this regard, there is also value in associating all groups with an interest in forest and trees even when they are not economically dependent on them. In addition to "traditional" forest actors, forest owners, managers and users, also need to be associated the actors involved in urban forests, agroforestry, horticulture, as well as in relevant value chains for cocoa, coffee, rubber, shea butter and other tree commodities, as they share common interests and concerns. Given the need for adaptation decisions to be grounded on a sound economic analysis as much as possible, it is necessary to ensure that competencies in economics be present or can be called upon.

Given the above, a national group could include representatives of:

- forest managers, private and public, including of community forests;

- forest extension services (public and private);

- forest dependent communities;

- forest owners and "holders" (with long term management rights), different categories and scales;

- forest users (including with informal use rights);

- producers of forest products, wood and non wood;

- transformers and distributors of forest products;

- producers, transformers and distributors of tree products and associated (coffee, cocoa, rubber, horticulture, palm oil);

- organizations involved in conservation and multiplication of genetic resources;

- forest farm organizations;

- farmers practising agroforestry;

- civil society and NGOs;

- state, district or local planning authorities (including cities); and

- academia and research.

Depending on the specificities of forestry, agroforestry and tree-based crops in the country it may be useful to organize specific groups focused on particular aspects, for instance a value chain associating all the actors from production to transformation and distribution, or on specific issues like genetic resources, from identification and conservation to distribution of appropriate germplasm. Other such dedicated groups could follow more closely and contribute to the work of specific sections of the NAP such as energy, 
biodiversity or water. To ensure the credibility, transparency and inclusiveness of the process it is necessary to give it some formalization, with a published list of those involved and written minutes, or lists of decision points after each meeting.

The actors involved in the process may also need some training, at least on the NAP process itself. In addition, new knowledge, skills and expertise may be needed to participate effectively in the process and its implementation. Forest managers and other stakeholders should have sufficient knowledge and expertise to allow them to undertake vulnerability and risk assessments; design and revise management plans; implement actions to adapt to climate change; and monitor the impacts of climate change and the outcomes of climate change actions. In fact, such capacity development activities are also part of the NAP and essential to its implementation.

\subsection{Liaise with other agriculture subsectors}

Forestry, crops, livestock, fisheries and aquaculture have a great deal in common. They are particularly dependent on climate conditions. They all depend on the use of natural resources, in particular land and water, for which they sometimes compete. They also share numerous economic and social characteristics, including the sheer number of people depending on them and their particular importance for LDCs. Rural people often depend for their livelihoods on a combination of activities in the various sub sectors, forests often being the last option for those who have lost everything. Therefore, the climate change induced risks faced by these sectors represent common challenges. Common solutions are available, such as monitoring systems of weather and ecosystems (including pests and diseases) or conservation and sustainable use of genetic resources for instance. And there are also shared issues such as the need to manage synergies and trade-offs for water management and land use planning. In particular, the development of agriculture has a direct impact on forests as it is the main driver of deforestation; at the same time, forests and trees make an important contribution to the resilience of other agricultural activities.
As a result, the establishment of regular exchanges between the agricultural subsectors (crops, livestock, forestry, fisheries and aquaculture) to foster collaboration and progress towards common approaches on adaptation is fundamental. Furthermore, these exchanges could help build integrated approaches at landscape level. At national level, regular meetings could be organized between the participants of the agricultural subsectors and the various work streams to exchange information, build common strategies on crosscutting issues and elaborate joint proposals on intersectoral issues of common interest. Broader meetings could assemble all members of groups working respectively on forestry, agriculture, fisheries and aquaculture. These meetings would provide the opportunity for an overall update on the state of advancement of the NAP, as well as support crucial steps in its preparation, implementation and review. Such gatherings could also include sessions dedicated to learning, capacity development and exchanges of lessons learned. At the subnational level, such meetings could pave the way for the implementation of the NAP at the landscape level, at various scales, including through EbA.

\subsection{Organize the participation of the forestry sector in the national adaptation planning, including clarifying mandates and engaging stakeholders}

This step involves understanding the NAP process established at national level, in order to identify how the forest and trees sector can make an appropriate contribution and interact with other sectors. Some of the specific sector groups' mandates and composition may need clarifying. It also deals with the identification of the actors to engage in the sector reflection and planning (see also Figure 4). Particular attention needs to be given to the inclusion of women, indigenous people and marginalized groups, often the most forest dependent especially in times of crisis. It is also important not to forget groups that are 
interested in forests, even in an indirect way, such as fisherfolks for mangroves for instance. It is necessary to organize proper representation of the forestry sector in the overall NAP process as well as in those sectoral processes of relevance to forests and trees or for which forests and trees can be of relevance, like water management, land use planning or energy.

The participation of the forestry sector in the process has the following main objectives:

- increase the level of understanding of all actors invested in adaptation of the specificities of forest and trees, and related challenges and opportunities (as described in 4.2), for example, by bringing to the attention of the conservation community the need to take into account the role of forests for indigenous and local livelihoods-;

- ensure that the needs of the sector are properly taken into consideration at the national level and in other sectors' strategies and policies; and

- promote and strengthen the role of forests and trees as an adaptation mean.

The first step is to have a clear picture of the different work streams in the overall NAP process and of their mandates. As there is not often a work stream dedicated solely to forests and trees, it is important to identify the one that has the most potential for a stronger focus on forests as well as those that are of relevance, either because dealing with some sub categories (plantations, horticulture, urban forestry...), because having an impact on forests, or because of the importance of forestry for their own adaptation (water, energy, human settlements). For instance, plantations can be dealt with in a workstream on agriculture, livestock and plantations such as in Chile, while natural forests might be part of a workstream on biodiversity. In other cases, plantations can be part of cash crops (Sri Lanka). Agroforestry is generally dealt with as part of the agriculture agenda. Urban forestry would be best dealt with in a group on human settlements and urban planning. The protection of dams against silting could be dealt with either in the water group or/and in the energy group. It is critically important for the forest sector to be aware of all of these discussions in order to be able to benefit from the opportunities for raising awareness on the potential of forests and trees to contribute to adaptation.
For each of these work streams, the composition (formalized or not) of the group leading the activities should be identified, in addition to its modalities of work (periodicity of meetings, usual means for gathering and sharing information), and whether it relies mainly on previous reports, if it has launched specific studies, and if it welcomes external contributions. The main focus will generally be the workstream that is the most active on forests and trees. It is worth considering the possibilities to extend this group to include at least a forest expert and/or to propose auditions of forest specialists and stakeholders. It is also important to get engaged with the other workstreams of interest and keep updated on their activities in order to propose contributions in a timely manner. Such contributions should be concise, evidence-based and should also integrate economic data as much as possible. Having these contributions informed by a large network of experts and actors is likely to give them more weight. Given the importance for forestry of land planning as well as its links with other issues that are often dealt with at local level, in particular natural resources management, land, water and biodiversity, an active presence in subnational mechanisms of preparation and implementation is essential, particularly to prepare implementation in a landscape perspective.

The world's primary objectives of ending poverty and achieving sustainability will be greatly enhanced by strengthening legal frameworks that recognize and secure the rights of local communities and smallholders to access forests and trees. Access to land, resources and investments in and around forests can propel women, youth and other rural entrepreneurs to be agents of change in the transformation to a sustainable world. A positive enabling environment is fundamental for attracting the private sector to pro-sustainability activities. Stakeholder engagement and a commitment to good governance are both essential for effective policy implementation. Finally, investing in effective monitoring at national and subnational levels will provide countries with vital information on which groups of people or areas of the country to focus on. 


\section{FIGURE 4.}

Possible process flow for addressing the agriculture sectors in the formulation and implementation of NAPs

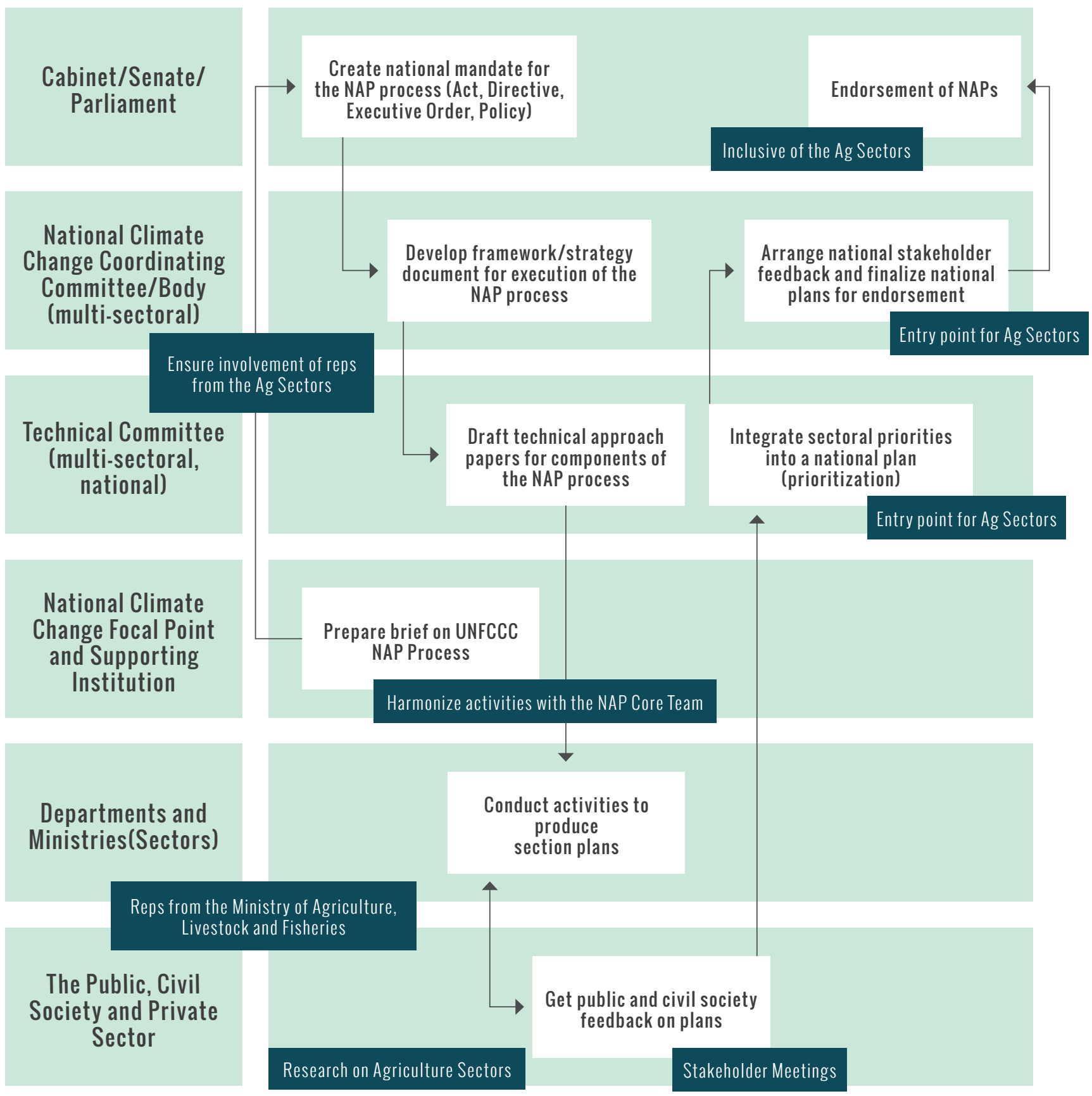

Supported by Research, Systematic Observation, Education, Training, Communications, Stakeholder Inputs, etc 


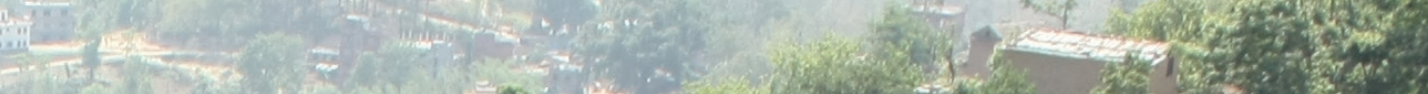

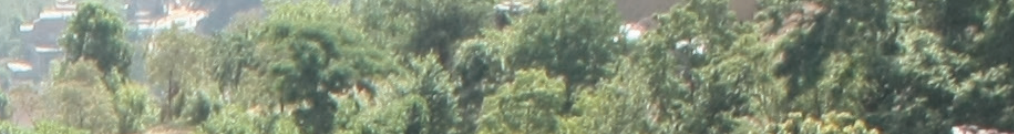

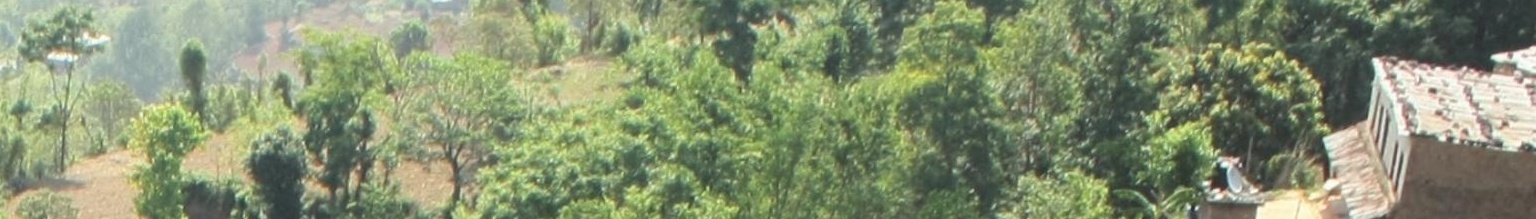
in: $x^{4} \cdot x^{4}$

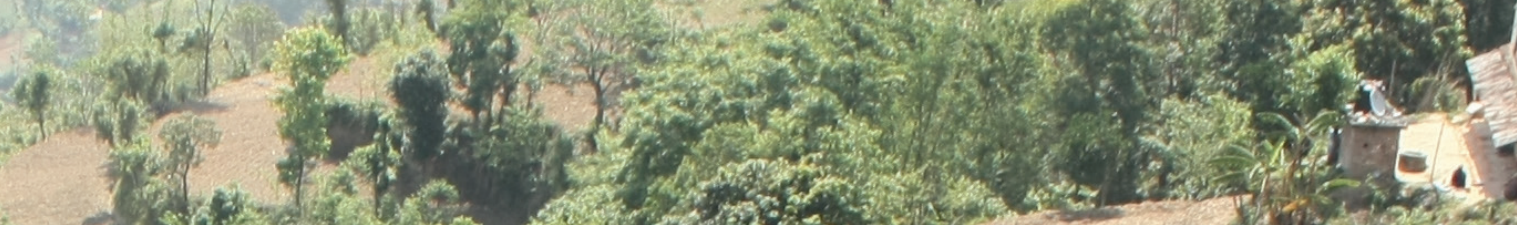

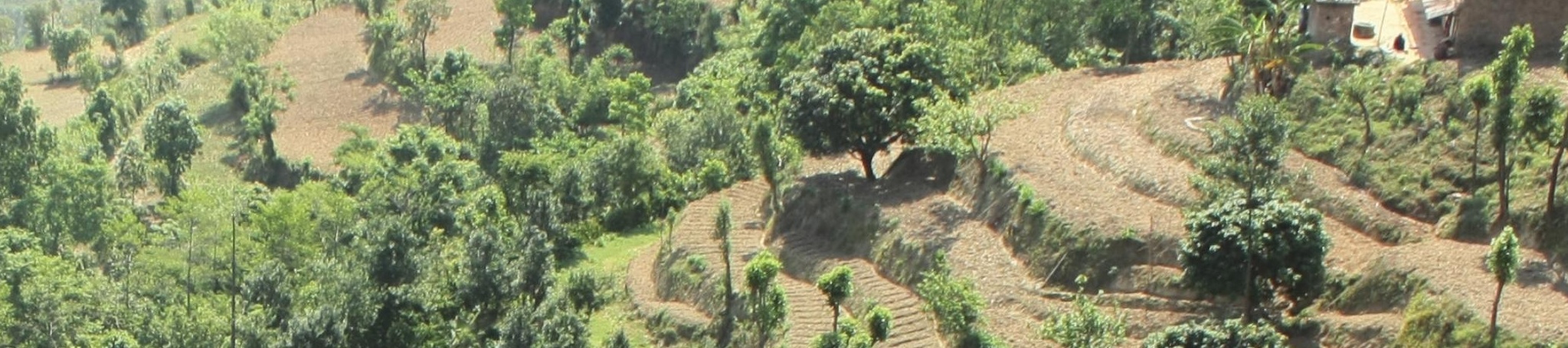

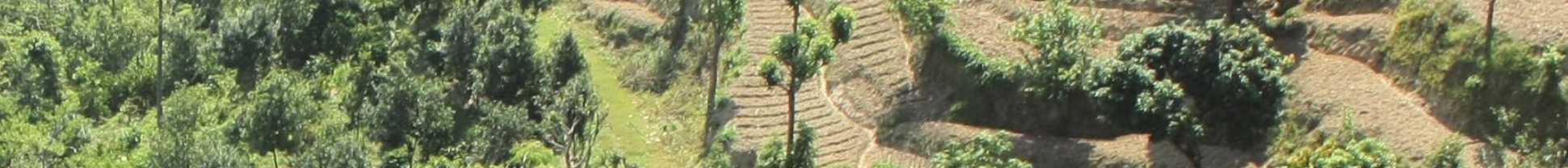
a 14

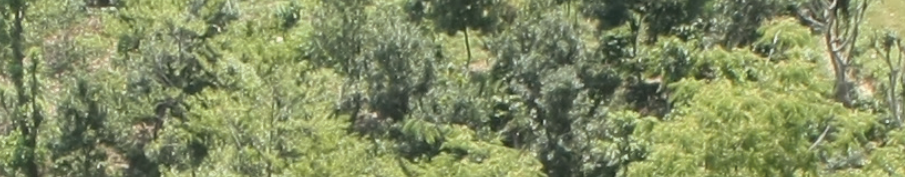

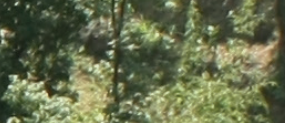
(3)

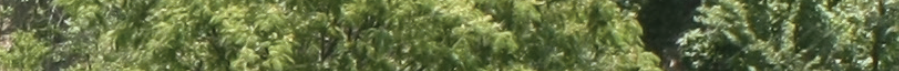

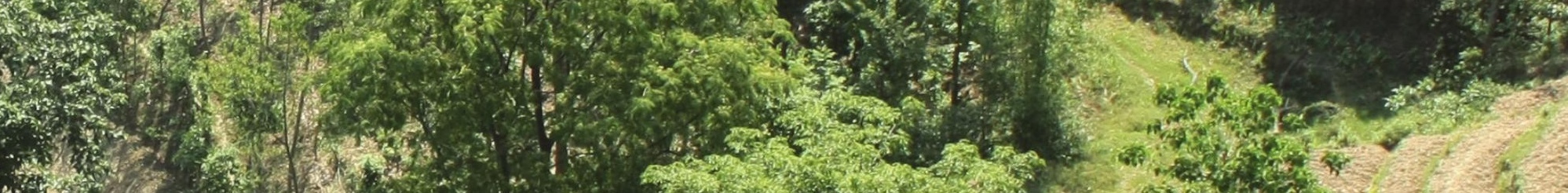
$-36 x^{2}$

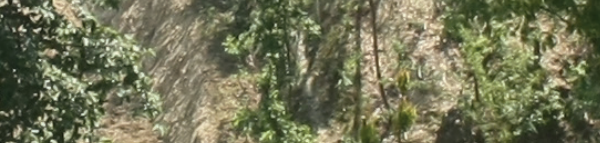

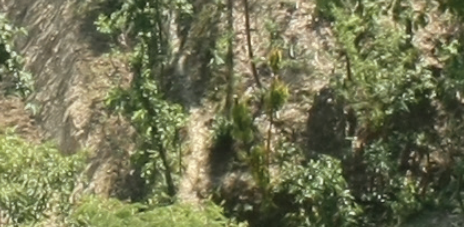

$-x^{2}+4$

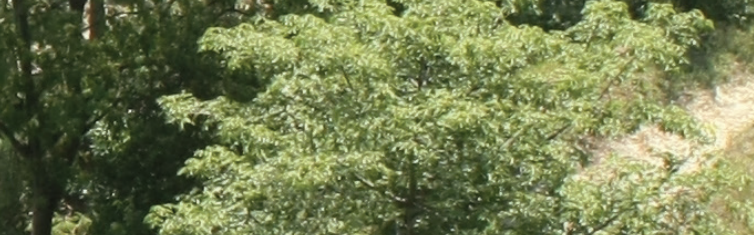

.

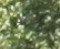

$6 x+2+2=$

26) $5,3+2$

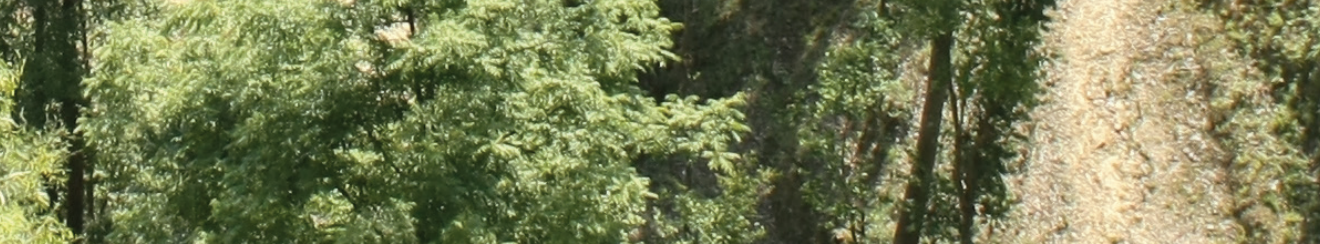

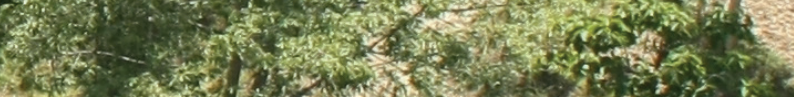

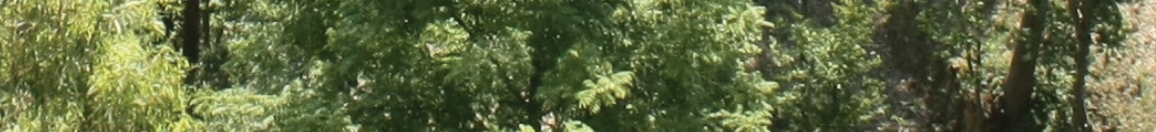

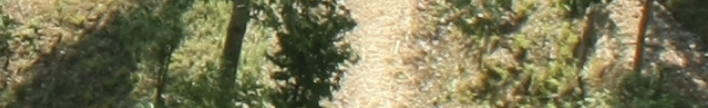

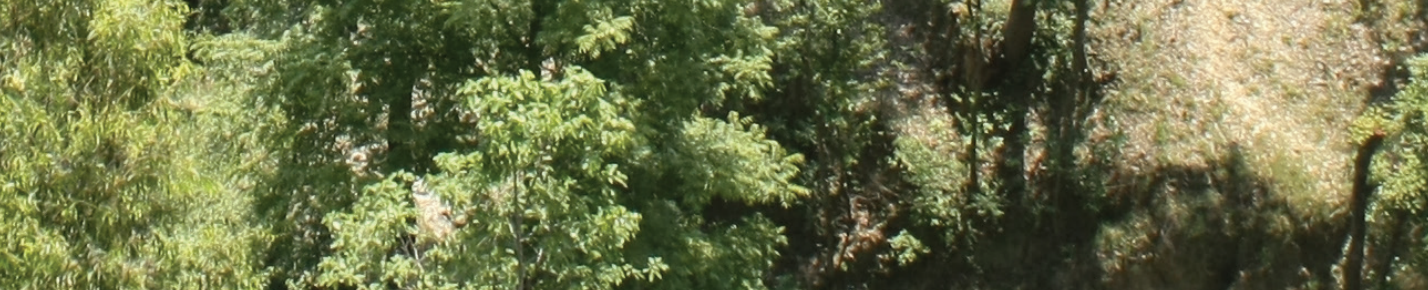

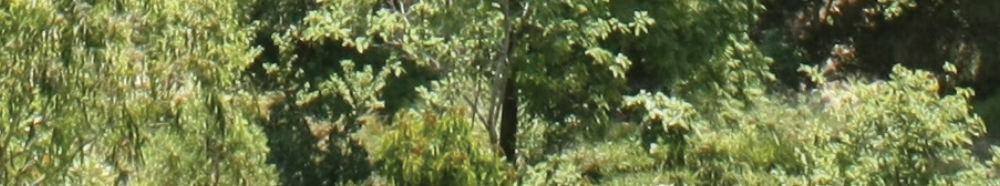




\section{- Laying the groundwork and addressing gaps}

The purpose of
this section is to
describe the main
steps of the first
element of the NAP
process, intended
to prepare the
work and identify
gaps. The section
corresponds, along
with the previous
one, to element A of
the NAP technical
guidelines.

\section{NEPAL}

Sloping agroforestry Tree in field integrated agroforestry system with animal husbandary. OICRAF

\subsection{Take stock of existing forest sector knowledge and policies and identify gaps}

The objective of this step is to gather all useful elements required to support the integration of forestry and agroforestry in the NAP and to identify knowledge gaps. This step includes:

- gathering data and information to assess the importance of forestry and agroforestry (including tree crops), as an economic sector, as providing means of existence to part of the population, as providing other ecosystem services;

- a review of institutions, policies and measures that have implications on forestry and agroforestry, in forestry, agriculture, fisheries as well as in other related sectors such as water management, land planning, energy;

- main points of the NDC related to the contribution of forests and trees to mitigation and adaptation, including restoration, afforestation, reduction of deforestation;

- other related commitments, such as restoration commitments;

- taking stock of existing vulnerability and risk assessments for forests and trees;

- identifying strategies, policies, plans and investments that will have an influence on the forest sector, including for instance, land use planning strategies, agriculture and food security objectives;

- perspectives of evolution, including a projection of potential drivers of change

- identifying main knowledge gaps; and

- identifying institutional and capacity gaps.

This step should have a national scope with, as appropriate, a focus on specific geographic areas, forests, productions and value chains. General information on existing vulnerability and risk assessments can be retrieved from the documents transmitted to UNFCCC, such as national communications, NDCs and NAPAs. 
This broad overview can be complemented by using IPCC assessments, especially the regional sections and sectoral sections - those on forests in particular - and the scientific literature that they reference. It is also likely that various vulnerability and risk assessments have already been conducted in the country, including at the local level. The FAO framework methodology for vulnerability assessments of forests and forest-dependent people (Meybeck, Rose and Gitz, 2019) provides examples and references.

One important element is to map the national and/ or sub-national public instruments that orient forest management. There is a great variety of such instruments potentially in place: laws and regulations, direct or delegated management of public forests, incentives, including taxation regimes, support to market-based instruments, often in combination. National legislations define what is a forest, areas that are deemed permanent forest, and forest and tree tenure rights. They can also contain provisions regarding forest governance and management, with various degrees of detail. Different rules often apply to different categories of forests, e.g. permanent forest estate, community forest, private forest lands, or to forests for different functions, e.g. production vs. protection forest. National laws can contain specific provisions for protected areas or for specific status granted to certain forests because of their situation or function. Such a status generally goes with specific management rules that influence the vulnerability of the forest itself as well as the people depending on it. Such rules can be determined at the national level or be partially or totally delegated to subnational authorities or to specific entities. These policies and institutions constitute a key basis on which to establish adaptation measures (see section 6.5 How to improve the enabling environment).

Many countries have set very ambitious objectives in terms of forest conservation, restoration and/ or afforestation in their NDC, and restoration commitments and development plans. Such objectives need to be taken into account when preparing the NAP. First, because these projects need to be carried out in such a way that they are resilient to climate change. Second, because the way they are conducted can also contribute to the adaptation of other sectors. For example, a commitment to plant a certain number of hectares of forest could provide adaptation benefits if situated in areas where they can reduce the impact of floods, erosion or sea level rise.

Another essential element of the NAP process, given its aim to mainstream adaptation in existing policies, is to understand the numerous policies that have an influence on forests and trees, as well as their potential contribution to the adaptation of other sectors, particularly land-use planning, biodiversity, agriculture, water, energy, and human settlements.

Finally, at this preliminary stage it is also particularly useful to identify the main knowledge gaps related to the forest sector so that complementary studies can be conducted. Among the most frequent knowledge gaps the following are worth mentioning:

- Criteria for evaluation of health conditions of forests

- the composition and health conditions of forests;

- the extent and composition of other tree-based systems, including agroforestry;

- the value of wood and particularly non-wood forest products;

- the contribution of forests to local livelihoods, including self-consumption and informal economy, with distribution by social groups and gender;

- the number of jobs and added value generated by transformation and distribution of wood and non-wood forest products;

- estimations of the economic value created by the ecosystem services generated by forests and trees; and

- vulnerability of forests and/or species of major importance for environmental, economic, social or cultural and religious reasons, as well as of vulnerable forest-dependent people.

Complementary studies to fill the most urgent knowledge gaps and gather information and data should be launched at this stage, based on the available resources and timeframe. It is also important to remain aware of these gaps in knowledge and their relevance to the NAP, so that when new studies are launched or forest data collection systems are expanded or improved, this information can be efficiently channelled into the NAP process. 
This stock take shall also relate to the analysis conducted on other vulnerable sectors and areas for which forests and trees can contribute to increase resilience, linking with these sectors.

\subsection{Assess capacity needs and develop capacities for forest and trees-related adaptation planning}

This step focuses on developing the institutional and technical capacity for adaptation of forests and trees, and raising awareness on the potential of forests and trees to contribute to adaptation, including communication and training. Its aim is to identify the main areas where capacity gaps and weaknesses need to be identified and reviewed and to propose potential ways to address these gaps, as well as examples of communication and training activities building upon countries' experiences.
Such capacity assessments need to be conducted not only at national level but also at various sectoral and sub-national levels such as: local government, local civil society, local universities and other knowledge providers, since this can be a major impediment for effective planning, programme development and implementation.

The United Nations Institute for Training and Research (UNITAR) has designed a framework to assess institutional capacity for the preparation of NAPs (MacKay et al., 2015). Box 4 hereunder has adapted the framework for assessments in forestry. This framework can help determine the level of existing capacities and skills to engage in broader NAP processes, to formulate and implement climate change adaptation planning within the sector, as well as to fund and monitor the effectiveness of adaptation actions. It can also provide an effective way of collecting and analysing information on a country's existing skills profile and identify gaps and capacity building strategies (MacKay et al., 2015) as shown in the examples provided in Box 4.

\section{BOX 4 .}

Example questions for assessing forestry institutional capacity for climate change adaptation planning

\section{Cross-sectoral NAP engagement readiness of the forests, trees and agroforestry sector}

Is there a national, cross-sectoral NAP planning/coordination body (e.g. task force, working group)?

Is there a requirement (or invitation) for the forestry sector to take part in national, cross-sectoral adaptation planning and implementation (e.g. NAP development)?

Is the forestry sector represented in the cross-sectoral NAP body at national or sub-national levels?

Is the process and timeline for NAP development and implementation clear to the forestry sector?

Is there a cross-sectoral NAP engagement strategy for the forestry sector?

\section{NAP policy readiness of the forestry sector}

Is there a clear understanding/agreement of the climate change impacts/ risks for the forests and tree systems, sectors, communities?

Is there a requirement/demand for the development of sector-specific adaptation plans/NAP? 
Are impact and vulnerability assessments in forestry required by the policy/ legal framework for use in adaptation planning?

Is there a forest climate change adaptation plan?

Is adaptation integrated into forests, trees and agroforestry policies, strategies and plans?

- to what extent? (e.g. LOW: a brief mention of climate change, to HIGH: specification of climate change vulnerabilities and adaptation actions/ adaptation strategy/plan for forests)

Are relevant DRM plans and policies integrated in Forestry development or adaptation plans?

\section{NAP organizational readiness within the forestry sector}

Is there a formal climate change unit (task force, working group, etc.) in the forestry institution?

Has this forestry climate change unit a clear mandate for planning and coordinating adaptation in the sector?

Does the climate change unit have high-level legitimacy (e.g. endorsement by minister of forestry) for its actions?

Is there a climate change focal point in the Forestry ministry/department (at national and provincial levels)?

- Are the focal point's responsibilities regarding climate change and line of response well defined?

- How connected to other sectors affecting and/or affected by forestry (e.g. crops and livestock, land use planning, inland waters, energy, ...) is the work of the focal point?

- Has the focal point regular interactions with the NAP body to facilitate cross-ministerial discussions?

Is the current visibility of climate change in the organizational structure of forestry institutions sufficient? How visible are the role and actions of the focal point?

Does the visibility of climate change in the work of the Forestry ministry need strengthening?

(e.g. increase the number of staff, promote their position, move to different line of authority within the ministry)

\section{NAP technical readiness of the forestry sector}

Are data regularly collected on environmental, weather and climatic parameters and made available for use in planning/management?

- Is there a climate and environmental information system/seasonal forecasting system available to forest managers on a recurrent basis?

- Is there a bio-climatic information system to inform on, e.g., changes in species abundance, distributions available to forest managers and stakeholders on a recurrent basis?

Have the climate change impacts/risks for forests, trees and agroforestry, as well as for the people depending on them been assessed? 
Do vulnerability assessments exist for forests and forest dependent people?

- Are analytical tools such as vulnerability and risk assessment, scenario analysis, cost-benefit analysis used to understand the adaptation needs of the sector?

- Do these analyses take into account sub-sectors, diversity of actors (smallscale, large-scale) geographic areas (provinces/districts, community, national) and ecosystems?

Are the results of these analyses fed into or driven by planning and policy making?

Have appropriate adaptation options been identified for forests and tree systems?

\section{NAP financial, monitoring, communication readiness of the forestry sector}

Does a shared climate change financing framework for adaptation exist between forestry and other sectors of the economy?

Have the costs of adaptation for the sector been assessed?

- How do they compare to (i) the value of the sector, (iii) the development budget for the sector (iii) the sector allocations for adaptation?

Is a budget for climate change vulnerability assessments and adaptation activities in forestry clearly earmarked?

- Can this budget be easily accessed?

Is there a national adaptation M\&E system in place for the sector to monitor vulnerability reduction/adaptive capacity and effectiveness of adaptation actions?

- Are adaptation data regularly collected for monitoring and evaluation purposes?

Is there a communication strategy and budget for the forestry department's Ministry's adaptation work?

\section{BOX 5.}

Kenya national drought management authority capacity needs assessment for NAP

As part of the NAP-Ag programme, a comprehensive assessment was conducted on the Kenya National Drought Management Authority's (NDMA) capacity to support the planning and implementation of adaptation and priority adaptation actions relevant to the agriculture sectors. The NDMA's mission is to provide leadership and coordination of Kenya's effort in the management of drought risks and enhancing adaptation. Its role, functions, management structure and institutional arrangements for climate change were screened in order to refine the scope of the capacity assessment. It focused on NDMA's capacity for normative and policy function, knowledge, partnering and implementation capacity to support the short, medium- and long-term adaptation actions outlined in the Kenya Climate Change Action Plan and NAP. 
The assessment for each functional capacity addressed the enabling environment, the organization and individual capacities. A score from 1 to 5 was assigned (1=None; 2=Low; 3=Moderate; 4=High; and 5=Full Capacity). A summary of the findings from the quantitative assessments is presented in the figure below. Responses were collected from key staff through a combined use of staff interviews and a participatory self-assessment questionnaire to enhance ownership of the findings.

The findings of the assessment revealed that the NDMA has: (i) moderate to high-level functional capacities, despite some specific limitations regarding institutional arrangements to address adaptation and disaster risk reduction (DRR) priorities and implement the mandate of the NDMA; and (ii) gaps in its organizational and individual capacity to enhance its functions and effectiveness. The establishment of a climate change unit within the Ministry of Decentralization and Planning (MoDP) was one of the main evaluation recommendations. The findings served as the basis for the development of a capacity development strategy and action plan for the NDMA.

\section{Summary analysis of capacity needs assessment within the Kenya National Drought Management Authority}

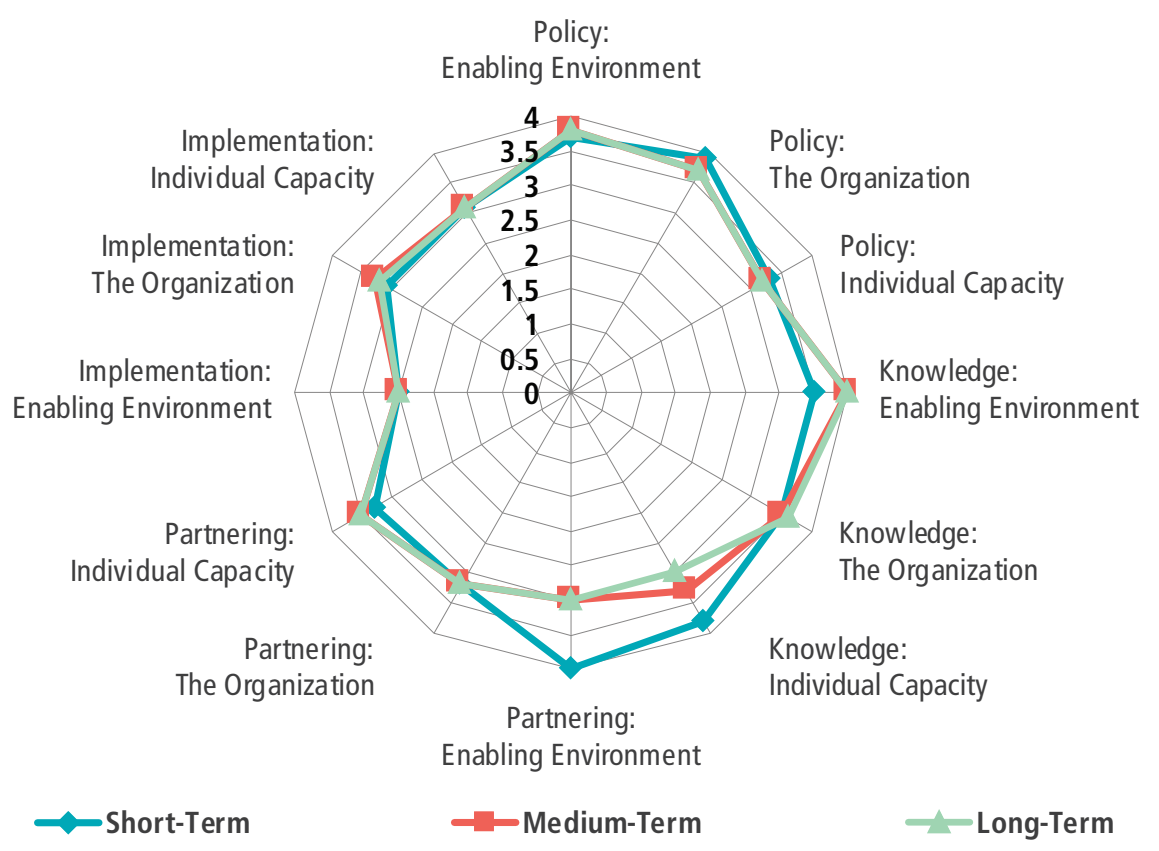

Source: FAO, $2018 \mathrm{~b}$

Another important aspect of research is to what extent the forestry sector has been involved in earlier climate adaptation planning and efforts and how this can be capitalized upon.
The following questions may support this analysis:

$\checkmark$ Does the country have a NAPA or other national adaptation planning document/strategy 5 ?

- If so, does it include forestry?

5 This could include climate change strategy, mechanisms for the implementation of NDC, climate change action plan or policy, etc., and may include both adaptation and mitigation priorities 
- How was the sector included in its elaboration? If not included, what were the constraints to its inclusion?

- Who were the key non-government forest, trees and agroforestry stakeholders involved in this process (research institutions, private sector, NGOs)?

- What has been achieved from the NAPA with regards to forests and tree systems adaptation to climate change?

- How is the development of the forestry sector impacted by the existing adaptation plan?

- Are there examples of sub-national plans or strategies and how is the forestry sector covered?

\section{$\checkmark$ Is the forestry sector formally engaged in the process to formulate and implement the country's NAP?}

- If so, how and to what extent? (mechanisms of engagement, contributions so far, etc.).

- Which stakeholders are engaged (research, private sector, NGOs)?

- How are local communities, small holders associated?

- If not, how to rectify this?

$\checkmark$ Has the sector taken part in any climate change discussions, plans or strategies?

- If yes, what came out of this and how can it be taken further? If not, why?

- Are consultation mechanisms in place?

- Is climate change adaptation in forestry specifically mentioned in any of the country's strategic documentation?

$\checkmark$ Do past and current forestry development policies, strategies and plans make any considerations of climate change factors?

- How does the National Forest Programme in the country address climate change?

- Do we know what is needed, what are these considerations?

- How do they affect the sector?

- How relevant are they?

- Could they be lifted out for inclusion in the NAP as they are or after revision or validation?

- If no, why is that and could it (or does it need to) be amended?
The objectives of this step are to:

- identify entry points, including the country's nfp for engaging forests, trees and agroforestry in the NAP;

- understand the existing opportunities for forestry to engage in the process to formulate and implement NAP;

- identify the policy and organizational gaps to be addressed to support adaptation planning within the forestry sector, including through the $\mathrm{nfp}$, and facilitate participation of the sector in broader, cross-sector climate change adaptation planning;

- identify a dedicated focal point, unit or task force or other officially recognized mechanism or body mandated to spearhead the mainstreaming of forests, trees and agroforestry during the process to formulate and implement NAP; and

- identify skill gaps and a strategy to fill them.

\subsection{Assess and identify links between adaptation needs and development goals}

The purpose of this step, based on section 5.1, is to assess how adaptation objectives could be linked to development objectives. It also includes the reviewing of development strategies and plans with an adaptation lens to assess if and to what extent they integrate adaptation concerns, or how they could be modified to better integrate adaptation.

Among the key documents to review for this step are:

- national poverty reduction strategy papers, medium- and long-term national development goals (e.g. Millennium Development Goals);

- national development plans and/or economic strategies, sectoral policies, strategies and plans;

- disaster preparedness and risk reduction policies and plans;

- multi and bilateral cooperation plans; and

- development aid strategies and programs, including with international organizations, international and regional development banks, as well as other donors. 
Such a review should be conducted in light of the need for these types of documents to also be reviewed and updated to integrate the orientation provided by the 2030 Agenda for Sustainable Development.

The 2030 Agenda for Sustainable Development and its 17 SDGs has become the central framework for guiding development policies in countries throughout the world. It has purposely been designed to integrate 'interlinked and indivisible' goals. It has been noted that one-third of all SDG targets are found to contribute to climate change adaptation and mitigation, with the greatest potential to generate synergies in agriculture, water, food waste and marine and forest ecosystems (WRI, 2018).

The State of the World's Forests 2018 (FAO, 2018a) provides a detailed analysis aimed at capturing the contribution of forests and trees to 28 targets relating to ten SDGs. The key findings can help orient the reflection to enhance synergies and minimise trade-offs between development goals as well as with adaptation objectives. Forests and trees make vital contributions both to people and the planet, bolstering livelihoods, providing clean air and water, conserving biodiversity and responding to climate change. Forest management influences water quantity and quality, essential to the health and life of both rural and urban populations.

These linkages between forests and other sectors should be emphasised and explored, taking into consideration their influence on the achievement of the SDGs, and vice versa on how actions in other sectors towards other SDGs may (or not) facilitate the adaptation of forests. Actions towards some development goals may provide synergies for the adaptation of forest and forest-dependent people and also strengthen the role of forest for adaptation more broadly.

One of the great challenges of our times is how to increase agricultural production and improve food security without reducing forest area. Improved resource efficiency, sustainable production and new technologies (SDG 12) and increased agricultural productivity (SDG 2) can reduce the pressures being placed on forests. From a poverty reduction perspective (SDG 1), actions should carefully look at forests and forest-dependent people, as those people left furthest behind are often located in areas in and around forests.
Energy (SDG 7) is another key example, as many households in developing countries rely on traditional bioenergy coming from forests for cooking and heating. Modernizing the traditional wood energy sector has the potential to improve livelihoods, create sustainable value chains and unlock resources for investments in sustainable forest management. In fact, the transition to modern energy alternatives and improved efficiency technologies can alleviate the dependence on wood-fuel, while efficiency can be improved and the consequential pressures on forest resources minimised.

There is quantitative evidence showing that forests and trees contribute to the achievement of SDGs related to livelihoods and food security for many rural poor, as well as access to affordable energy, sustainable economic growth and employment (in the formal sector), sustainable consumption and production, climate change mitigation, and also sustainable forest management. Moreover, qualitative evidence suggests that forests and trees make significant contributions to SDGs in the informal sector, agroforestry, opportunities to empower women, sustainable water management, tourism, sustainable cities, climate change adaptation, and tackling land degradation and biodiversity loss.

However, interrelations between forests and the SDG also need to recognize the reality of existing trade-offs (e.g. Katila et al., 2019) between the set of sustainable development goals and forests. These trade-offs must be managed with the objective to avoid compromising the capacity of forests and forest dependent people to adapt to climate change. For example, the expansion of agricultural crops for food or energy (SDGs 1 and 7) can compete with forests in many locations, and SDG 9 (Industry, innovation and infrastructure) may encourage infrastructure development and other activities at the expense of the forest area.

As mentioned in section 2.1, most countries that have integrated an adaptation component into their NDC have defined a long-term vision guiding it. Agriculture has often a prominent role because of its potential for both sustainable development and climate change actions. Its integration into the NAPs offers considerable opportunities to make a contribution to the SDGs (Juergenliemk-Avagyan et al., 2017) thanks to the multiple co-benefits of adaptation in the agriculture and land-use 
sectors (FAO, 2020a). An analysis of the agriculture sectors in the INDCs (Strohmaier et al., 2016) has noted that countries perceive adaptation and mitigation synergies and associated benefits as important elements of their long-term development strategies. An analysis of the NDCs of countries in Southern Eastern Europe and Central Asia (FAO, 2019) highlights that actions in the forestry sector are particularly prone to generating adaptation and mitigation co-benefits and that increasing convergence between the implementation of climate change objectives and of the SDGs provides great opportunities to accelerate progress towards both agendas. The regional NDC analysis for Asia has drawn similar conclusions (FAO, 2020b). Most mitigation and adaptation actions in the agriculture sectors are concentrated in the forestry sector and stress the uniqueness of its ability to provide global goods (stabilization of the climate) and support local livelihoods. About 60 percent of the countries in Asia explicitly recognize co-benefits, either between adaptation and mitigation or with the SDGs in the agriculture sectors, especially in forestry. new to the forestry sector. The United Nations General Assembly (UNGA, 2008) recognizes "that sustainable forest management (SFM), as a dynamic and evolving concept, is intended to maintain and enhance the economic, social and environmental values of all types of forests for the benefit of present and future generations".

The very purpose of SFM is to enhance synergies and manage trade-offs between objectives, including in the very detail of management and practices. Such an undertaking can often be best conducted at landscape level (see example of Indonesia Box 6). Forest landscape planning needs to take into account the needs of other sectors (e.g. bioenergy production, crops production) and integrate these needs as criteria in the choice of the species to be used (e.g. high growth rate species, leguminous species to increase availability of soil nutrients for intercropping systems). These multiple objectives require to fully integrate climate change into national forest policies (FAO, 2018e).

The need to pursue multiple objectives is not

\section{BOX 6}

\section{Extract of Indonesia's NDC}

The strategic approach of Indonesia's NDC is predicated on the following foundational principles:

- Employing a landscape approach: Recognizing that climate change adaptation and mitigation efforts are inherently multi-sectoral in nature, Indonesia takes an integrated, landscape-scale approach covering terrestrial, coastal and marine ecosystems.

- Highlighting existing best practices: Recognizing significant strides in multi-stakeholder efforts in combating climate change, Indonesia intends to scale up the diversity of traditional wisdom as well as innovative climate change mitigation and adaptation efforts by the government, private sector, and communities.

- Mainstreaming climate agenda into development planning: Recognizing the needs to integrate climate change into development and spatial planning and the budgeting process, Indonesia will include key climate change indicators in formulating its development programme's targets.

- Promoting climate resilience in food, water and energy: Recognizing the importance of fulfilling the needs of a growing young population for food, water and energy, Indonesia will improve its management of natural resources to enhance climate resilience by protecting and restoring key terrestrial, coastal and marine ecosystems. 


\section{Preparatory elements}

This section
corresponds to
element B of the
NAP technical
guidelines.
First, it deals
with the analysis
of climate
projections and
their implications
for forests, trees,
agroforestry and
forest-dependent
people. Second,
it reviews
potential risks and
vulnerabilities, in
order to provide
guidance for the
identification,
selection and
prioritization of
adaptation options.

BURKINA FASO, AFRICA

Shea oil (liquified shea butter) being filtered before packaging. @AFOR/Ollivier Girard

\subsection{Analyse current and future climate scenarios in relation to forests and forest dependent people}

This step considers the climate information used in the NAP process, its relevance for forest and trees and the main variables, changes and hazards of importance for the sector. It could stress the specific needs for the sector, for instance longer historical series, projections on a longer period or disaggregated at a more local scale, or attention to specific factors like wind or fire risks. Subsequently, it will highlight the main changes and hazards that need to be examined for the vulnerability assessment of the sector.

The first step is to consult the climate information and projections used for the overall NAP process and to consider if it is relevant for forests and trees. One of the advantages of using this same information is that forest-related analysis may be promoted more easily when based on the same premises and scenarios. In the case where different hypothesis and parameters are used, they should be explained and justified, for instance, by a specific situation or by the specific sensitivity of the forest or of specific trees of importance (for instance coffee, cocoa, rubber) to certain parameters.

In the case where vulnerability is being estimated for current climatic conditions, it may be possible to use weather records to determine the historical mean and range in climate values considered important, including occurrence of extreme weather events (e.g., Borja-Vega and De la Fuente 2013, Dasgupta et al., 2014). In addition to national sources, historical climate information may be obtained from global sources, such as the National Oceanic and Atmospheric Administration (NOAA). When not available for the precise location due to the lack of meteorological stations for example, proxies can be used, such as recordings from a comparable station, or averages at broader 
scales. However, when using these means, topographic specificities must be taken into account.

This information may be supplemented with or if necessary, replaced by, observations of climate events by people (e.g., Bele et al., 2013; Dazé et al., 2009; Obeng et al., 2011; Parkins and MacKendrick, 2007). In such cases the accuracy of quantitative variables may be lower. On the other hand, using such observations could facilitate the understanding of links between observed phenomena and concrete impacts on both forests and livelihoods. In the event where both instrumental records and personal observations are used, attention should be given to the relative weighting of recollections by affected people versus records of climate and extreme events determined by weather station instrumentation (Dasgupta et al., 2014).

It can be useful to mobilise different scenarios and methods or a range of results in order to describe a range of possible scenarios. For instance, the representative climate futures method (Whetton et al., 2012) aims to identify a small set of possible scenarios that are differentiated according to the main variables of interest and their likelihood. Within the range of potential scenarios derived from projections can be selected a hotter, drier climate or a more variable, windier climate, with identification of their likelihood, as well as the most likely climate. This enables stakeholders to get prepared to contrasted scenarios, both the most likely and the worst, this depending on variables of interest for a specific system.

\subsection{Identify and assess vulnerabilities of forests, trees and forest dependent people to climate change}

This section builds on the Framework methodology for climate change vulnerability assessments of forests and forest dependent people (Meybeck, Rose and Gitz, 2019) that can be adapted in order to give a national perspective, complemented by more detailed assessments of priority areas and/or productions.
The objective is to cover three main areas:

- vulnerabilities of forests and trees;

- vulnerability of landscapes, economic sectors that are linked to, depend upon, forests and trees; and

- vulnerability of people that depend on these sectors and landscapes.

An assessment of vulnerabilities must start from a stocktake of the sector and by its importance in the country, as well as its links with other sectors (see section 5.1), thus allowing for the identification of the most important areas to be examined. For example, it could stress the importance of tree commodity crops for the economy and employment in the country, or the importance of some tree species that play an important role in ecosystems of major interest because of their extension or specificity. It may be oriented towards ranking the relative vulnerability of species to climate or evaluating the risks of climate change altering unique ecosystems with an ecological or social significance. It could also be focused on processes that are important for economic reasons, e.g., growth rates and regeneration of commercially important trees and nontimber forest products. This identification of priority areas needs to also take into account the results of the assessment of the vulnerability of other sectors to climate change, and potential contributions of forests, trees and agroforestry (see following section) to reduce this vulnerability. For instance, the importance of mangroves and coastal forests should be emphasized due to their role in the protection of human settlements.

There are various sources of information mapping the future potential distribution of species under climate change, by comparing climate in a specific area to what are favourable conditions for a specific species. An increasing number of studies are modelling potential impacts of climate change for species of interest in a determined area, for instance, food tree species in Burkina Faso (Gaisberger et al., 2017) to project banana and coffee production zones in Nepal (Ranjitkar et al., 2016a) or to support agroforestry species selection in Yunnan Province, China (Ranjitkar et al., 2016b). The Atlas entitled 'Suitability of key Central American agroforestry species under future climates' (de Souza et al., 2017) presents current and future suitability maps for 54 species that are commonly used as shade in agroforestry 
systems in Central America. The 54 tree species that were selected include 24 species of fruit trees, 24 timber trees and six species used to improve soil conditions.

It is important to consider the indirect impacts, perturbations and changes in the ecosystem such as fires, pests, diseases, perturbations of ecosystem functioning including pollination and relations between pests and their natural enemies, and changes in species composition. Drought has often indirect consequences such as forest fires, increased pests and diseases incidences benefitting from trees weakness, which in turn create dead biomass and favours the spreading of fire; subsequently, fire has an impact on the distribution of species. In fact, a study has modelled current and future fire regimes and described their influence on natural vegetation in Ethiopia (van Breugel, Friis, Demissew et al., 2016). Climate change can also modify pest dynamics, such as for the pine processionary moth species in Europe. Dendrochronology studies can be particularly helpful as they give information on the conditions existing trees have experienced in the past (Gebrekirstos et al., 2014).

It is essential to analyze potential interactions of climate change driven changes with other causes of vulnerability and especially other human pressures on forests. The identification of other threats and changes (than those related to climate change) such as deforestation and forest degradation and how they affect the forest is fundamental, particularly when the assessment is being conducted with a long-term perspective. This analysis should begin with the current vulnerabilities such as degradation, overexploitation of NWFP, the introduction of invasive species, the lack of good governance, poor enforcement of existing laws and demographic pressure before predicting how these factors might evolve in the future.
One way to do this is to examine past and on-going trends of deforestation and forest degradation as well as their causes and drivers. At global level there are increasing demands on forests for conservation, for more wood and NWFP, with competition from other activities, especially agriculture for land. However, these demands express themselves differently at local level. There are also areas where in fact agriculture (crops and livestock) is abandoning the land and where there is spontaneous reforestation or plantations. There is also a tendency for more sustainable forest management in many areas. This can be complemented by studying human activities that are taking place in or around forests, their potential impacts, and their own trend, stable, increasing, decreasing. An additional source of information can be found in strategies and plans that could impact the forest, positively, such as a project for conservation or sustainable management, and negatively, such as new roads and mines. The combination of these elements makes it possible to identify possible orientations of various factors of vulnerability that might in turn be influenced by climate change or interact with its impacts.

The effects of climate change and other events on local populations can create additional stress for forests and should therefore be considered as an additional source of vulnerability. For instance, settlements of displaced people create additional pressure on forests, particularly due to the increased demand for woodfuel, which needs to be assessed and subsequently addressed to avoid environmental degradation (d'Annunzio et al., 2016).

Impacts on forests and trees have in turn impacts on the people who depend on them. As shown in Box 7, the notion of forest-dependent people can cover a great number and diversity of people and needs to be examined for each specific situation. 


\section{BOX 7.}

Forest dependent people

The notion of forest dependence has often been mainly defined by the direct economic contribution to livelihoods of forest products, either directly consumed or sold. Fisher et al., (1997) distinguish three types of forest-dependent people:

(a) People who live in and around natural forests or on the forest frontier, often living as hunter-gatherers or shifting cultivators, and who are heavily dependent on forest resources for their livelihoods, primarily, but not always, on a subsistence basis. Shifting cultivation is a major contributor to their food security. People in this category are often indigenous peoples or people from minority ethnic groups. They are, thus, usually outside both the political and economic mainstream.

(b) People who live in proximity to forests and are usually involved in agricultural practices either within or outside the forest, and regularly use forest products (timber, fuelwood, bush foods, medicinal plants etc.) partly for their own subsistence purposes and partly for generating income. For those more involved in agriculture, dietary supplements from forests are often of critical importance to Food Security and Nutrition.

(c) People engaged in commercial activities like hunting, collecting minerals or forest industries such as forest management and logging. Such people may be part of a mixed subsistence and cash economy and depend on the forest mainly as a source of cash income. However, it is important to note that this type of people-forest interaction can exist even in a highly monetized context: for example, some small rural communities in highly industrialized countries such as Australia and Canada can be almost totally dependent on wages from commercial logging.

Following the conclusions of Newton et al., (2016) on the necessity to adapt the definition to the objectives of the study, it should be expanded to cover some other categories of people for the purpose of vulnerability assessments.

In light of the ecosystem services provided by forests and trees to agricultural production, a fourth category should be included as forest dependent: d) people depending economically on agricultural systems that are heavily dependent on the services provided by forests and trees. For instance, farmers who grow crops depending on wild pollinators for their reproduction, or fisherfolks relying on fish and aquatic species that depend on mangroves for their reproductive and growth cycle are all forest dependent. This category is coherent with the interpretation of dependence from an economic perspective as it more accurately defines the degree of forest dependency of communities living close to forests. Often, they depend on forests not only to complement their diets and livelihoods but to provide the ecosystem services that are indispensable to the agricultural activities that constitute their main source of food and income. Moreover, this approach allows to better take into account communities and people 
downstream or downwind that depend on forests for water for their farming system.

Due to the increasingly long value chains and the development of recreational activities, there is also a fifth category: e) people depending on forest services (including for tourism for example) and on forest products' transformation and distribution as a source of income. This category is different from the c) category of Fisher et al. because those populations may have more easily other options, including using another forest for instance.

In addition to economic dependence there are populations, including in urban areas, that could constitute a sixth category: f) people depending on forests for the provision of services like cooling, protection against floods or provision of water (quantity and quality), whether living in urban or rural areas.

Finally, a seventh category could also be included in the vulnerability assessments: g) people interested in forests and trees, or in a specific forest, for cultural, religious, environmental, moral or recreational reasons. Strictly speaking these people are not economically forest dependent, but their physical and psychological well-being can be very dependent on them.

Forest-dependent people can be directly impacted by changes that occur in the forest, such as forest fires, increased risks of flood, effects on water availability and quality. For instance, in many countries forest fires represent a major risk for populations living close to forests. Such risks are likely to increase in frequency, intensity and extension. In addition to the direct risks, burned areas can experience two or three years later, following violent precipitations, wildfire debris flows that are particularly destructive. Depending on the situation of the forest, some of the effects can be felt at long distances, especially from the aspect of water regulation. In particular, the increasing frequency and intensity of wildfires, flooding events, landslides and water shortages caused by the degradation or unsustainable management of the forest and tree resources located in and around the city, are seriously affecting the livelihood and life of urban communities worldwide.

The economic effects of the impacts of climate change on forests and trees can be wide-ranging and include non-formal economy and selfconsumption. The economic effects of climate impacts on a single species, domesticated or not, can be assessed quite easily. In some cases, such as for timber production or tree-based commodities, simple estimations of economic consequences of decreased yields can be made. The biomass production of a specific forest under modified conditions can also be modelled with a derived economic production of wood. These results can be used to estimate potential effects on the livelihood of people, not only those directly benefitting from the collection of harvest, but also along value chains. In some cases, the impact of a single production is such that it can also have indirect effects at community level, due to the general reduction of income. Urban dwellers, for instance, depend on tree resources for the provision of quality water, as well as of timber, wood-fuel, and food provided by the forests surrounding their cities.

Effects on species of interest for tourism or recreational hunting can be estimated following the same type of approach, starting from the number of people interested in the species or activity, for example by using the number of registered recreational hunters in countries where such a registration exists or number of entries in national parks. The effects of the modified composition of a forest might be more difficult to quantify precisely because they generally cover a wide range of goods and services, many of which are not economically quantified. 
The impacts of climate change on a forest may require remedial interventions such as the restriction of access to protect it or to protect a specific species, or to reduce fire risks, etc. These measures, in turn, will affect forestdependent people and therefore warrant being included in the scope of the analysis.

The impacts on forest-dependent people will depend on their individual vulnerability, which would depend on their exposure and sensitivity to the consequences of the impacts of climate change on forests, as well as on their adaptive capacity, most of which depend on other factors than the forest itself (including institutional factors and access rights). Four points of particular interest are: the importance of forest-related resources in overall livelihoods, alternative sources of income and food and their level of vulnerability to climate change and other stresses, general indicators of vulnerability such as poverty and level of education, and institutional factors. The lack of secure tenure and access rights is an additional factor of vulnerability. For instance, this analysis might include aspects related to poverty, the lack of rights for access and control of forest resources and poor institutional support from governments to indigenous communities and local populations. An important percentage of tropical forests are located in communal/indigenous lands where the majority of the populations lives under the poverty line. The underlying causes of vulnerability and how this issue should be addressed in the NAP requires the appropriate attention, as the diverse factors of vulnerability are often concentrated in specific groups. Safety nets and social protection schemes, whether institutionalized or resulting from traditional forms of solidarity, can reduce vulnerability at the household level and must be assessed case by case. In fact, traditional community-based systems that are more reactive may be overwhelmed by a shock, such as drought, which impacts the whole community.

A particular focus must be placed on the potential effects on the most vulnerable groups:

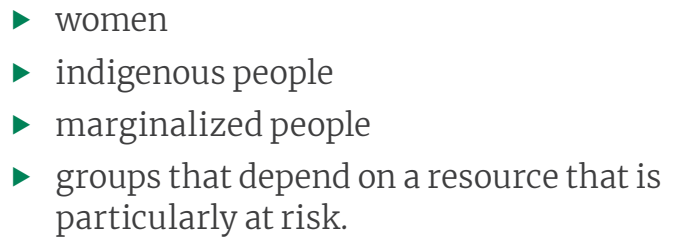

Women and men have different roles in liaison to forests and also different vulnerabilities and adaptive capacities (Balikoowa et al., 2018). The different cultural, domestic and economic roles that women and men play in their households and communities influence the sets of knowledge they develop about forest and tree resources and the environment (Bee, 2016). Globally, there tends to be significant gender differentiation as regards the collection of forest products, with important regional differences (Sunderland et al., 2014). These differences in knowledge and roles contribute to differentiated adaptive capacities and strategies in the face of a changing natural resource base (Djoudi and Brockhaus, 2011). Gender inequalities and norms limiting women's access to and control of resources, such as land, capital and technical services, can hinder their capacities for addressing the challenges of a changing climate (Brody et al. 2008; Lambrou and Piana, 2006; Rodenberg, 2009). For these reasons, specific vulnerabilities need to be fully integrated in the NAP process (see example of Uganda in Box 8).

\section{BOX 8.}

\section{A gender-responsive agriculture NAP progress in Uganda}

Climate change impacts all members of Ugandan society. However, systemic gender inequalities at all levels discriminating against women and privileging men make women more vulnerable to the effects of climate change. Unequal intra-household power relations, especially in the areas of decision-making, access and control over assets and financial resources, access to knowledge for sustainable agriculture practices, the unpaid care work as well as discriminatory laws, policies and institutional structures, limit women's opportunities. 
Awareness of the significance of gender in climate change is growing and the policy framework for promoting gender equality in Uganda is favorable. In this context the Government of Uganda adopted a gender-responsive approach to developing a NAP for the agriculture sectors. The ultimate goal of this approach is to enhance women's and men's capacity to respond to climate change effects and strengthen their resilience.

The gender-responsive adaptation planning process in agriculture was led by the Ministry of Agriculture, Animal Industries and Fisheries (MAAIF), through its Climate Change Task Force. Technical assistance was provided by FAO and UNDP, in collaboration with the Climate Change Department (CCD) of the Ministry of Water and Environment (MWE).

The participatory process involved actions throughout the NAP cycle, including:

- Stocktaking to clarify gender gaps in agriculture (Element A): The Climate Change Task Force identified and formulated a thematic area to address the gender gaps and facilitate the development and implementation of a gender-responsive NAP for the agriculture sectors.

- Stakeholder analysis and consultations (Element B): This identified the need for capacity development in gender analysis.

- Workshops to strengthen gender capacity at all levels (Element C): Four workshops were held for Parliamentarians, Central Government, District Local Governments and Non-state actors. Topics covered included: gender-responsive policy analysis, and gender-responsive policy development, planning, budgeting and implementation.

The gender-responsive planning process resulted in a NAP for the agriculture sectors that is gender-responsive; gender is one of eight priority themes in the plan and is included in the budget and the monitoring and evaluation framework. The process also resulted in co-benefits, such as improved collaboration across ministries and improved skills among key stakeholders at parliamentary, national, district, non-state actors, private sector and local communities. Uganda's experiences point to the following recommendations:

- Employ a participatory and inclusive approach in adaptation planning processes to capture diverse perspectives from women and men across different socio-economic and regional backgrounds and from across levels of government, including community, local, central levels and civil society organizations.

- Operationalize existing acts, regulations and guidelines that address gender issues, such as budget regulations.

- Draw on research and evidence on gender-based vulnerabilities and impacts in order to improve awareness and acceptance of addressing gender among different sectors.

- Develop institutional/staff capacity in gender analysis and mainstreaming for government and non-state stakeholders. 
Addressing gender capacity development promotes women's equitable representation and participation in implementation of the climate change interventions.

- Strengthen partnerships with state and non-state actors to support gender mainstreaming and gender specific actions and cost leveraging.

\section{Lessons learned:}

- In Uganda, local government implements climate change action while the central government plays a stronger role in policy making. This calls for engagement of different levels of government in the planning process.

- Strengthening gender-responsive planning and budgeting for adaptation in the agricultural sector requires recognizing and building on different stakeholders' mandates and capacities and tailoring capacity development.

- Cultural and religious institutions are key in promoting and advancing gender equality and management of the natural resources at the community level.

Uganda's approach was particularly successful because it was a sustained effort over a period of multiple years with gender experts ensuring consistency and coordination. The Uganda approach drew upon existing evidence to justify the inclusion of gender in the NAP for agriculture and also built upon existing policy mandates (especially the budget call circular on gender) to identify gender-responsive means of implementation. In addition, it linked up gender-related actions across the different elements of the NAP process, drawing upon the gender contributions of stakeholders at different planning levels along the way.

\section{Further information}

Gender and adaptation planning in the agriculture sectors - the case of Uganda: http://www.fao.org/3/I8282EN/i8282en.pdf

Video including Uganda planners, Addressing Gender in Climate Change Policies for Agriculture: https://youtu.be/nsIxsSOXups

Equal footing: working together to face climate change in Uganda: https://youtu.be/34G2Zzq3_oo

Given the multiple roles of forests in providing income, nutritious foods and cooking wood, and as providers of support functions for agriculture (HLPE, 2017), it is recommended to further examine the impacts of climate change on food security and nutrition in its four dimensions of availability, access, utilization and stability, particularly in areas where food insecurity and nutrition deficiencies are prevalent. 


\subsection{Identify where forests and trees can contribute to strengthen climate change adaptation in identified vulnerable sectors}

This section briefly provides examples of some of the contributions that forests and trees can make to adaptation:

- farming systems (crops, livestock);

- regulation of the water cycle;

- erosion control;

- protection of coastal areas against the consequences of sea level rise (including mangroves);

- cooling effects for cities (including urban forests);

- cooling effects for rivers and inland fisheries.

The aim is to support the design of adaptation measures using forests, trees and agroforestry to address some of the vulnerabilities identified in other sectors. The following tables were compiled based on the analysis of published NAPs and comparable documents complemented by relevant scientific and technical literature. As they are organized by systems or sectors, some measures may reappear in several tables. The objective is to fuel discussions within the relevant groups.

In for instance its NAP for the agriculture sectors, Uganda gives particular importance to the role of forestry in the adaptation of all agriculture sectors (see Box 9).

\section{Crops and livestock}

\begin{tabular}{|c|c|c|c|}
\hline CLIMATE CHANGES & ASSOCIATED RISKS & $\begin{array}{l}\text { CROP AND LIVESTOCK RELATED } \\
\text { IMPACTS }\end{array}$ & FORESTS AND TREES-BASED SOLUTIONS \\
\hline $\begin{array}{l}\text { Changing and more } \\
\text { variable climate. }\end{array}$ & & $\begin{array}{l}\text { Reduced yields and animal } \\
\text { productivity. } \\
\text { Loss of harvest. }\end{array}$ & $\begin{array}{l}\text { Diversification of production. } \\
\text { Forest resources buffering losses. }\end{array}$ \\
\hline \multirow{3}{*}{ Higher temperatures. } & $\begin{array}{l}\text { Increased } \\
\text { evapotranspiration. }\end{array}$ & Reduced yield. & $\begin{array}{l}\text { Agroforestry systems - low water } \\
\text { demand species - in shading systems } \\
\text { (to shade crops). }\end{array}$ \\
\hline & \multirow{2}{*}{$\begin{array}{l}\text { Increased frequency of } \\
\text { heat waves. }\end{array}$} & $\begin{array}{l}\text { Reduced yields and animal } \\
\text { productivity. }\end{array}$ & $\begin{array}{l}\text { Agroforestry in shading systems (to } \\
\text { shade crops and livestock). }\end{array}$ \\
\hline & & Less water available. & $\begin{array}{l}\text { Conserve and establish trees along } \\
\text { rivers, irrigation canals and water } \\
\text { storage to provide shade. }\end{array}$ \\
\hline \multirow[t]{2}{*}{$\begin{array}{l}\text { Reduced and more } \\
\text { variable precipitations. }\end{array}$} & \multirow[t]{2}{*}{ Drought. } & $\begin{array}{l}\text { Land degradation. } \\
\text { Reduction of yield (crops, } \\
\text { grasslands). }\end{array}$ & $\begin{array}{l}\text { Agroforestry systems - low water } \\
\text { demand species - including on contour } \\
\text { lines (to increase water infiltration } \\
\text { rates and water retention capacity). }\end{array}$ \\
\hline & & $\begin{array}{l}\text { Reduction of fodder } \\
\text { availability. }\end{array}$ & $\begin{array}{l}\text { Agroforestry systems for fodder } \\
\text { production. }\end{array}$ \\
\hline $\begin{array}{l}\text { More violent } \\
\text { precipitations. }\end{array}$ & Increased soil erosion. & $\begin{array}{l}\text { Land degradation and } \\
\text { erosion. }\end{array}$ & $\begin{array}{l}\text { Conserve and develop forests in areas at } \\
\text { higher risk of erosion. } \\
\text { Agroforestry (to increase soil organic } \\
\text { matter will improve the water balance). }\end{array}$ \\
\hline
\end{tabular}




\begin{tabular}{|l|l|l|l|}
\hline $\begin{array}{l}\text { Change of precipitations } \\
\text { from snow to rain. }\end{array}$ & $\begin{array}{l}\text { Changes in river flows; } \\
\text { more variability in } \\
\text { flows. }\end{array}$ & $\begin{array}{l}\text { Changes in availability of } \\
\text { surface water for irrigation. } \\
\text { Increased frequency } \\
\text { of flooding events and } \\
\text { landslides. }\end{array}$ & $\begin{array}{l}\text { Maintain and develop forest coverage in } \\
\text { the water basin. } \\
\text { Forestry practices to protect and } \\
\text { conserve watersheds with the aim of } \\
\text { facilitating infiltration in the soil and } \\
\text { reduce run off. }\end{array}$ \\
\hline Stronger winds. & $\begin{array}{l}\text { Stress for plants and } \\
\text { animals. } \\
\text { Increased soil erosion. }\end{array}$ & $\begin{array}{l}\text { Reduction of crop yields and } \\
\text { animal productivity. }\end{array}$ & $\begin{array}{l}\text { Wind breaks and agroforestry (to } \\
\text { reduce winds speed). }\end{array}$ \\
\hline Sea level rise. & $\begin{array}{l}\text { Expansion of areas at } \\
\text { risk of floods. } \\
\text { Salinization. }\end{array}$ & $\begin{array}{l}\text { Reduction of cultivable } \\
\text { areas. }\end{array}$ & $\begin{array}{l}\text { Protection and restoration of } \\
\text { mangroves. } \\
\text { Establish coastal protection forests. }\end{array}$ \\
\hline Climate change. & $\begin{array}{l}\text { Reduction of wild } \\
\text { and domesticated } \\
\text { pollinators. } \\
\text { Increase in the } \\
\text { populations and } \\
\text { activity of insect pests. }\end{array}$ & $\begin{array}{l}\text { Reduction of yields of } \\
\text { pollinated crops. }\end{array}$ & $\begin{array}{l}\text { Protection and establishment of } \\
\text { forests, forest patches, hedgerows and } \\
\text { agroforestry systems to provide shelter } \\
\text { and food to wild pollinators. }\end{array}$ \\
\hline
\end{tabular}

\section{Water}

\begin{tabular}{|c|c|c|c|}
\hline CLIMATE CHANGES & $\begin{array}{l}\text { ASSOCIATED WATER RELATED } \\
\text { RISKS }\end{array}$ & WATER RELATED IMPACTS & FORESTS AND TREES-BASED SOLUTIONS \\
\hline \multirow[b]{2}{*}{ Higher temperatures. } & Evaporation. & Less water available. & \multirow[b]{2}{*}{$\begin{array}{l}\text { Conserve and establish trees along } \\
\text { rivers, irrigation canals and water } \\
\text { storage to provide shade. }\end{array}$} \\
\hline & $\begin{array}{l}\text { Higher temperature of } \\
\text { surface waters (rivers } \\
\text { and lakes). }\end{array}$ & Fish mortality. & \\
\hline $\begin{array}{l}\text { Reduced and } \\
\text { more variable } \\
\text { precipitations. }\end{array}$ & Drought. & $\begin{array}{l}\text { Land degradation. } \\
\text { Reduction of yield (crops, } \\
\text { grasslands). }\end{array}$ & $\begin{array}{l}\text { Trees (appropriate species and } \\
\text { density) can improve water } \\
\text { conservation and circulation in the } \\
\text { soil. }\end{array}$ \\
\hline \multirow[t]{2}{*}{$\begin{array}{l}\text { More violent } \\
\text { precipitation. }\end{array}$} & Increased erosion. & $\begin{array}{l}\text { Silting in dams. } \\
\text { Degradation of fish spawning } \\
\text { grounds. } \\
\text { Reduced navigability of rivers. } \\
\text { Degradation of water quality. }\end{array}$ & $\begin{array}{l}\text { Conserve and develop forests in areas } \\
\text { at the most risk of erosion. }\end{array}$ \\
\hline & Floods. & $\begin{array}{l}\text { Loss of lives. } \\
\text { Loss of property. } \\
\text { Degradation of water quality. }\end{array}$ & \multirow{2}{*}{$\begin{array}{l}\text { Maintain and develop forest coverage } \\
\text { in the water basin to facilitate } \\
\text { infiltration in the soil and reduce } \\
\text { running off. }\end{array}$} \\
\hline $\begin{array}{l}\text { Change of } \\
\text { precipitations from } \\
\text { snow to rain. }\end{array}$ & $\begin{array}{l}\text { Changes in river flows; } \\
\text { more variability in flows. }\end{array}$ & $\begin{array}{l}\text { Floods } \\
\text { "Flushing" of fish spawning } \\
\text { grounds. }\end{array}$ & \\
\hline Sea level rise. & $\begin{array}{l}\text { Changes in rivers' } \\
\text { profiles, especially closer } \\
\text { to the sea. }\end{array}$ & $\begin{array}{l}\text { Expansion of areas at risk of } \\
\text { flood. }\end{array}$ & Establish protection of forests. \\
\hline
\end{tabular}




\section{Cities, human settlements, infrastructures}

\begin{tabular}{|c|c|c|c|}
\hline CLIMATE CHANGES & ASSOCIATED RISKS & $\begin{array}{l}\text { IMPACTS ON CITIES AND URBAN } \\
\text { POPULATIONS }\end{array}$ & FORESTS AND TREES-BASED SOLUTIONS \\
\hline Higher temperatures. & Heat waves. & Health risks in urban areas. & $\begin{array}{l}\text { Establish tree systems in and around } \\
\text { urban areas for cooling effect and to } \\
\text { reduce heat island effects. }\end{array}$ \\
\hline \multirow[t]{2}{*}{$\begin{array}{l}\text { More violent } \\
\text { precipitations. }\end{array}$} & Floods. & $\begin{array}{l}\text { Loss of lives and property. } \\
\text { Reduced water quality. } \\
\text { Water-related illnesses, } \\
\text { diarrheas. }\end{array}$ & $\begin{array}{l}\text { Maintain and develop forest coverage } \\
\text { in the water basin to facilitate } \\
\text { infiltration in the soil, reduce run off, } \\
\text { and increase water quality through } \\
\text { filtration of pollutants and sediments. }\end{array}$ \\
\hline & Landslides. & Loss of lives and property. & $\begin{array}{l}\text { Maintain and develop tree systems, } \\
\text { particularly on slopes. }\end{array}$ \\
\hline Increased wind erosion. & Air pollution. & $\begin{array}{l}\text { Increased respiratory } \\
\text { symptoms, such as irritation } \\
\text { of the airways, coughing } \\
\text { or difficulty breathing. } \\
\text { Decreased lung function. } \\
\text { Premature death in people } \\
\text { with heart or lung disease. }\end{array}$ & $\begin{array}{l}\text { Conserve and develop forests and } \\
\text { tree systems in areas at risk of wind } \\
\text { erosion in order to keep soil natural } \\
\text { coverage and make it less susceptible } \\
\text { to wind erosion. }\end{array}$ \\
\hline \multirow[t]{2}{*}{$\begin{array}{l}\text { Increased frequency of } \\
\text { wildfires. }\end{array}$} & Air pollution. & $\begin{array}{l}\text { Increased respiratory } \\
\text { symptoms, such as irritation } \\
\text { of the airways, coughing } \\
\text { or difficulty breathing. } \\
\text { Decreased lung function. } \\
\text { Premature death in people } \\
\text { with heart or lung disease. }\end{array}$ & \multirow[t]{2}{*}{$\begin{array}{l}\text { Prevent and manage forest fires. } \\
\text { Properly manage the wildland-urban } \\
\text { interface in order to minimize the risk } \\
\text { of wildfire. }\end{array}$} \\
\hline & Direct damages. & Loss of lives and property. & \\
\hline Sea level rise. & Inundations & Loss of lives and property. & $\begin{array}{l}\text { Conserve and restore mangroves. } \\
\text { Establish coastal forests. }\end{array}$ \\
\hline
\end{tabular}

\section{Energy}

\begin{tabular}{|c|c|c|c|}
\hline CLIMATE CHANGES & ASSOCIATED RISKS & ENERGY RELATED IMPACTS & FORESTS AND TREES-BASED SOLUTIONS \\
\hline \multirow[b]{2}{*}{ Higher temperatures. } & $\begin{array}{l}\text { Higher average } \\
\text { temperature in summer. }\end{array}$ & $\begin{array}{l}\text { Increased consumption of } \\
\text { energy for air conditioning. }\end{array}$ & \multirow{2}{*}{$\begin{array}{l}\text { Establish and manage trees in and } \\
\text { around urban areas for a cooling } \\
\text { effect and to reduce heat island } \\
\text { effects; also reduces the use of air } \\
\text { conditioning. }\end{array}$} \\
\hline & Heat waves. & $\begin{array}{l}\text { Peak energy consumption for } \\
\text { air conditioning. }\end{array}$ & \\
\hline $\begin{array}{l}\text { More violent } \\
\text { precipitations. }\end{array}$ & Increased erosion. & $\begin{array}{l}\text { Silting in dams, reducing their } \\
\text { water storage capacity with } \\
\text { impacts on hydroelectricity } \\
\text { potential. }\end{array}$ & $\begin{array}{l}\text { Conserve and develop forests in areas } \\
\text { the most at risk of erosion. }\end{array}$ \\
\hline $\begin{array}{l}\text { Reduced and } \\
\text { more variable } \\
\text { precipitations. }\end{array}$ & \multirow{2}{*}{$\begin{array}{l}\text { Changes in river flows; } \\
\text { more variability in flows. }\end{array}$} & \multirow{2}{*}{$\begin{array}{l}\text { Irregularity in hydropower } \\
\text { potential. } \\
\text { Reduced water availability for } \\
\text { cooling of thermic and nuclear } \\
\text { energy facilities. }\end{array}$} & \multirow{2}{*}{$\begin{array}{l}\text { Maintain and develop forest coverage } \\
\text { in the water basin to facilitate } \\
\text { infiltration in the soil and reduce } \\
\text { running off. }\end{array}$} \\
\hline $\begin{array}{l}\text { Change of } \\
\text { precipitations from } \\
\text { snow to rain. }\end{array}$ & & & \\
\hline
\end{tabular}




\section{Fisheries and aquaculture}

\begin{tabular}{|c|c|c|c|}
\hline CLIMATE CHANGES & ASSOCIATED RISKS & $\begin{array}{l}\text { POTENTIAL IMPACTS ON } \\
\text { FISHERIES AND AQUACULTURE }\end{array}$ & FORESTS AND TREES-BASED SOLUTIONS \\
\hline \multirow[b]{2}{*}{ Higher temperatures. } & Evaporation & Less water available & \multirow{2}{*}{$\begin{array}{l}\text { Conserve and establish trees to provide } \\
\text { shade along rivers, irrigation and water } \\
\text { storage. }\end{array}$} \\
\hline & $\begin{array}{l}\text { Higher temperature of } \\
\text { surface waters (rivers } \\
\text { and lakes). }\end{array}$ & Fish mortality. & \\
\hline \multirow[t]{2}{*}{$\begin{array}{l}\text { More violent } \\
\text { precipitation. }\end{array}$} & Increased erosion. & $\begin{array}{l}\text { Degradation of fish } \\
\text { spawning grounds. } \\
\text { Degradation of water } \\
\text { quality. }\end{array}$ & $\begin{array}{l}\text { Conserve and develop forests in areas at } \\
\text { the most risk of erosion. }\end{array}$ \\
\hline & Floods. & $\begin{array}{l}\text { Degradation of water } \\
\text { quality. }\end{array}$ & \multirow{2}{*}{$\begin{array}{l}\text { Maintain and develop forest coverage in } \\
\text { the water basin to facilitate infiltration } \\
\text { in the soil and reduce running off. }\end{array}$} \\
\hline $\begin{array}{l}\text { Change of precipitations } \\
\text { from snow to rain. }\end{array}$ & $\begin{array}{l}\text { Changes in river flows; } \\
\text { more variability in } \\
\text { flows. }\end{array}$ & $\begin{array}{l}\text { Floods } \\
\text { "flushing" of spawning } \\
\text { grounds. }\end{array}$ & \\
\hline Sea level rise. & Mangroves at risk. & $\begin{array}{l}\text { Degradation of } \\
\text { habitat, critical for fish } \\
\text { reproduction. }\end{array}$ & Protect and restore mangroves. \\
\hline
\end{tabular}

\section{Health}

\begin{tabular}{|c|c|c|c|}
\hline CLIMATE CHANGES & ASSOCIATED RISKS & IMPACTS ON HEALTH & FORESTS AND TREES-BASED SOLUTIONS \\
\hline \multirow[b]{2}{*}{ Higher temperatures. } & \multirow[b]{2}{*}{ Heat waves. } & $\begin{array}{l}\text { Occupational health risks for } \\
\text { farmers and agriculture workers. }\end{array}$ & $\begin{array}{l}\text { Establish trees in the fields to provide } \\
\text { shade at the hottest hours of the day. }\end{array}$ \\
\hline & & Health risks in urban areas. & $\begin{array}{l}\text { Establish trees in and around urban } \\
\text { areas for cooling effect and to reduce } \\
\text { heat island effects. }\end{array}$ \\
\hline $\begin{array}{l}\text { More violent } \\
\text { precipitations. }\end{array}$ & Floods. & $\begin{array}{l}\text { Water-related illnesses, } \\
\text { diarrheas. }\end{array}$ & $\begin{array}{l}\text { Maintain and develop forest coverage in } \\
\text { the water basin to facilitate infiltration } \\
\text { in the soil and reduce running off. }\end{array}$ \\
\hline $\begin{array}{l}\text { Increased wind } \\
\text { erosion. }\end{array}$ & Air pollution. & $\begin{array}{l}\text { Increased respiratory symptoms, } \\
\text { such as irritation of the airways, } \\
\text { coughing or difficulty breathing. } \\
\text { Decreased lung function. } \\
\text { Premature death in people with } \\
\text { heart or lung disease. }\end{array}$ & $\begin{array}{l}\text { Conserve and develop forests in areas } \\
\text { the most at risk of wind erosion. }\end{array}$ \\
\hline $\begin{array}{l}\text { Increased frequency } \\
\text { of wild fires. }\end{array}$ & Air pollution. & $\begin{array}{l}\text { Increased respiratory symptoms, } \\
\text { such as irritation of the airways, } \\
\text { coughing or difficulty breathing. } \\
\text { Decreased lung function. } \\
\text { Premature death in people with } \\
\text { heart or lung disease. }\end{array}$ & $\begin{array}{l}\text { Prevent and manage forest fires. } \\
\text { Properly manage the wildland-urban } \\
\text { interface in order to minimize the } \\
\text { risk of wild fire. }\end{array}$ \\
\hline
\end{tabular}




\section{BOX 9.}

\section{Forestry in Uganda's NAP for agriculture}

Forestry is one of the priority areas for adaptation action in Uganda's National Adaptation Plan for the Agricultural Sector. While the contribution to agricultural GDP by forests is not large - only 4 percent - the plan recognizes the importance of agriculture for maintaining climate-resilient environments that support agricultural productivity and adaptation. During the analysis the Plan takes a forests-for-adaptation approach:

- Loss of forest and land degradation. Uganda's greatest environmental threats are the sustained destruction of wetlands, deforestation and lake contamination. Annually, it is losing over 2 percent of its forest cover and wetlands. Estimates of economic loss attributed to land degradation in Uganda in the 1990s ranged from 4 to 12 percent of GDP.

- Conversion to agriculture. Crop productivity is on the downward trend and agricultural land area has expanded at a rate of 1 percent per year over the last decade, meaning that by 2040 more than 90 percent of Uganda's land will be used for agriculture thus threatening forests and wetlands. In order to avoid risks due to these changes, Ugandan agriculture must shift from extensive uses of the land to intensive farming.

- Forests for fuel. Ugandans rely largely on traditional biomass energy, which is already in short supply due to the high rates of deforestation. Deforestation caused by an increased demand for biomass increases land degradation, which also reduces agricultural productivity. Climate change will likely reduce the availability of biomass, therefore, the transition to alternative energy sources for household use should be prioritised.

- Securing water availability for agriculture. Forests feature in prioritized actions relating to the future availability of water for agriculture and other uses. This is seen as integral to improving land use systems and reducing forest, soil and environmental degradation. Actions taken towards this goal include strengthening catchment management in agricultural planning, adopting sustainable agricultural land, forest land and water management to reduce degradation, and promoting appropriate forest and ecosystem management practices to increase the resilience of agrarian communities to the impacts of a changing climate. 


\subsection{Identify adaptation options for forests, tree systems and forest dependent people}

Following the identification of risks and vulnerabilities for forests and trees as well as for forest-dependent people, adaptation pathways and measures can be sketched. These pathways and measures will also need to take into account other pressures on forests as well as other objectives, including the potential contribution to the adaptation of other sectors (see section 6.3).

Maintaining forest ecosystems in a healthy state is the most straightforward measure to be taken in order to retain their resilience (FAO, 2016a). Healthy forests are better able to cope with stress, recover from damage and adapt autonomously to change. Healthy ecosystems are more resilient to negative biotic and abiotic influences than are ecosystems under stress whose ecological processes are impaired. Best practices include integrated pest management, forest fire management, employment of reduced impact logging (RIL) in production forests, limitation of gathering of non-wood forest products or livestock grazing in forests at sustainable levels, and forest law enforcement. Restoring degraded forests to healthy states, thereby re-establishing ecosystem functions, is a major strategy for increasing resilience. An estimated two billion hectares of land can potentially be restored or reforested. Biodiversity is a key factor underlying the resilience of forest ecosystems and trees to existing stresses and is a basic ingredient for building their adaptive capacity in the face of future stress factors. Particular attention shall be given to EbA, which is the management of ecosystems and ecosystem services to reduce human vulnerability to climate change. This calls for improved monitoring of the state of forests and impacts of climate change on them, including monitoring of native pests and invasive species.

Adaptive forest management is essential for reducing forest vulnerability and maintaining forest productivity. Adaptation measures might include, for example, the selection of heattolerant and drought-tolerant species in planted forests, planting stock originating from a range of provenances, planting of tree varieties adapted to expected climatic conditions, and the assisted natural regeneration of adapted species and varieties. The probable impacts of climate change on tree and forest growth when determining sites and selecting species for the establishment of all types of forests and systems with trees requires close examination. Table 7 hereunder indicates some of the main adaptation measures that can be included. More detailed options are available in FAO's Climate change guidelines for forest managers (FAO, 2013). 


\section{TABLE 2.}

\section{Examples of measures to increase forest resilience to various impacts of climate change}

\begin{tabular}{|c|c|c|}
\hline RISKS/IMPACTS & $\begin{array}{l}\text { IMPLICATIONS( SOCIAL, ECONOMIC AND } \\
\text { ENVIRONMENTAL) }\end{array}$ & $\begin{array}{l}\text { RESPONSE MEASURES FOR RISK REDUCTION AND } \\
\text { INCREASED RESILIENCE }\end{array}$ \\
\hline $\begin{array}{l}\text { Decreased forest vitality } \\
\text { and productivity }\end{array}$ & $\begin{array}{l}\text { Reduced revenue from wood and non-wood } \\
\text { forest products; reduced forest ecosystem } \\
\text { services. }\end{array}$ & $\begin{array}{l}\text { Adjust silvicultural practices, change } \\
\text { composition of species and varieties; } \\
\text { increase forest biodiversity; implement } \\
\text { forest restoration measures. }\end{array}$ \\
\hline $\begin{array}{l}\text { Increased forest pests } \\
\text { and diseases }\end{array}$ & $\begin{array}{l}\text { Reduced forest revenue; reduced forest } \\
\text { ecosystem services. }\end{array}$ & $\begin{array}{l}\text { Implement and intensify pests and diseases } \\
\text { management measures; adjust silvicultural } \\
\text { practices. }\end{array}$ \\
\hline Increased wildfires & $\begin{array}{l}\text { Loss of life; damage to infrastructure; } \\
\text { reduced forest revenue and ecosystem } \\
\text { services; wildlife losses. }\end{array}$ & $\begin{array}{l}\text { Implement and intensify wildfire } \\
\text { management; adjust silvicultural practices. }\end{array}$ \\
\hline $\begin{array}{l}\text { Increased water erosion } \\
\text { and landslides }\end{array}$ & $\begin{array}{l}\text { Damage to forest and infrastructure (towns, } \\
\text { roads, dams); reduced water quality. }\end{array}$ & $\begin{array}{l}\text { Undertake watershed management } \\
\text { measures, including protecting and } \\
\text { increasing vegetation cover; reduce } \\
\text { intensities of harvesting and other uses. }\end{array}$ \\
\hline $\begin{array}{l}\text { Drought-induced forest } \\
\text { and tree dieback and } \\
\text { land degradation }\end{array}$ & $\begin{array}{l}\text { Reduced availability of forest products; } \\
\text { increased wind damage; reduced grazing } \\
\text { values. }\end{array}$ & $\begin{array}{l}\text { Plant windbreaks; maintain tree cover; } \\
\text { change composition of species and varieties. }\end{array}$ \\
\hline Increased storm damage & $\begin{array}{l}\text { Reduced forest revenue and ecosystem } \\
\text { services; increased risk of pests and diseases. }\end{array}$ & $\begin{array}{l}\text { Change species to adjust tree spacing to } \\
\text { reduce risk; salvage harvesting; pests and } \\
\text { diseases control. }\end{array}$ \\
\hline $\begin{array}{l}\text { Reduced extent and } \\
\text { vitality of mangroves } \\
\text { and coastal forests }\end{array}$ & $\begin{array}{l}\text { Increased exposure of land to storm damage; } \\
\text { reduced productivity of coastal fisheries. }\end{array}$ & $\begin{array}{l}\text { Increase protection, restoration and } \\
\text { enhancement of mangroves and other } \\
\text { coastal forests. }\end{array}$ \\
\hline $\begin{array}{l}\text { Changes in species } \\
\text { ranges and species } \\
\text { extinctions }\end{array}$ & $\begin{array}{l}\text { Reduced forest ecosystem functions; loss of } \\
\text { forest biodiversity. }\end{array}$ & $\begin{array}{l}\text { Restore or increase forest connectivity and } \\
\text { wildlife corridors; assist migration; take } \\
\text { ex-situ conservation measures. }\end{array}$ \\
\hline
\end{tabular}

Source: FAO, $2016 a$

Forest managers must take numerous factors and objectives (see Figure 5) into account. Climate change is one more of these. It also modifies most of the other factors. Adaptation options should thus be understood as part of sustainable forest management and consequently integrated into the country's national forest programme. Their potential contribution to sustainable development and mitigation co-benefits, as well as possible social consequences should also be taken into consideration. Of particular importance for their feasibility is a thorough understanding of costs and benefits of options, in particular their distribution in time and among categories of actors. It has also been noted that the amount of funding available for adaptation can be a critical factor in deciding on options aimed at minimizing species extinction in a biome of South Africa (Wintle et al., 2011): with a small budget fire management was the best option; at intermediate level of budget the best strategy was more habitat protection; with again more budget the best option is to put more into fire protection. 


\section{FIGURE 5.}

\section{Forest managers respond to a wide range of factors}

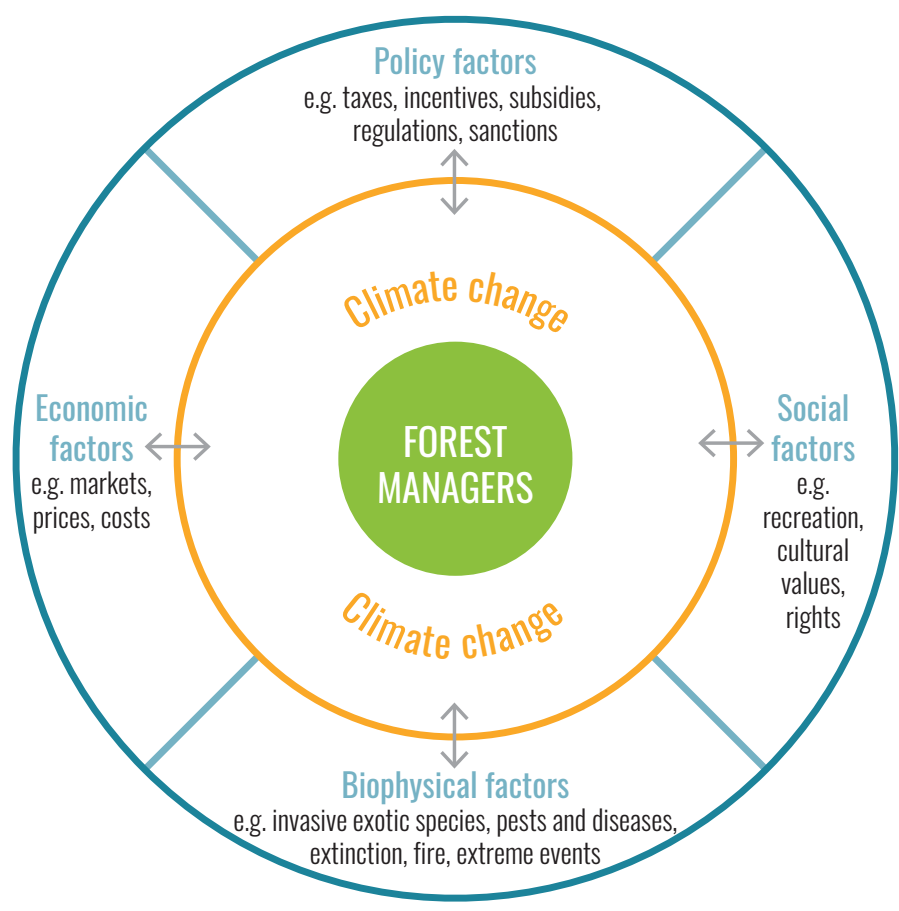

Source: FAO, 2013

The identification of adaptation options should be accompanied by an estimate of their costs and benefits (see Box 10).

\section{BOX 10.}

\section{Assessing the financial and economic viability of agroforestry-related adaptation options for Kenyan farmers}

Agroforestry is considered one of the best options for farmers in Kenya to adapt to climate change risks. According to the projected changes in seasonal mean temperatures and expected impacts on the pattern of short rains, drought conditions resulting in crop and livestock losses are expected to intensify. Agroforestry - growing crops together with trees for shade and wood - is reported to have a positive impact on livelihoods (Nyaruai, 2016). Agroforestry offers the potential to diversify household income sources through the production of fruits, fodder, wood for fuel and construction, medical substances, fibres and waxes.

Kenya's NAP proposed a series of actions over 2015-2030 in agriculture. Their successful implementation depends on adjustments by farmers to adopt new technologies, reallocate labour, and make investments. It is therefore important to address the barriers to adoption. In 2018, under the NAP-Ag programme, a study was conducted using cost-benefit analysis to compare the financial and economic costs and benefits for adopting 
adaptation practices (in particular, agroforestry and soil and water conservation). These sets of practices are already commonplace - a survey of 642 households across 5 counties showed that 89 percent of farmers planted trees in their fields.

However, there are various barriers to more widespread adoption. The study, which employs a representative survey and secondary data, showed that there are clear economic and financial benefits for farmers in the long run. Nevertheless, as trees mature there is a trade-off with the productivity of adjacent crops; for example, it was found that in Eastern Kenya the maize planted on the same plots as woody plants had 30 percent less yield than when planted in fields without trees (Ndlovu, 2013). Nevertheless, woody species provided substantial returns for farmers (between USD 50-80 depending on size and quality) when harvested after 8 years; consequently, this income can offset the annual income losses due to a reduced yield by generating a positive incremental benefit for the farmers, as well as a range of environmental benefits for society at large.

However, the profitability of agricultural technologies is not enough to guarantee the adoption of desirable adaptation practices. The examples provided in the case of Kenya have demonstrated some of the ways in which governments can facilitate this by:

- creating awareness and enhancing access to agricultural extension;

- establishing land tenure security and addressing drivers of adoption;

- increasing productive inputs and finance; and

- enhance access to credit.

For more information, see FAO \& UNDP, $2020 b$.

\subsection{Identify how to improve the enabling environment}

The impacts of climate change on forests need to be addressed and managed on various scales, requiring action at a landscape, subnational and/or national level, and by various actors in a coordinated way. In order to accomplish this, a proper enabling environment and coherent mobilization of technical, jurisdictional and financial levers should be put into place. A good example is fire prevention, early detection and early action, each of which call for organized collective action at landscape, subnational and national levels. The publication prepared by FAO that accurately describes all principles and measures to be implemented, Fire management Voluntary guidelines: Principles and strategic actions is available in the $6 \mathrm{UN}$ languages (FAO, 2006).

Prevention and monitoring of pests are another important issue to be addressed ${ }^{6}$. Several countries 7 have established a system for pest monitoring making available tools to identify pests, from posters to online databases, means for reporting pests' outbreaks, and guidelines for early action.

A critical issue for adaptation is the conservation, multiplication and distribution of appropriate genetic material, in diversity and quality. Disposing of adequate organization for it is one of

6 For general information and principles and a global review of forests pests see http://www.fao.org/forestry/pests/94183/en/

7 See for instance for New Zealand, recommendations and tools available at https://www.mpi.govt.nz/growing-and-harvesting/ forestry/new-zealand-forests-and-the-forest-industry/protecting-nz-forests/taking-care-of-your-forest/ 
the key elements of adaptive capacity. It entails multiple institutional arrangements, including for the collection and conservation of genetic material and associated knowledge on its specificities (growth rate, optimal conditions, etc.) and ways to use it (both for production and as a product, food for instance). It also requires rules facilitating the exchange of genetic material between countries and public and private institutions that can multiply as well as distribute material with the appropriate training (Lilles $\emptyset$ et al., 2018; Nyoka et al., 2014; Lilles $\emptyset$ et al., 2011).8

The implementation of adaptation actions for forests, trees and agroforestry generally requires a long-term perspective as well as large-scale management, which in turn requires an enabling environment that to a great extent, is actually the same as that of sustainable forest management.

The long-term visibility of the areas destined to remain forests is an essential element of sustainable forest management. Studies have shown that often forest managers in developing countries do not consider adaptation to be a priority or even a concern, simply because there is a higher risk that the forest will cease to be a forest (Guariguata et al., 2012). In the case where there is uncertainty about the future of the forest there is no incentive to adapt, especially if measures for long-term benefits induce short-term costs, whether it be for investment or due to forgone income.

Ownership, tenure and access rights condition incentives for long-term and sustainable management of forests, trees and the resources they generate (wood and non-wood products) as well as other ecosystem services. Of particular importance is the length, stability and protection of rights against encroachment by other actors.

Tenure and access rights governing forests and trees also condition the capacity for people to rely on them as a source of goods and income and as a buffer. Many of these rights are customary or informal and can be threatened when formalized conventions are established such as concessions granted to private companies for instance. The most vulnerable, including women and marginalized groups, are often the most dependent on forest resources, and have also the less recognized rights (whether formal or customary) and the most difficulties to enforce them. Consequently, while analysing legal arrangements and institutions particular attention shall be devoted to informal access rights, which is often a key element for the livelihood strategies of the most vulnerable groups.

Many adaptation measures require not only long-term but also large-scale management, for example, establishing buffer zones to reduce fire impacts or creating corridors for biodiversity. Both long-term and large-scale measures require forms of decision making and management that take into account interests and perspectives of diverse categories of actors, with forms of compensation between them.

Adaptation measures with trees may be constrained by difficulties in the preparation of forest management plans, restrictions on use of specific tree species, bureaucracy and paperwork involved in harvest of wood and non-wood tree/ forest products, high taxation and/or various permits needed for harvest and transport of tree/forest products. These can lead to very high transaction costs for local communities in use of tree and forest products, and result in increasing importance of middlemen who further take away significant part of the monetary incomes generated from such resources.

A large selection of public instruments is available that can be put into place to orient forest management, promote collective and long-term management and compensate for differences in costs and benefits along time and between categories of actors: laws and regulations, direct or delegated management of public forests, incentives, including taxation regimes, support to market-based instruments, often in combination.

The successful design and implementation of such measures require the full engagement of all actors since proposed adaptation measures can modify the balance between objectives and between interests (Kolström et al., 2011). Community-based management approaches are often presented as particularly effective (Keenan, 2015) as is ecosystem-based adaptation that, when effectively applied, provides biodiversity 
and social co-benefits, which strengthen the implementation of NAPs. For example, EbA benefits from active engagement and inclusion of diverse stakeholders promoting local governance of forest resources, multi-sector engagement and intra-sectoral communication (IIED, 2019). Once adaptation options have been identified, along with the measures needed to improve the enabling environment, it can be useful to prioritize them, either by sector or more broadly. Annex 4 provides an overview of some of the methodological approaches that can be used to do so.

\subsection{Compile and communicate perspectives about forests and trees}

The NAP is a long-term process that includes monitoring and periodic review (see Chapter 7). Therefore, it is important to keep track of the work being done, the data being gathered, as well as discussions and decisions, in order to evaluate progress and improve the process. It is essential that the work conducted at national level and also the relevant information gathered at subnational and local levels be included. This systematic compilation could provide a useful contribution to the preparation of specific information for the various categories of stakeholders (see Chapter 8).

One of the key requirements for the NAP process is to ensure that its stakeholders are aware of the specificities and challenges encountered by the forest sector, and that they are updated on developments as the process evolves. In order to accomplish this, there should be a short document summarizing the main findings and recommendations for forests and trees that can be used to provide feedback to all stakeholders involved, to prepare communication material in the sector, and serve as a reference for more ad hoc material for specific sector activities. This document will summarize the information gathered through steps 5.1 to 6.4, including the methodology used, data and sources. Existing documents and information can be compiled in an organized and regularly updated repository with easy access for all stakeholders. In addition, a specific contribution to the NAP process should be prepared, based on this background material, as well as contributions targeted to several groups or sections, depending on the way the work has been organized.

Given the links of forests, trees and agroforestry with multiple sectors at national and local levels, it is essential to organize effective communication channels with them. This communication will take different forms, depending on the organization of the process at national and local levels. It should be in line with the different steps of the process in order to provide appropriate information in a timely manner. It can start by preparing a synthesis document summarizing the results of the stock taking, describing the sector, its contribution to the economy, employment and livelihoods at national and local levels, with a focus on vulnerable populations as well as its perspectives of development, vulnerabilities to climate change, potential contributions to the adaptation of other sectors and potential adaptation means (see stock take in section 5.1 and annex 2). During the development of the NAP, more focused documents could be prepared for actors of another specific sector, answering their own needs and/or highlighting how the sector could contribute to the adaptation of forests, trees and agroforestry (see tables in section 6.3). For instance, there could be a specific document on the interactions between crops, livestock and trees, highlighting the contributions of forests, trees and agroforestry to crop and livestock production, potential contributions to support their adaptation and what is required in order to facilitate such contributions in terms of land and tree tenure. Such documents may include the identification of precise measures, of their costs and benefits and of the resources needed for their implementation. Such communication documents should also stress the benefits of adaptation for sustainable development, including mitigation co-benefits (see section 5.3). Communication of these perspectives will be done both formally and informally through the regular exchanges established as part of the process, with other sectors, at both national, subnational and local levels. 


\subsection{Review the integration of climate change adaptation in national and subnational forest strategies, programs and plans}

This section aims to analyse how climate change adaptation can be better integrated into current and future strategies as well as plans at national and subnational levels (see section 5.1). This requires a thorough understanding of the relevant institutional arrangements and cycles as well as the engagement of diverse government and nongovernment actors. This aspect of climate change adaptation is particularly important for forests and trees, given the fact that competencies for the various sectors and issues that relate to them are generally shared between various national and subnational entities: line ministries, specific public entities, local governments; with repartition of competencies that vary between sectors and issues.

Given the breadth of sectors as well as of government levels that can influence forest management we propose to effectuate this review in an organized way:

At national level:

- first, examine national level forest strategies, programs and plans;

- second, examine other national general and sectoral documents that could influence forests: development strategies and plans, plans for land planning, water, agriculture, food security;

- refer to national level forest strategies, programs and plans to consider how they could be modified to integrate the objectives of broader national strategies and plans, sectoral national strategies and plans as they relate to forests, trees and agroforestry;

- integrate in them what needs to be done at the national level for the adaptation of forests, trees and agroforestry and to strengthen their contribution to the adaptation of other sectors;

- prepare guidelines for a review at subnational and local levels, along the lines hereunder.
At subnational and local level and for all forest types and management objectives:

- first, examine subnational (for instance provincial) level forest strategies, programs and plans;

- second, examine other subnational general and sectoral documents that might influence forests: development strategies, programs and plans, plans for land planning, water, agriculture, food security;

- refer to subnational level forest strategies and plans to consider how they should be modified in order to integrate the objectives of broader national strategies and plans, sectoral subnanational strategies and plans as they relate to forests, trees and agroforestry;

- integrate in them what needs to be done, at the subnational level for adaptation of forests, trees and agroforestry and to strengthen their contribution to the adaptation of other sectors;

- prepare guidelines for a review at local level, covering specific forests' management strategies and or plans.

The reviews at subnational and local level can identify issues to be addressed at a broader level. The Canadian Council of Forest Ministers (CCFM) has carefully implemented the integration of climate change in forest strategies, programs and plans. In fact, it has recognized that climate change will pose challenges (in terms of meeting sustainable forest management (SFM) goals) and in some cases, bring opportunities to Canada's forestry sector through enhanced forest productivity (Johnston et al., 2009). It has therefore recommended that consideration of climate change and future climatic variability be incorporated in all aspects of SFM in Canada (CCFM, 2008). Following this recommendation, the Climate Change Task Force (CCTF) was created with a mission to gather relevant information and develop tools to help forest resource managers and professionals across the country to identify how best to include climate change considerations into SFM plans, practices and policies. Some key products developed by the task force include an adaptation framework (Williamson et al., 2012), a vulnerability assessment guidebook (Edwards et al., 2015) and other user-friendly technical reports that support the framework and guidebook.

In addition, the NAP can be a main vehicle of implementation for the NDC (see Box 11). 


\section{BOX 11.}

Fostering linkages between National Adaptation Plans (NAPs) and Nationally Determined Contributions (NDCs) to enhance agriculture sector adaptation planning in Viet Nam

Viet Nam's NDC identifies agriculture as a priority sector for developing climate change response strategies. The agriculture sector has also been given prominence in Viet Nam's NAP process, with an emphasis on reducing the vulnerabilities of the agriculture sector to climate change by integrating adaptation into agriculture development planning at all levels, in the medium- to long-term.

While NDCs represent countries' integrated mitigation and adaptation commitments at the strategic level and NAPs allow for adaptation priorities to be elaborated and implemented at the operational level, it has been increasingly recognized that despite their distinctive characteristics, climate planning instruments - including NAPs and NDCs - should be linked, sequenced and aligned to foster linkages and accelerate climate action. Such an alignment between Viet Nam's NAP process and the revision of its NDC for submission to the UNFCCC by 2020 provides a great opportunity to harness linkages, enhance the mainstreaming of adaptation goals across climate planning instruments and develop integrated strategies to address climate change.

As a result, the NAP-Ag programme in Viet Nam was chosen to provide support to the Ministry of Agriculture and Rural Development (MARD) by creating entry points to engender an alignment of the development of successful adaptation strategies under the NAP process, with a view to use inputs to review and update the NDC. The subsequent steps contributed to a sound base of evidence to support the alignment of the NDC revision with the NAP process.

1. A stocktaking of climate change adaptation practices. An extensive stocktaking exercise was conducted on 124 structural (e.g. infrastructure development and improvement of irrigation systems), and 907 nonstructural (e.g. development of new crop varieties) climate change adaptation projects in agriculture. The stocktaking demonstrated the imbalance between these measures with over 63 percent of funds being allocated to improve the resilience of large infrastructure projects. This led to the NAP-Ag recommendation that these two types of measures should be integrated to achieve low-carbon sustainable development. A gap analysis further complemented the stocktaking by identifying the lack of coherence between climate change and agricultural policies, the lack of financial mechanisms to scale-up successful models/pilot programmes, the lack of technical capacity to understand risks, and the modest private sector involvement.

2. An assessment of vulnerability and climate risk. During the NDC drafting process, policymakers identified the lack of consistent climate data as an impediment to prioritizing programs and making risk-informed decisions. Subsequently, UNDP developed the Viet Nam Climate Risk website as an open-source knowledge platform (UNDP, 2018). Climate risk indices were developed by combining numerous 
data sources such as climate change and hazard maps, vulnerability indices, and socio-economic statistics. Under the auspices of MARD, discussions between national and international experts took place to select indicators and allocate weights for vulnerability. A primary output of this activity was the development of a common methodology to assess the vulnerability of four key agriculture sectors prioritised by MARD: crops, livestock, aquaculture, and irrigation infrastructures.

3. An evaluation of loss and damage in agriculture. Loss and damage are defined as the climate change impacts that reach beyond the limits of adaptation. Ensuring that long-term climate change impacts are included in national adaptation planning is key to managing risks and delivering cost-effective adaptation investments. The evaluation revealed that climate change causing sea-level rise and drought constitutes a severe threat to Viet Nam's agriculture sectors. In the absence of adaptation measures, a $22 \mathrm{~cm}$ sea level rise would reduce cultivable land by 1 million hectares compared to a 2004 baseline, and significantly reduce rice output in the Mekong Delta, whilst a onemetre sea level rise would pose a risk of inundating almost a third of Viet Nam's railway network. Furthermore, the evaluation highlighted that the insurance sector is likely to play a key role in Viet Nam as it will increasingly provide partial coverage for loss and damage that is unavoidable. Recommendations based on this study stress that as the agriculture sector grows, directing such investments towards a more resilient economy is crucial, for example, in climate-proof infrastructure.

In addition to detailed insights, these alignment activities have also contributed key lessons to the knowledge base that will inform the adaptation component in the review and update of the NDC and also provide the foundational basis for further work to elaborate Viet Nam's NAP. These activities include:

- ongoing efforts to build capacity for adaptation planning, increase efficiency and optimize resource allocation;

- alignment between NAPs and NDCs can be enhanced through formal and informal collaboration;

- institutional coordination and linkages between NAP-Ag and the NDC update increased coherence between policy frameworks;

- 'Test and trial' approach used in the agriculture sector can inform overall adaptation planning; and

- information and risk assessment for adaptation planning will require greater investment. 


\section{9}

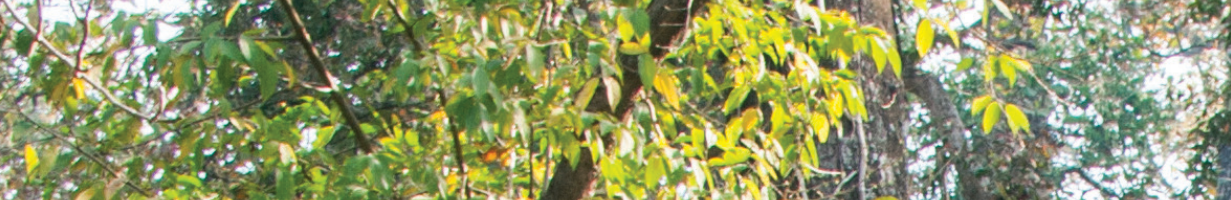

(2.2.

C.

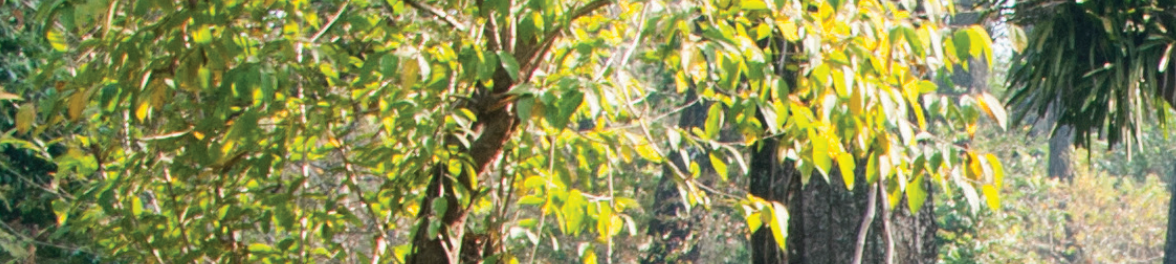

(x)

$40,5 \times 12$

$\left(\left.\begin{array}{c}1 \\ 0 \\ 0\end{array}\right|^{2}\right.$

3.13)

-1. 1.5

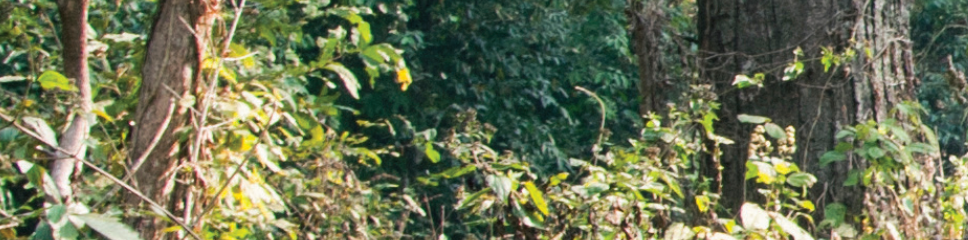

(n)

How ator.

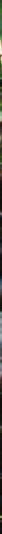

2

The

c) 5 .

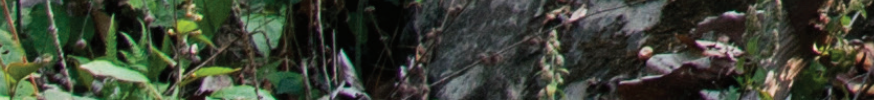

,

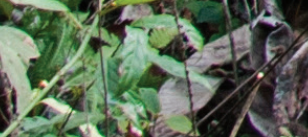




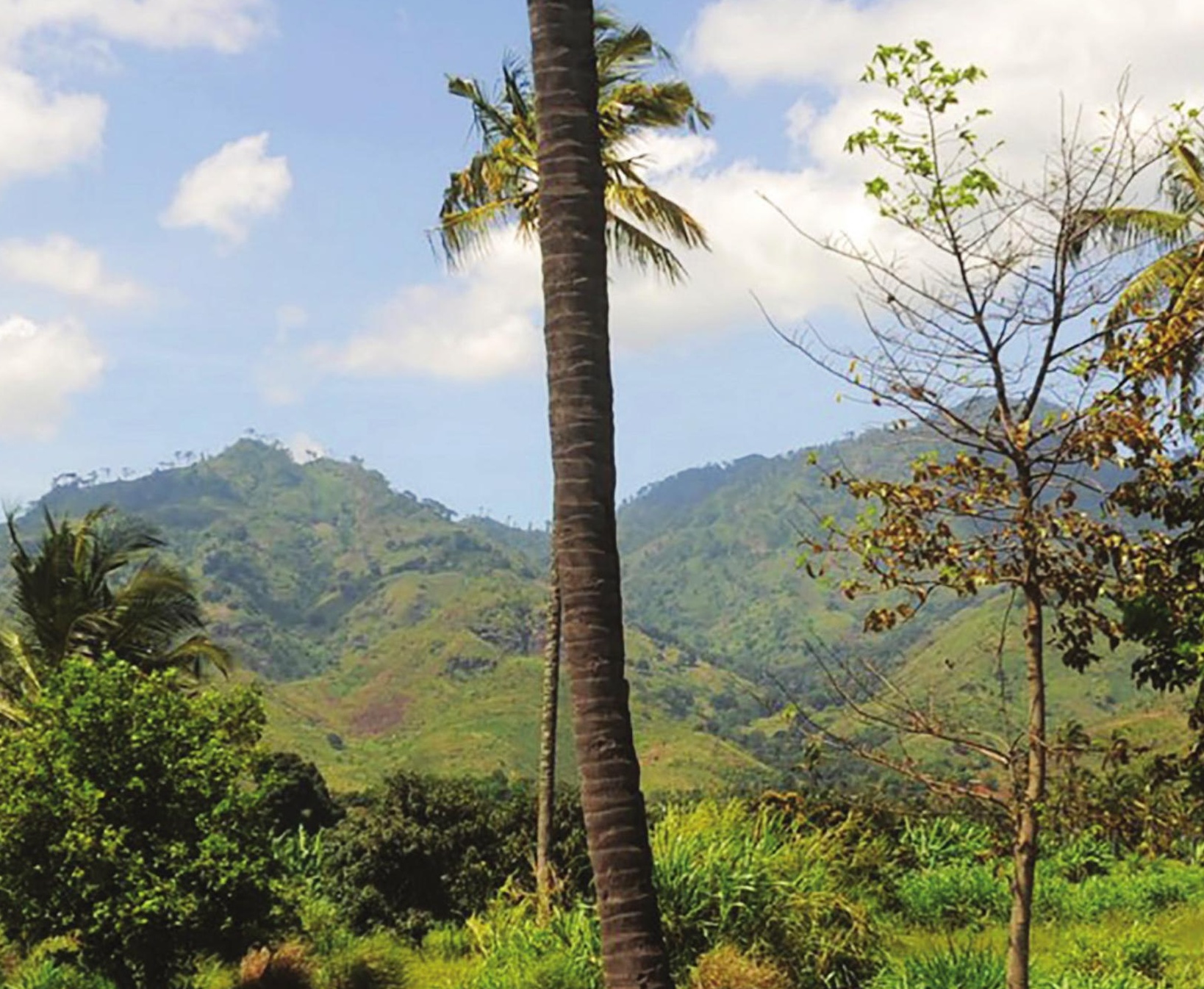

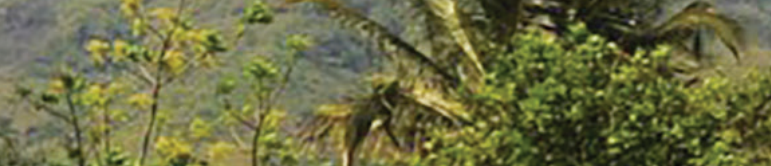

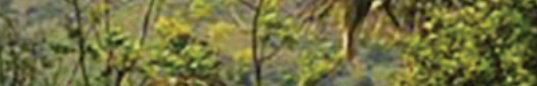

- 7 (x)

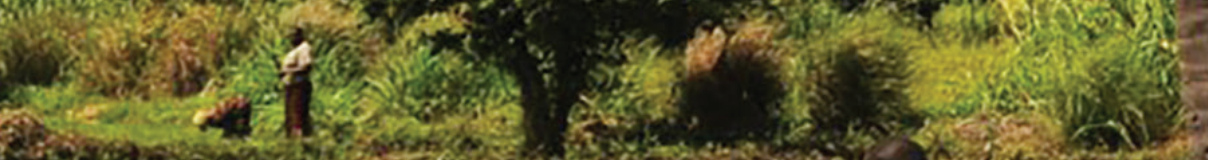

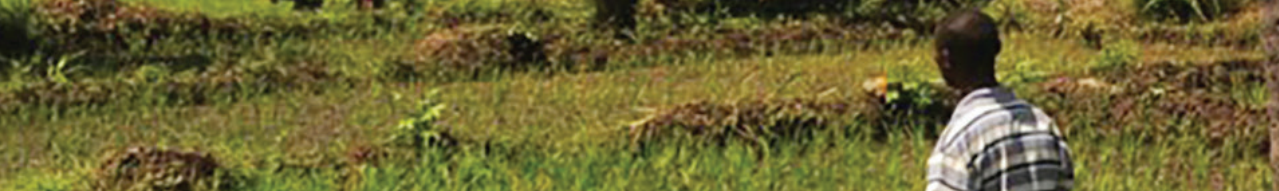

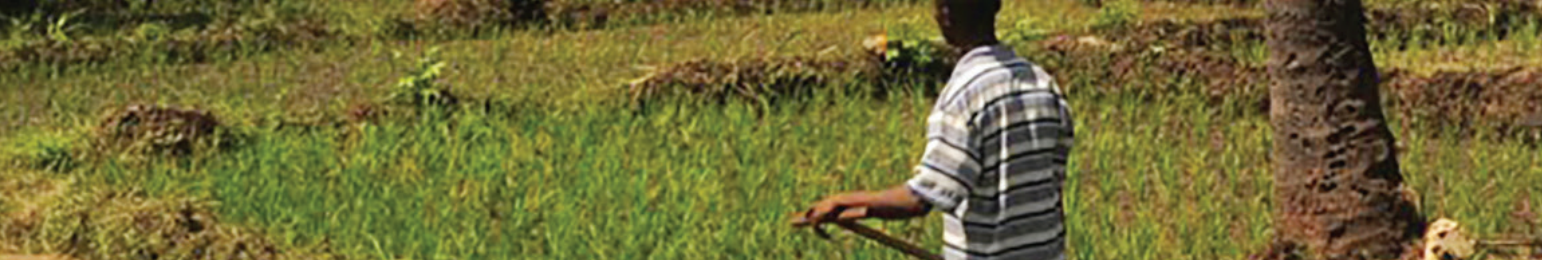

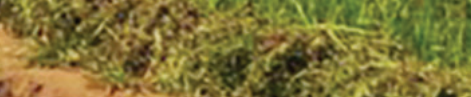

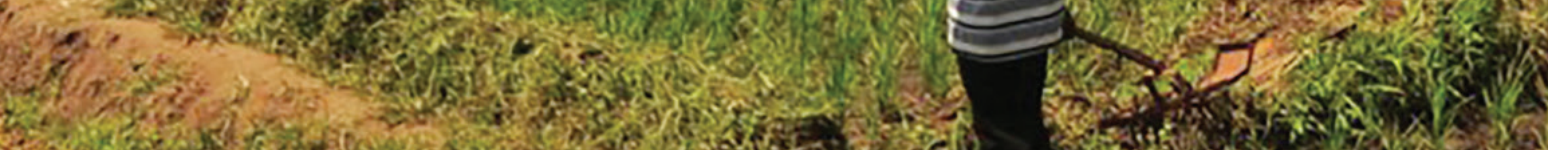
?

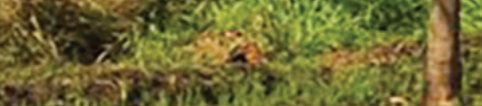
6. a 7. (2) 4. -3.

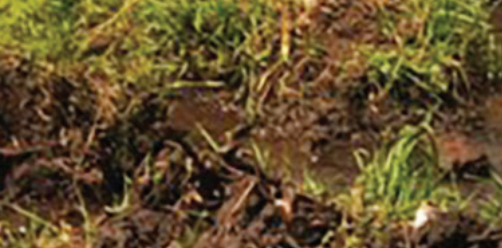

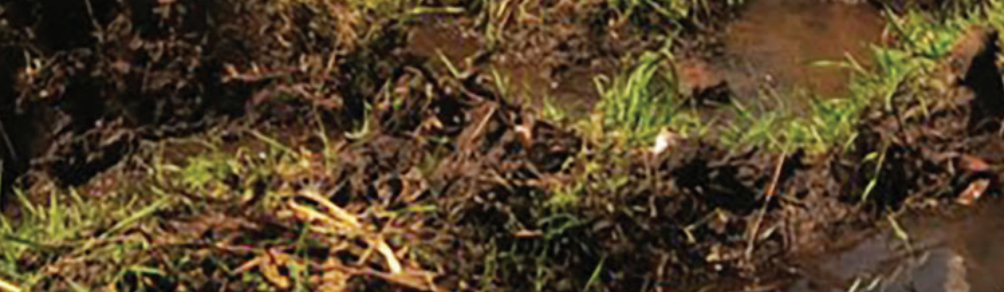

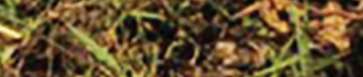
2. 1)

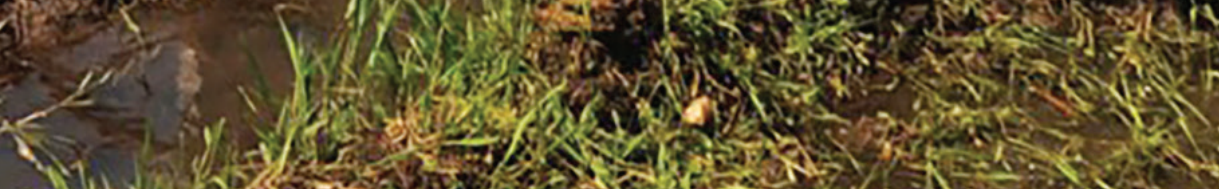

w.

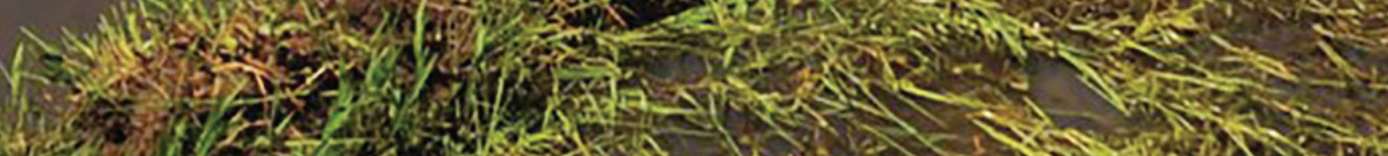




\section{- Implementation strategies}

\author{
The purpose of \\ this chapter, which \\ corresponds to \\ element $C$ of the \\ NAP technical \\ guidelines, is \\ to ensure that \\ forests, trees and \\ agroforestryare \\ appropriately \\ integrated into the \\ implementation \\ of the NAP with \\ the relevant \\ institutional, \\ human and \\ financial means.
}

- NEPAL

Agriculture and forestry in Nepal.

orAO

\section{UNITED REPUBLIC OF TANZANIA}

Overview of rice paddies in Kiroka.

(CFAO/Daniel Hayduk

\subsection{Ensure appropriate priorities for forests and trees in the NAP}

\begin{abstract}
The NAP process often identifies priority areas of action or even priority activities, whose scope and nature depend on the organization of the process itself (for instance regional or by sectors) as well as on criteria and process used for prioritization. In this regard, three points are important to highlight in order to appropriately integrate forests and trees: (i) the adaptation of forests and trees so they can fulfill their economic, social and environmental roles, including their contribution to mitigation, (ii) the essential contribution that forests and trees can make to adaptation in general, (iii) the need to act now, not in spite of the long time needed in forestry but precisely because of it.
\end{abstract}

These three points will need to be reflected in three different ways. First, by having a dedicated section on the adaptation of forests, trees and agroforestry, encompassing the needs of the sector and what it needs in order to contribute to the adaptation of other systems/sectors. Second, by having the potential contributions of forests and trees to the adaptation of other sectors adequately described in the appropriate sections of the document, referring when appropriate to the forest and trees dedicated section, for instance, regarding technical specificities. Third, by adopting a long-term perspective with an adequate planning strategy covering not only simple technical measures but addressing also the structural issues that condition a necessary enabling environment for actors to adapt and invest, like the stability of forested areas and security of land and tree tenure. 


\subsection{Putting in place the means to enable transformational change}

Adaptation to climate change and ensuring the resilience of the economy, people and anthropized ecosystems to climate change will not only require a set of technical responses, it will require profound systemic changes within the economy and in the relation between the economy and nature. Such transformational change will require an overarching enabling environment for adaptation and an alignment of a wide range of policies and means of implementation, in the long term. Adaptation objectives will need to be articulated with other strategies such as biodiversity conservation and economic development, at both national and subnational levels (see 7.5) as well as the mobilization of additional resources, including climate finance (see 7.3). This can be facilitated by the development of a long-term adaptation strategy, endorsed at the highest level. Such a strategy shall not be a stand-alone document. The purpose of a long-term strategy is to ensure coherence in the rolling out of adaptation activities by providing a general orientation, and listing concrete modifications to be made in rules, policies and measures.

The implementation of adaptation measures by forest managers, or forest communities, farmers, and other actors often requires coordination of different supporting institutions and actors as well as enabling conditions (see in particular section 6.5). Also, implementation of adaptation actions for forests, trees and agroforestry generally require a long-term perspective and large-scale management.

Therefore, it is not enough to identify adaptation options and measures related to the forest and tree-based sectors and their role for adaptation: it is also necessary to consider what is needed to facilitate their implementation, what would be the role of various actors and the enabling conditions. Such an analysis shall be done taking into account the sectoral and general stock take conducted previously, in particular the existing laws, regulations and institutional arrangements as well as economic and social conditions (see section 5.1). The potential of existing institutions and rules to make possible (or not) long term and collective action is a critical point to examine.

Agroforestry and the integration of trees in farming systems provides a good example of the critical importance of a proper enabling environment. Many NDCs and NAPs promote agroforestry. However, there are often constraints limiting its development. The development of an agroforestry policy by the government of Nepal (see Box 12) shows how these constraints can be identified and addressed. Most of the published NAPs include recommendations to plant trees for various adaptation purposes. However, measures related to the enabling environment needed for planting trees, like on tenure, on seed and seedlings systems, are often lacking, especially for countries with no established tradition of planted forests. 


\section{BOX 12.}

\section{The development of an agroforestry policy in Nepal}

The development of a National Agroforestry Policy is in line with the NDC (2016) and the Climate Change Policy (2011) of Nepal that identify forests and trees as extremely important to promote both adaptation and mitigation to climate change, including agroforestry. It was supported by the Climate Technology Centre and Network (CTCN) together with the World Agroforestry Centre (ICRAF).

During 2016, the Government of Nepal constituted an Inter-Ministerial Coordination Committee (IMCC) comprised of the Ministry of Agriculture Development (MoAD), the Ministry of Forest and Soil Conservation (MFSC), the Ministry of Population and Environment (MOPE), the National Designated Entity (NDE) and ICRAF to coordinate and provide overall support to policy development. IMCC has developed and approved a road map for drafting a national agroforestry policy. An analysis of 30 existing relevant policies and laws affecting agroforestry in Nepal was completed. Three regional workshops were organized in high, medium and low mountain areas of Nepal, with representatives of Government ministries and departments, research institutes and universities, farmers, farmers' associations and cooperatives, NGOs and INGOs, and service providers. These workshops have provided essential information on the constraints in adopting agroforestry, currently available support to farmers through various players, and the expectations of farmers from an agroforestry policy. A study visit for IMCC members was arranged to India, the only country having approved a national agroforestry policy, and currently implementing it. IMCC members interacted with senior Indian officers and policy makers who had actively contributed to the development of the Indian agroforestry policy and are involved in its implementation.

The information generated through the review of existing Government policies and inputs from the regional workshops provided the basis for the development of the first draft of the agroforestry policy. The draft was reviewed and modified by the IMCC and subsequently shared with stakeholders during three national level workshops. Inputs received during these workshops were incorporated by the IMCC into the draft policy, after which the document was revised by the line ministries who provided more suggestions to further improve the policy. In September 2018 the drafts in English and Nepali were submitted to the IMCC for final processing through the Government system.

The National Agroforestry Policy adopted in 2019 addresses some of the main constraints identified including through the recognition of agroforestry systems, a facilitation of transportation and selling of forest-based products from agroforestry practice, provisions to facilitate loans and insurance for agroforests, testing of agroforest systems, minimizing human-wildlife conflicts, and training and support on agroforestry. 
The design of adaptation strategies for tree commodity crops such as coffee, cocoa and rubber, provides another good example of how the enabling environment can be critical to supporting a widescale shift in planted varieties and/or adoption of new tree farming practices, such as introducing shade trees. Such changes will need upfront investments and could reduce income derived from farming in the short term. On the other hand, given that in many countries the plantations are ageing and, in some cases, experiencing a decrease in yields, an opportunity to replace the trees could present itself. This would mean making the appropriate germplasm available, to make knowledge available and to devise technical transition pathways that are economically feasible for smallholders, as well as appropriate financial support from other actors in the value chain and/ or from the public sector, subnational, national or international.

Gaps in the enabling environment need to be properly identified and addressed: what needs to be done, by what actors and the links between these actions. First, the laws on forestry may require modifications that will, in turn, need to be implemented by subnational authorities in order to secure long-term land and/or tree tenure so that private actors, such as forest managers and farmers will be able to invest in adaptation measures. Second, a calendar of implementation should be arranged, possibly starting with measures that are the easiest to implement so as to show the rapid progress while initiating broader structural changes. Finally, the strategy would include broad objectives and a series of steps organized in a progressive and coherent manner with a time frame and regular reviews of progress (see Chapter 8).

\subsection{Mobilize financial resources}

This section covers the financial resources that can be oriented, or reoriented, towards the objectives of a long-term strategy for adaptation of forests and trees to climate change. These include national public resources, private sector investments (national and international) and international public support. International public support includes ODA, funding from regional and international development banks, dedicated mechanisms such as the Global Environment Facility (GEF) and climate finance (Green Climate Fund, Adaptation fund).

A useful preliminary step in making the case for proper financial resources towards forests and trees is to quantify the sector's contribution to the economy by using elements of the stock taking (section 5.1) and gathering a convincing quantification of the costs and benefits of adaptation measures, including indirect benefits for other sectors.

A first category of financial resources are those that are devoted directly to the forestry sector by public actors, national government, specific agencies, subnational authorities either as direct investment or to orient private investment and practices. One has to note that such resources are likely to be insufficient to cover the entire spectrum of adaptation needs, particularly in many developing countries where the forestry sector is already severely underfinanced, without even taking climate change related needs into account.

Besides increased funding, the very rules governing the attribution of resources to the sector (and their use by the sector) will often need to be modified in order to facilitate or upscale the implementation of adaptation measures in forestry, agroforestry and tree-based systems. For example, the mobilization of resources for agroforestry and the integration of trees in farming systems and landscapes could require making some changes to the attribution conditions and rules on the provision of support for forestry, crop and livestock. Another example relates to mobilizing mitigation-oriented measures. Most NDCs contain important commitments to increase the contribution of forests to mitigation. As indeed forest and tree-based mitigation will occur only if forests and trees have adequately adapted to climate change, adaptation measures - and funding - could be integrated into the policies and measures geared towards mitigation commitments. Adaptation considerations need to be integrated in measures and projects specifically focused on mitigation.

A second category of resources could be found by promoting $\mathrm{NbS}$ and reorienting accordingly towards forestry some of the resources affected by public actors, national government, specific agencies, subnational authorities to sectors that will benefit from actions in the forestry sector, 
either for their own adaptation or for other development benefits like water, energy, cities and human settlements, infrastructures, biodiversity and health. Private actors in these sectors may also be encouraged or incited by public policies and measures to finance forestry actions. The mobilization of ODA, funding from regional and international development banks, dedicated mechanisms such as the GEF and climate finance can be supported by putting an emphasis, as appropriate, on the multiple long-term benefits of specific measures not only for adaptation but also for mitigation and various sustainable development goals.

Many of these international funds, mechanisms and donors have quite specialized objectives, which often makes it difficult to promote multipurpose projects. This specialization can lead funds or donors not to select a project because it is not scoring enough on their own specific objective. There are however evolutions in that regard, with more receptiveness towards diverse objectives driven both by the SDGs and the scarcity of funding as compared to the needs. Here one can try to leverage the fact that adaptation projects related to forestry often bear multiple benefits (for example, healthy ecosystems, reduced fire risks, wildlife conservation etc.), and those can be strategically put in the fore depending on the main purpose of the fund or interest of the donor. There might thus be new opportunities for forestry, provided that the benefits are well articulated and quantified.

The Green Climate Fund (GCF) has to devote half of its resources to adaptation projects. It has two results areas particularly relevant for forests: forest and land use (under mitigation), and ecosystems (under adaptation). However, the GCF is now looking at these together under cross cutting mitigation and adaptation projects. That will come out in forthcoming sectoral guides that the GCF is currently preparing. As highlighted in the recent special report of the IPCC on climate change and land, adaptation, mitigation and sustainable development benefits will need to be considered altogether when looking at land-based measures, and such an integration is also a way towards costefficiency. The GCF's Readiness and Preparatory Support Programme, in particular, offers support for countries to strengthen their institutional capacities, governance mechanisms, and planning and programming frameworks, that can lay the groundwork for larger-scale, transformational projects.

Finally, new forms of finance can be mobilized for adaptation, especially when considering the productive and economic risk-buffering component of adaptation measures: blended finance, that is, the strategic use of public or philanthropic development capital to leverage the mobilization of private commercial finance; green bonds, a form of debt obligation linking the generated funds to climate or environmentally friendly investments; and crowd-funding, which is the pooling of small amounts of capital from a potentially large number of interested funders (Louman et al., 2020).

\subsection{Improve capacity for planning and implementing adaptation for forests and tree systems}

Long-term perspectives and planning are indispensable to forests, trees and agroforestry adaptation. In some countries long-term planning of forestry activities already exists often with several levels of planning, down to the forest management unit. In such cases adaptation can be mainstreamed quite easily as an additional factor to be taken into account, as part of sustainable forest management and countries' national forest programmes. When these planning instruments do not exist or are not widely used, they need to be created and promoted as part of the adaptation strategy. Capacity-building initiatives will need to consider the particularity of the forest sector and its systemic interrelation with a range of other sectors (See section 4). Clearly, adaptation must be coherent with the plans of the sectors with which they interact: crops and livestock, land planning and urban development, biodiversity, water and energy. Such an integrated approach is best implemented at the landscape level where the synergies and tradeoffs are to be addressed.

Capacity for planning and particularly for "integrated" planning will thus be needed at the various levels of public authorities, as well as for forest managers and actors involved in the 
preparation of the plans at the various levels. Capacity building initiatives have thus to address the needs of these actors.

\subsection{Promote coordination and synergy at national and subnational levels}

The NAP needs also to consider the various means that can be mobilized to promote coordination between levels, from local to national, between sectors, and between actors. This aspect is particularly important for forests, trees and agroforestry, given the fact that competencies for the various sectors and issues that relate to them are generally shared between various national and subnational entities such as: line ministries, specific public entities, local governments; with repartition of competencies that vary between sectors and issues.

The NAP process itself, as discussed in Chapter 4 , presents a good opportunity for initiating or strengthening links between levels and sectors. Coordination efforts should be conducted both between levels, in the forestry sectors, and between sectors at each level, taking into account the differences in organization between sectors. Two levels are of particular importance, including because they are common to most issues: the national level, between line ministries, and the landscape level, mobilizing the public and private institutions and entities that are operating in landscapes, because this is where most of the issues interact and need to be jointly taken into account (see Box 13).

BOX 13

Integrating landscape-based approaches in the adaptation planning process in the Philippines

The Philippines has been a pioneer in responding to climate change with the creation of the Inter-Agency Committee on Climate Change as early as 1991, because of the persistent and numerous climate and climate-related disaster risks it has faced. Today its successor - the Climate Change Committee coordinates adaptation planning across departments and agencies. Interdepartmental collaboration is defined within the articulation of seven strategic priorities in the National Climate Change Action Plan (NCCAP, 2011-2028). These priorities are: (i) food security; (ii) water sufficiency; (iii) ecological and environmental stability; (iv) human security; (v) climatesmart industries and services; (vi) sustainable energy; and (vii) knowledge and capacity development.

Dealing with these cross-cutting priorities within the Department of Agriculture involves a number of offices. The Bureau of Soils and Water Management has been most effective supporting the adoption of field-level adaptation guidance, given its network of extension service providers. The Field Programs Operational Planning Division mainstreams adaptation plans into routine operations of the Department, for example pre- and postdisaster assessments. The Systems-Wide Climate Change Office (SWCCO) has been tasked to coordinate these multiple efforts, in order to address climate change risks and vulnerabilities while implementing the country's Agriculture and Fisheries Modernization Plan. Forestry is the mandate of the Forest Management Bureau of the Department of Environment and Natural Resources. The Philippine Master Plan for Climate Resilient Forestry Development (2016) has identified adaptation as one of the focuses for 
enhancing resilience and responding to the Climate Change Act of 2009, which mandates all government agencies in the Philippines to integrate climate change adaptation in all programs and policies. A strong emphasis on local and landscape-scale governance permeates adaptation planning activities. The Philippines' Climate Change Act of 2009, enshrined in law, mandates that Local Government Units (LGUs) should formulate individual Local Climate Change Adaptation Plans (LCCAPs). The government provided support by launching the People's Survival Fund with a 1 billion Philippine peso yearly allocation.

To enhance the uptake of EbA articulated in the NDC of the Philippines, the NAP-Ag programme supported the development in the Philippines of Guidelines for landscape-based integrated area development planning. These guidelines encompass the rationale for such approaches and suggest practical actions for using a landscape approach to integrate adaptation with DRR into agriculture development plans and sectoral plans at the LGU level, aimed at regional and provincial agricultural technical officers and colleges. Forestry plays a significant role in implementing landscape-based planning, for example in risk and vulnerability assessments as well as land capability assessments. Support for landscape-based planning for agriculture was set within the NAP process, and importance was given to proper groundwork, consultation and awareness raising. In this light, landscape-based planning was one of the key policy dialogues conducted at national and subnational levels during the inception phase of the NAP-Ag process in the Philippines (Element A, Step 1). Early efforts focused on building capacities of national and regional field officers to implement landscape-based climate risk assessment and adaptation and DRR planning approaches. 


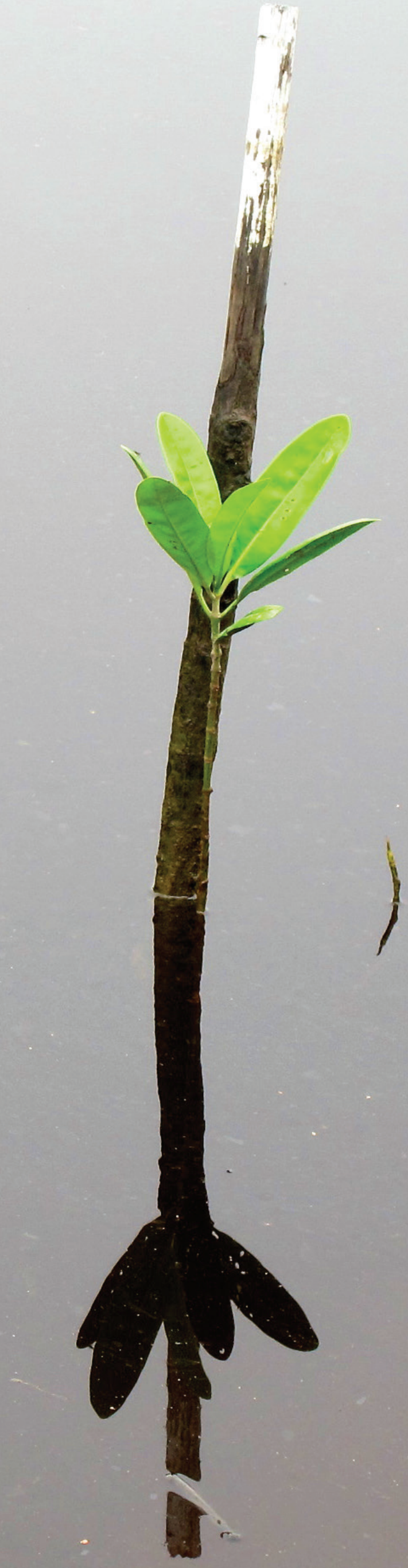




\section{Reporting, monitoring and review}

\author{
This chapter \\ corresponds to \\ element $D$ of the \\ NAP technical \\ guidelines \\ that focus on \\ building effective \\ monitoring and \\ review systems.
}

\section{KUBU RAYA, WEST}

\section{KALIMANTAN, INDONESIA}

Indonesia mangroves - A mangrove sapling at high tide during CIFOR's study on above-ground and below-ground biomass in mangrove ecosystems, part of Sustainable Wetlands Adaptation and Mitigation Program (SWAMP).

(c) GFOR/Sigit Deni Sasmito
The purpose here is to ensure that the reporting, monitoring and review process established for the NAP pays adequate attention to the forestry sector, its priorities and needs as well as the adaptation opportunities it provides for other sectors. This step is based on the identification of areas in the NAP process deserving particular attention in terms of measuring progress, for instance integration of the sector in the NAP, mainstreaming of adaptation in on-going strategies and plans, or implementation. It includes the definition of indicators to assess progress of the adaptation plan as well as the outputs and outcomes deriving from the implementation of the NAP. This requires that the forestry sector is appropriately integrated into the reporting, monitoring and review system established for the NAP, that the sector itself has the tools and means to contribute to the system and its improvement. It is especially important to ensure that the system established does not duplicate other reporting mechanisms but rather builds upon them.

\subsection{Prepare for monitoring adaptation planning and implementation}

Monitoring can be effectuated at several levels. Specific projects and activities described in the NAPs generally include indicators to assess outputs of the project and its outcomes. More broadly, the NAP process needs to integrate indicators to monitor the implementation of the whole plan and to assess the results of adaptation interventions. The approach for building indicators can be two-fold: first, national economy wide indicators can be selected in the NAP and designed so as to appropriately integrate the forests and tree-based sectors; second, a limited number of indicators specific to forests, trees and agroforestry can be integrated into the NAP. 
Such indicators should facilitate the monitoring of outputs, outcomes and impacts of adaptation options on both forests and people. These indicators would require a sufficient level of specificity or granularity (for example spatially), especially to incorporate hotspots, for instance to monitor forest or tree-based systems of critical importance, either from a production and economic perspective, an environmental protection perspective or threatened ecosystems perspective (such as mangroves). Moreover, monitoring adaptation success for people and communities will require in most cases the disaggregation of indicators by gender and social groups, lending special attention to those groups identified as most vulnerable.

The selection of indicators will build on existing data and mechanisms as much as possible. In this regard, it can rely for forestry on various existing processes and tools such as the Global Forest Resources Assessment (FRA) reporting (see Box 14), satellite data-based monitoring systems such as GFW, REDD+ MRV systems being prepared or available in many countries.
The data gathered as part of the FRA could be particularly useful as it is collected at national level at regular intervals and can therefore be used to evaluate changes. The following sets of data can be selected as part of the NAP monitoring figure data:

- forest extent, characteristics and change;

- forest growing stock, biomass and carbon;

- forest management objectives, including protected areas and long-term management plans;

- watershed protection;

- forest disturbances, including forest fires and degraded forest;

- area of permanent forest estate;

- NWFP;

- employment.

\section{BOX 14}

\section{The Global Forest Resources Assessment (FRA)}

FAO has been assessing the state of the world's forests resources with key reports published at 5 to 10 years intervals since 1946. The Global Forest Resources Assessment (FRA) is now produced every five years in an attempt to provide a consistent approach to describing the world's forests and how they are changing. The Assessment is based on two primary sources of data: Country Reports prepared by National Correspondents and remote sensing that is conducted by FAO together with national focal points and regional partners. For the 2015 FRA, data were compiled for 234 countries and territories: 155 reports came from countries themselves (covering 98.8 percent of the world's forests) and the remaining 79 were desk studies prepared by FAO.

The country reporting process was initiated in 2018 in preparation for the next FRA in 2020. The option to provide annual updates on key variables was introduced in order to provide support for countries to report their progress towards the SDGs. A new online platform has been implemented to facilitate the process of reporting and to improve the transparency and reliability of results, as well as the review process, data access and usability for end-users of FRA data. Resulting data were analyzed throughout 2019 and the final results will be released in 2020.

More information on the Global Forest Resources Assessment can be found at: http://www.fao.org/forest-resources-assessment/en/ 
The United Nations Forum on Forests (UNFF), supported by the Collaborative Partnership on Forests (CPF) has proposed a draft Global Core Set (GCS) ${ }^{9}$ of forest related indicators to support the implementation of the 2030 Agenda and the strategic plan on forests. The GCS includes indicators for sustainable forest management, indicators for progress towards the forest-related SDGs and targets, and possible indicators for the targets of the strategic plan. These indicators, representing the "health" of the forest sector can be considered as a source as well.

\subsection{Monitor implementation and update the NAP}

The NAP process is an iterative process. This step of the process deals with monitoring and periodically updating the NAP, taking into account new assessments and knowledge as well as changes in situations and also the results of implemented adaptation activities.

It first involves reviewing the whole draft of the NAP in order to:

- check that the priorities identified in 7.1 are appropriately integrated;

- show some additional potential contributions from forests and trees to the adaptation of other sectors; and

- introduce corrective actions if necessary.

Along the implementation of the NAP it requires to assess how the plan itself is implemented, using the indicators defined during the step described above and the impacts it has on the adaptation of the sector. The Ministry of Agriculture and Forestry in charge of adaptation in Finland has devised a method for assessing sectors' adaptation by steps (see Box 15). This method relies on questionnaires and interviews and highlights the fact that crosssectoral activities, of particular importance for forests, trees and agroforestry, generally happen at later stages of the process.

\section{BOX 15 .}

\section{Assessing sectors' adaptation by steps in Finland}

The Ministry of Agriculture and Forestry of Finland conducted an evaluation in 2013 of the climate change adaptation plan. It included an assessment of the level of adaptation by sectors in 2009 and 2013 using the evaluation conducted in 2009 and assessment questionnaire as well as interviews conducted in 2013. It identifies 5 levels of adaptation.

\section{LEVEL OF ADAPTATION}

Step 1

- need for adaptation recognized among a group of pioneers in the sector;

- littleresearch done on the impacts of or adaptation to climate change; some adaptation measures identified but not yet implemented.

9 See: Monitoring, assessment and reporting on progress towards implementing the United Nations strategic plan for forests 2017-2030, including the United Nations forest instrument and voluntary national contributions.

Provisional Agenda http://www.cpfweb.org/48715-0dfc673f9958ed5b6909f2e5b45b711fc.pdf; http://www.cpfweb.org/96344/en/ 


\begin{tabular}{|c|c|}
\hline Step 2 & $\begin{array}{l}\text { need for adaptation measures recognized to some extent in the sector } \\
\text { (some decision-makers); } \\
\text { impacts of climate change known indicatively (qualitative information), } \\
\text { taking account of the uncertainty involved in climate change scenarios; } \\
\text { adaptation measures identified and plans made for their implementation, } \\
\text { some of them launched. }\end{array}$ \\
\hline Step 3 & $\begin{array}{l}\text { need for adaptation measures quite well recognized (majority of decision } \\
\text { makers); } \\
\text { - impacts of climate change quite well known (quantitative information), } \\
\text { taking account of the uncertainty involved in climate change scenarios; } \\
\text { - adaptation measures identified and their implementation launched; } \\
\text { - cross-sectoral cooperation on adaptation measures started. }\end{array}$ \\
\hline Step 4 & $\begin{array}{l}\text { need for adaptation measures widely recognized and accepted in the } \\
\text { sector; } \\
\text { impacts of climate change well known within the limits of the } \\
\text { uncertainty involved in climate change scenarios; } \\
\text { - implementation of adaptation measures widely launched and their } \\
\text { benefits assessed at least to some extent; } \\
\text { cross-sectoral cooperation on adaptation measures an established } \\
\text { practice. }\end{array}$ \\
\hline Step 5 & $\begin{array}{l}\text { adaptation measures under the Adaptation Strategy or recognized } \\
\text { otherwise implemented in the sector. }\end{array}$ \\
\hline
\end{tabular}

\subsection{Outreach on the process and report on progress and effectiveness}

The dissemination of the documentation relative to the NAP process, as well as the results of the monitoring is an integral part of the process. It is key to raise awareness, provide transparency, ensure engagement and coordination of actors and facilitate mobilization of resources.
Outreach needs to be conducted at various levels, for different audiences, with appropriate documentation and channels. Several types of audiences should be given particular attention: first, the forests, trees and agroforestry sectors and actors at the national level with, when appropriate, targeted communication for specific productions and value chains; second, targeted communication could focus on the other sectors where there is the most interactions. In addition, particular attention should be given to outreach at local/landscape level, involving as much as possible the wide range of actors that are involved in land use and natural resources management, in particular crops, livestock, fisheries, and the water sector. 


\section{Conclusion}

Climate changes impacts on forests and trees are already apparent all over the world. They are not only threatening forests themselves, but also their mitigation potential and a wide range of ecosystem services on which we rely. They are already undermining the capacity of trees and forests to support the adaptation of the most vulnerable populations in rural areas and cities. Immediate action is needed to create the conditions for adaptation of forests and forest-dependent people.

The NAP process provides the opportunity to create these conditions. Because it is a national process that embraces all sectors of the economy, it allows to take into consideration all interactions between forests, trees and all the other sectors related to them: agriculture, water, land use, infrastructure, energy and biodiversity, to identify the main conditions required to enhance the contributions of forests to climate risk reduction and adaptation, and to develop the necessary enabling environment. The effectiveness of the process will depend on its capacity to integrate all relevant commitments, strategies and plans, to involve all relevant organizations and actors, especially the most vulnerable and to include various levels of decision making, from value chains to landscapes to appropriately take into account specific vulnerabilities and agency.

If given proper importance at national level, the NAP process can be a major implementation vehicle, not only for the NDCs but also for the SDGs considering how, especially with regards to forests and trees, mitigation, adaptation and sustainable development objectives are linked. As such, it can frame planning of action and ultimately individual projects on the ground. Conversely, because it is an iterative process, it will, in return, inform the periodic review of the NDCs. 


\section{Annexes}

Annex 1: Glossary

Annex 2: Check-list of stock-taking elements

Annex 3: Knowledge Tools

Annex 4: Sub-steps and methodologies to prioritize

adaptation options 


\section{Annex 1: Glossary}

\section{Adaptation}

Adjustment in natural or human systems in response to actual or expected climatic stimuli or their effects, which moderates harm or exploits beneficial opportunities. Various types of adaptation can be distinguished, including anticipatory, autonomous and planned adaptation (IPCC, 2007).

\section{Adaptation benefits}

The avoided damage costs or the accrued benefits following the adoption and implementation of adaptation measures (IPCC, 2007).

\section{Adaptive Capacity}

The ability of a system to adjust to climate change (including climate variability and extremes) to moderate potential damages, to take advantage of opportunities, or to cope with the consequences (IPCC, 2007).

\section{Adaptation costs}

Costs of planning, preparing for, facilitating, and implementing adaptation measures, including transition costs (IPCC, 2007).

\section{Agriculture sectors}

For FAO, agriculture covers crop-based farming systems and livestock systems, including rangelands and pasturelands, forestry, fisheries and aquaculture and the related resources they use (water, land, soils, genetic resources and biodiversity).

\section{Climate change}

Any change in climate over time, whether due to natural variability or as a result of human activity (IPCC, 2007).

\author{
Climate variability \\ Variations in the climate (as measured by \\ comparison with the mean state and other \\ statistics such as standard deviations and \\ statistics of extremes) at all temporal and \\ spatial scales beyond that of individual weather \\ events. Variability may be due to natural \\ internal processes within the climate system \\ (internal variability) or to variations in natural \\ or anthropogenic external forcing (external \\ variability) (IPCC, 2007).
}

\section{Climate-smart agriculture}

An approach that helps to guide actions needed to transform and reorient agricultural systems to effectively support development and ensure food security in a changing climate. CSA aims to tackle three main objectives: sustainably increasing agricultural productivity and incomes; adapting and building resilience to climate change; and reducing and/or removing greenhouse gas (GHG) emissions, where possible (FAO, 2014b).

\section{Disaster Risk Management}

The systematic process of using administrative directives, organizations and operational skills and capacities to implement strategies, policies and improved coping capacities in order to lessen the adverse impacts of hazards and the possibility of disaster (UNISDR, 2009).

\section{Disaster Risk Reduction}

The concept and practice of reducing disaster risks through systematic efforts to analyse and manage the causal factors of disasters, including through reduced exposure to hazards, lessened vulnerability of people and property, wise management of land and the environment, improved preparedness for adverse events. (UNISDR, 2009).

\section{Ecosystem-based adaptation}

An approach to adaptation that integrates the use of biodiversity and ecosystem services into an overall strategy to help people adapt to the adverse impacts of climate change. It includes the sustainable management, conservation and restoration of ecosystems to provide services that help people adapt to both current climate variability, and climate change. Ecosystem-based adaptation contributes to reducing vulnerability and increasing resilience to both climate and non-climate risks and provides multiple benefits to society and the environment (Colls, Ash and Ikkala, 2009).

\section{Exposure to climate change related events} The nature and degree to which a system is exposed to significant climatic variations. (IPCC, 2001). 


\section{Hazards}

A process, phenomenon or human activity that may cause loss of life, injury or other health impacts, property damage, social and economic disruption or environmental degradation (UNGA. 2016. Report of the open-ended intergovernmental expert working group on indicators and terminology relating to disaster risk reduction).

\section{Impact assessment of climate change}

The practice of identifying and evaluating, in monetary and/or nonmonetary terms, the effects of climate change on natural and human systems. Potential impacts are all the impacts that may occur given a projected change in climate, without considering adaptation. Residual impacts are the impacts of climate change that would occur after adaptation (FAO, 2014b).

\section{Institutions}

Formal organizations and contracts, as well as informal social and cultural norms and conventions, that operate within and between organizations and individuals (FAO, 2014b).

\section{Impact of climate change}

The effects of climate change on an exposed human or natural system and its components. This includes lives, livelihoods, health, economic, social and cultural dimensions, available services, infrastructure, ecosystems and the environment (FAO, 2014b).

\section{Integration of adaptation}

The integration of adaptation objectives, strategies, policies, measures or operations such that they become part of the national and regional development policies, processes and budgets at all levels and stages (Lim and Spanger-Siegfred, eds., 2005).

\section{Maladaptation}

Any changes in natural or human systems that inadvertently increase vulnerability to climatic stimuli; an adaptation that does not succeed in reducing vulnerability but increases it instead (IPCC, 2001).

\section{Landscape approach}

An approach to sustainable development that deals with large-scale processes in an integrated and multidisciplinary manner, combining natural resources management with environmental and livelihood considerations. It differs from ecosystem approaches in that it may include multiple ecosystems. The landscape approach also factors in human activities and their institutions, viewing them as an integral part of the system rather than as external agents (FAO, 2012C).

\section{Natural hazard}

Natural process or phenomenon that may cause loss of life, injury or other health impacts, property damage, loss of livelihoods and services, social and economic disruption, or environmental damage (FAO, 2014b).

\section{Resilience}

The ability of a social or ecological system to absorb disturbances while retaining the same basic structure and ways of functioning, the capacity for self-organization and the capacity to adapt to stress and change (IPCC, 2007).

\section{Sensitivity to climate variability or change} Degree to which a system is affected, either adversely or beneficially, by climate variability or change. The effect may be direct (e.g. a change in crop yield in response to a change in the mean, range or variability of temperature) or indirect (e.g. damages caused by an increase in the frequency of coastal flooding due to sea-level rise) (FAO, 2014b).

\section{Transformational change}

Deep, systemic, and sustainable change with the potential for large-scale impact.

\section{Urban forestry}

The practice of managing urban forests to ensure their optimal contributions to the physiological, sociological and economic well-being of urban societies. The urban forest of a city networks or systems comprising all woodlands, groups of trees, and individual trees located in urban and peri-urban areas; they include, therefore, forests, street trees, trees in parks and gardens, and trees in derelict corners.

\section{Vulnerability}

The propensity or predisposition to be adversely affected; a function of potential impacts (exposure and sensitivity to exposure) and adaptive capacity. (FAO, 2014b).

\section{Water scarcity}

The point at which the aggregate impact of all users impinges on the supply or quality of water under prevailing institutional arrangements to the extent that the demand by all sectors, including the environment, cannot be fully satisfied (UNWater, 2014).

\section{MINAS GERAIS STATE, BRAZIL}

Local farmers have developed an effective agricultural system combining flower gathering, agroforestry gardening, livestock grazing and crop cultivation. (c) FAO/Valda Nogueira/ FAO 


\section{Annex 2. Check list of the NAP stocktake elements}

This check list aims to facilitate the stock take (see section 5.1). It was prepared as part of the NAP-Ag programme and adapted for forestry and agroforestry, respecting its overall structure to facilitate the integration of forestry with the other agriculture subsectors (crops, livestock, fisheries and aquaculture).

\begin{tabular}{|c|c|c|c|c|}
\hline OUTLINE & & $\begin{array}{l}\text { COUNTRY } \\
\text { INFORMATION SECTION }\end{array}$ & & \\
\hline NAP-AG STOCKTAKING & DESCRIPTION & $\begin{array}{l}\text { INFORMATION } \\
\text { AVAILABLE - [Country] }\end{array}$ & SOURCE & YEAR \\
\hline \multicolumn{5}{|l|}{ Table of contents } \\
\hline \multicolumn{5}{|l|}{ List of figures and tables } \\
\hline \multicolumn{5}{|c|}{ Acronyms and Abbreviations } \\
\hline \multicolumn{5}{|l|}{ Executive summary } \\
\hline \multicolumn{5}{|l|}{ 1. Introduction } \\
\hline & $\begin{array}{l}\text { If published as a report: Reasons for } \\
\text { conducting a stock-take, e.g. Request for } \\
\text { support, supporting programmes towards } \\
\text { NAP or NAP-Ag, objectives of stocktake. }\end{array}$ & & & \\
\hline & $\begin{array}{l}\text { Overview of the NAP process and the } \\
\text { process of addressing forestry and } \\
\text { agroforestry in NAPs. }\end{array}$ & & & \\
\hline \multicolumn{5}{|c|}{$\begin{array}{l}\text { 2. Analysis of the NAP-relevant setting, processes and actors in } \\
\text { [country] }\end{array}$} \\
\hline $\begin{array}{l}\text { a. Overview of forestry, } \\
\text { agroforestry and } \\
\text { related sectors in } \\
\text { [country] }\end{array}$ & $\begin{array}{l}\text { Forestry and agroforestry overview, } \\
\text { including proportion of population } \\
\text { involved, major agro-ecological regions, } \\
\text { forestry and agroforestry system types, } \\
\text { growth and production rates, economic } \\
\text { contribution and export profiles, } \\
\text { employment, disease control. }\end{array}$ & & & \\
\hline $\begin{array}{l}\text { b. Vulnerability } \\
\text { of forestry and } \\
\text { agroforestry to } \\
\text { climate change }\end{array}$ & $\begin{array}{l}\text { Summary of major impacts, risks, } \\
\text { including projections used. Existing } \\
\text { environmental and natural resource } \\
\text { management challenges exacerbated by } \\
\text { climate change, e.g. on hydrology, soil } \\
\text { quality. }\end{array}$ & & & \\
\hline \multicolumn{5}{|l|}{$\begin{array}{l}\text { c. Policies, laws and } \\
\text { other entry points } \\
\text { for climate change } \\
\text { adaptation in forestry } \\
\text { and agroforestry }\end{array}$} \\
\hline $\begin{array}{l}\text { - National } \\
\text { and sectoral } \\
\text { development } \\
\text { planning } \\
\text { frameworks }\end{array}$ & $\begin{array}{l}\text { Climate change adaptation for forestry } \\
\text { and agroforestry in national development } \\
\text { plans. }\end{array}$ & $\begin{array}{l}\text { E.g. climate } \\
\text { change adaptation } \\
\text { framework (2015- } \\
\text { 2020) contains } \\
\text { policy /coordination } \\
\text { mechanism for } \\
\text { forestry adaptation in } \\
\text { country x }\end{array}$ & $\begin{array}{l}\text { E.g. National } \\
\text { Climate } \\
\text { Change } \\
\text { Strategy, } \\
2015\end{array}$ & \\
\hline
\end{tabular}




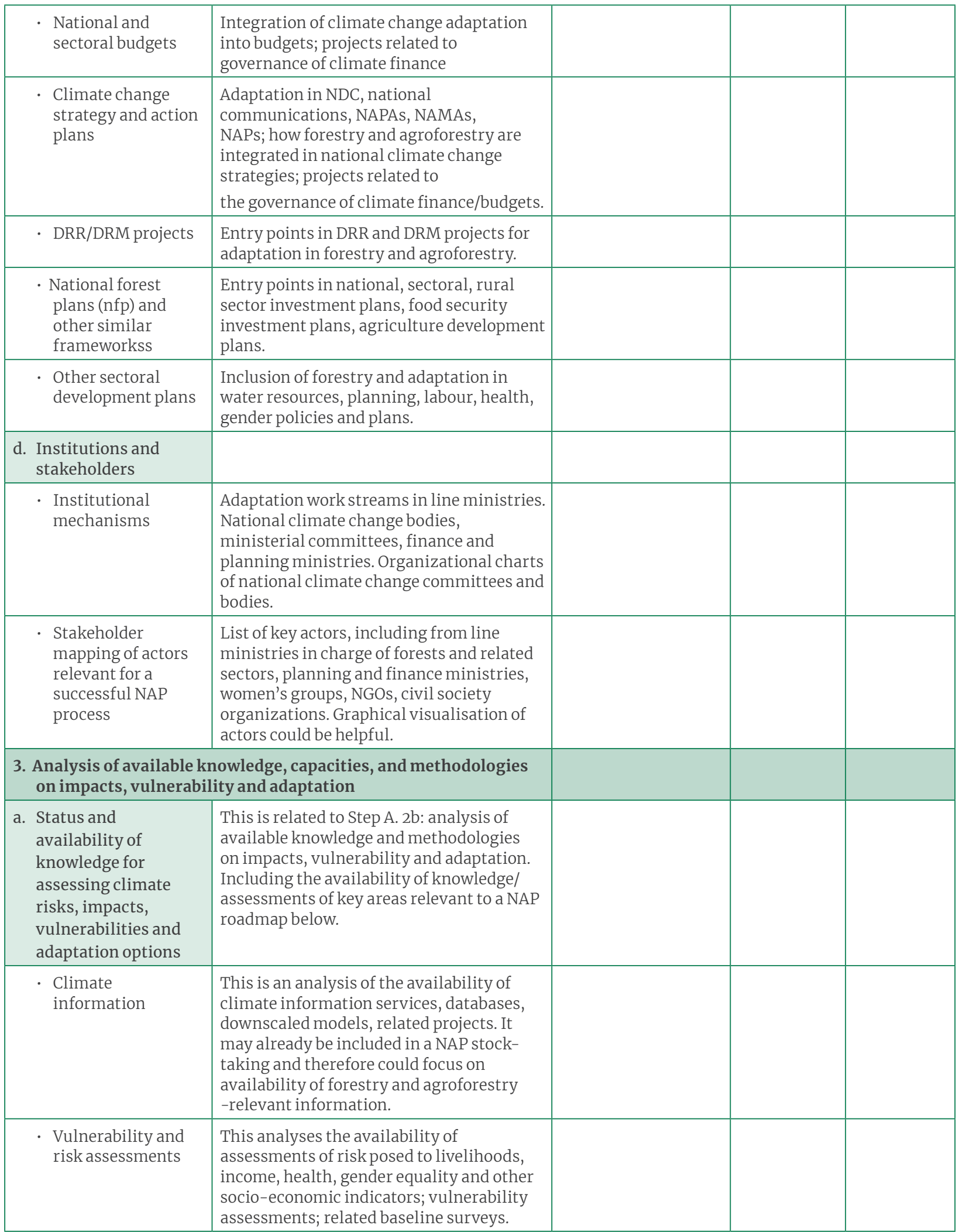




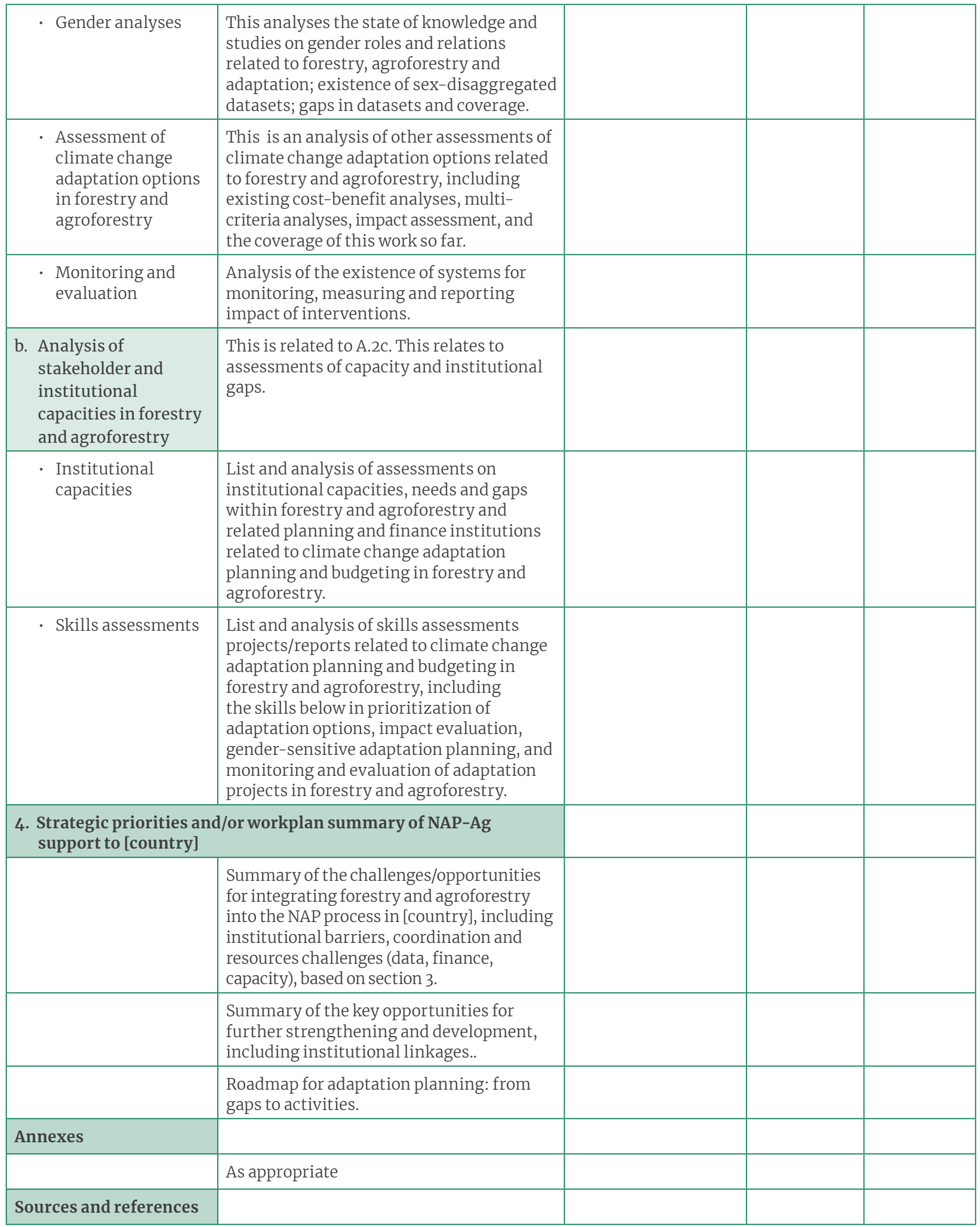




\section{Annex 3. Knowledge tools}

Below is an indicative and non-exhaustive list of knowledge tools that can be useful at various stages of the NAP process. It is organized around main topics related to data collection and climate change impacts on forests (1-2), vulnerabilities and risks (3-6), specific ecosystems (mangroves 7) or groups (8-9), ecosystem services and food security (10-13), forest management and adaptation (14-16)

1) Data collection and modelling

2) Climate change and forests

3) Vulnerability assessments

4) Extreme weather events

5) Pests and diseases

6) Wild fires

7) Mangroves

8) Indigenous people

9) Gender

10) Ecosystem services

11) Water

12) Biodiversity

13) Food security and nutrition

14) Forest management

15) Adaptation

16) Forests and landscapes restoration

\section{1) DATA COLLECTION AND MODELLING}

Global Agroecological Zoning (GAEZ): provides assessment, historical and future, of agricultural resources and potential including land and water resources, agro-climatic resources, suitability and potential yields, downscaled actual yields and production and yield and production gaps. http://www.fao.org/nr/gaez/en/\#

Modelling System of Climate Change Impacts on Agriculture (MOSAICC): Methodology and system of models designed to carry out interdisciplinary climate change impact assessment on agriculture through simulations. The main components of the system are a statistical downscaling portal to downscale Global Circulation Models (GCM) data to weather station networks, a hydrological model for estimating water resources for irrigation in major basins, two water balance-based crop models to simulate crop yields under climate change scenarios and a model to assess the effect of changing yields on national economies. http://www.fao.org/in-action/mosaicc/en/
Agriculture Stress Index Systems (ASIS). Global and country-level: Using data on vegetation and land surface temperature, ASIS monitors vegetation indices and detects hotspots where crops may be affected by drought. http://www.fao.org/resilience/ news-events/detail/en/c/296089/

Open Foris (including the System for earth observations, data access, processing and analysis for land monitoring (SEPAL), Collect Earth, Collect Earth Online and Earth Map): is a set of FAO's open-source software tools to facilitate flexible and efficient data collection, analysis, and reporting. Its platforms, tools and modules can be used for forest inventories, land use and land-use change assessment, and climate change reporting. www.openforis.org

\section{2) CLIMATE CHANGE AND FORESTS}

The CCAFS-Climate data portal. This provides global and regional future high-resolution climate datasets that serve as a basis for assessing the climate change impacts and adaptation in a variety of fields including biodiversity, agriculture, agroclimatology, ecosystem services and hydrology. http://ccafs-climate.org/

Agroforestry and Climate Change: Issues, Challenges, and the Way Forward (2019). This volume provides an abundance of valuable information on emerging eco-friendly technology and its potential role in combating climate change via agroforestry. https://www.taylorfrancis.com/ books/e/9780429057274

Forest disturbances under climate change (2017). This is a review article of forest disturbances that are sensitive to climate. There is an incomplete understanding of disturbance dynamics in response to climatic changes, particularly regarding largescale patterns, interaction effects and dampening feedbacks. This article provides a global synthesis of climate change effects on important abiotic (fire, drought, wind, snow and ice) and biotic (insects and pathogens) disturbance agents. https://www.nature.com/articles/nclimate3303 
Climate change and European forests: what do we know, what are the uncertainties, and what are the implications for forest management? (2014). Recent developments in climate change observations and projections, observed and projected impacts on European forests and the associated uncertainties are reviewed and synthesised with a view to understanding the implications for forest management. https://www.ncbi.nlm.nih.gov/pubmed/25156267

Climate change guidelines for forest managers (2013). These guidelines are published by FAO to support forest managers in responding to climate change challenges and opportunities at the forest management unit level. http://www.fao.org/3/i3383e/i3383e.pdf

CIFOR Forests and climate change toolbox (2010). This toolbox was developed by the Center for International Forestry Research to build understanding and technical proficiency on issues of climate change and forests, including mitigation, adaptation, carbon accounting and markets, and biofuels. The toolbox consists of a series of PowerPoint presentations with accompanying notes. wWw.cifor.cgiar.org/fctoolbox/

Impacts of forest landscape structure and management on timber production and carbon stocks in the boreal forest ecosystem under changing climate (2007). In this paper, a processbased growth and yield model was used to investigate the sensitivity of timber production and carbon stocks to management under different climate scenarios at the level of the FMU. The effects of initial age class distributions of an FMU on timber production and carbon stocks under different management and climate scenarios were also examined and the implications on the cost of carbon sequestration over the next 100 years presented. https://www.sciencedirect.com/science/article/pii/ S0378112707000412

\section{3) VULNERABILITY ASSESSMENTS}

Climate change vulnerability assessment of forests and forest-dependent people A framework methodology (2019). This FAO and FTA publication provides practical technical guidance for forest vulnerability assessment in the context of climate change. It describes the elements that should be considered for different time horizons and outlines a structured approach for conducting these assessments. The framework will guide practitioners in conducting a step-by-step analysis and will facilitate the choice and use of appropriate tools and methods. https://doi.org/10.4060/CA7064EN

Resilience Index Measurement and Analysis (RIMA-II): an innovative quantitative approach that allow explaining why and how some households cope with shocks and stressors better than others do. The direct measure provides descriptive information on household resiliencecapacity and it is avaluable policy analysis tool to inform funding and policy decisions of governments, international organizations, donors and civil society, as it allows to target and rank households from most to less resilient. RIMA-II also measures resilience indirectly to provide evidence on the main determinants of households' resilience capacity. The indirect measure of resilience can be adopted as a predictor tool for interventions that strengthen resilience to food insecurity. http://www.fao.org/3/a-i5665e.pdf

A review of existing approaches and methods to assess climate change vulnerability of forests and forest-dependent people (2018). An FAO publication on the approaches to assessing vulnerability. These can be categorized according to the focus they each provide. Contextual vulnerability addresses current issues of climate and is usually evaluated using participatory techniques with people who live in, or work with, forests. Outcome vulnerability looks at the biophysical vulnerability of forests; it is often used to assess the cause-andeffect of climate change on a biological system. Vulnerability assessments can be highly technical and quantitative, using advanced computer programs and geographic information systems, or they can be based on social science approaches to obtain qualitative information from people. http://www.fao.org/3/CA2635EN/ca2635en.pdf

AMulticriteria Risk Analysis to Evaluate Impacts of Forest Management Alternatives on Forest Health in Europe (2012). An evaluation of the effect of four forest management alternatives (FMAs) (i.e., close to nature, extensive management with combined objectives, intensive even-aged plantations, and short-rotation forestry for biomass production) on biotic and abiotic risks of damage in eight regional case studies. https://www.ecologyandsociety.org/vol17/iss4/art52/ 
Adapting sustainable forest management to climate change: scenarios for vulnerability assessment (2012). This report addresses the origins of the scenarios that will be needed to assess the impacts of climate change and other stressors on managed forest systems. It examines how scenarios can be constructed for application at local scales (such as a forest management unit), using both top-down (downscaling from global and regional projections) and bottom-up (accounting for local trends and projections) approaches. Practical examples of using scenarios for impact assessment in forestry are briefly reviewed in four case studies from across Canada. https://www.cabdirect.org/cabdirect/abstract/20133150126

An assessment of the vulnerability of Australian forests to the impacts of climate change (2011). This project is part of the Synthesis and Integrative Research component of NCCARF activities. It addresses the knowledge gap with regard to our understanding of the implications of climate change for Australia's forest estate including native forests, plantations, farm forestry and environmental plantings. It seeks to provide an improved understanding of current knowledge of the likely biophysical and socio-economic consequences of climate change for Australia's native and planted forest regions. It assesses the vulnerability of Australian forests from the perspective of both resource use and ecosystem services, identifying particularly vulnerable forests and communities in major forest areas. It also provides information on what is being done in Australia to understand and manage climate-related risks in relation to forests, and it offers guidance on key gaps to assist climate change adaptation. https://www.nccarf.edu.au/ content/assessment-vulnerability-australianforests-impacts-climate-change

A system for assessing vulnerability of species (SAVS) to climate change (2011). The SAVS is a simple and flexible tool designed for managers to assess the relative risk of individual species to population declines in response to projected changes in climate and related phenomena. The SAVS uses an easily completed questionnaire based on predictive criteria that translate the responses of terrestrial vertebrate species into scores indicating vulnerability or resilience to climate change. The SAVS also includes methods for calculating uncertainty, detailed instructions for scoring a species and guidelines for tool application. www.fs.fed.us/rm/pubs/rmrs_gtr257.pdf
Climate change in a living landscape: conceptual and methodological aspects of a vulnerability assessment in the Eastern Cordillera Real of Colombia, Ecuador and Peru (2011). This document by the Worldwide Fund for Nature presents the results of combined vulnerability analyses (biological, hydrological and socio-economic). The results demonstrate the need for actions oriented at maintaining the continued provision of ecosystem services as well as the biological and cultural riches of the region. Priority adaptation measures include actions to develop and strengthen the capacities and production systems of local communities and institutions, with the aim of maintaining and recovering ecosystem resilience, strengthening a regional policy framework with considerations of vulnerability and adaptation to climate change, and strengthening the capacity to generate and disseminate information necessary to increase citizen participation in decision-making processes. http://awsassets.panda.org/downloads/cc_ecr_ final_web.pdf

Methods and tools for assessing the vulnerability of forests and people to climate change (2009). This working paper by the Center for International Forestry Research provides an overview of methods and tools suitable for assessing the vulnerability of forests, forest ecosystem services and forestdependent people or sectors to climate change. It provides a typology of methods and tools and gives examples. WWW.cifor.cgiar.org/publications/pdf files/WPapers/WP43Locatelli.pdf

CRiSTAL (2009). The Community-based Risk Screening Tool - Adaptation and Livelihoods (CRiSTAL) is designed to help project planners and managers integrate climate change adaptation and risk reduction into community-level projects. www.iisd.org/cristaltool/

A framework for assessing vulnerability of forestbased communities to climate change (2007). This publication presents a general framework for and approach to assessing the vulnerability of forestbased communities to climate change and the potentially increased risks associated with such change. It identifies specific elements that should be considered in assessing vulnerability and outlines a series of steps that researchers and communities can follow to systematically determine sources of vulnerability to climate change.

https://cfs.nrcan.gc.ca/pubwarehouse/pdfs/27507.pdf 
Compendium on methods and tools to evaluate impacts of, and vulnerability and adaptation to, climate change (2005). This compendium provides a synthesis of key information about available frameworks and tools for assessing climate change vulnerability and adaptation options, special features of each framework or tool, and information about how to obtain documentation, training, or publications supporting each tool. https://unfccc.int/files/ adaptation/methodologies_for/vulnerability_and_ adaptation/application/pdf/200502_compendium_ methods_tools_2005.pdf

Assessing the vulnerability of Australia's urban forests to climate extremes (2019).

Urban forests are recognized for the multiple benefits they provide to city-dwellers. However, climate change will affect tree species survival and persistence in urban ecosystems. Tree failures will cause economic losses and jeopardize the delivery of societal benefits. The impacts of climate change will depend on the species' resilience and adaptive capacity, as well as management actions which may ameliorate some of the negative impacts. Here, we assessed the potential vulnerability of Australia's urban forests to climate extremes. https://nph.onlinelibrary.wiley.com/doi/ full/10.1002/ppp3.10064

\section{4) EXTREME WEATHER EVENTS}

Impacts of climate change, weather extremes and alternative strategies in managed forests (2019.) The growth rate of most tree species in boreal forests will increase with changing climate. This increase is counterbalanced by an increased risk of damage due to extreme weather events. It is believed that the risk of storm damage will increase over time, especially if forests continue to be managed as they are today. In this study, a new landscape-level hybrid forest growth model 3PG-Heureka was developed and simulations were performed to predict the damage caused by storm events in Kronoberg county, over a period of 91 years (2010-2100) with different alternative management regimes under various climatic scenarios (historic, RCP4.5 and RCP8.5). The results indicate that damage caused by storm events could drastically reduce the annual volume increment and annual net revenue obtained from forest landscapes if current forest management regimes are used. https://www.tandfonline.com/doi/full/10.1080/1195 6860.2018.1515597
Forest health and global change (2015). Although native forests are adapted to some level of disturbance, all forests now face novel stresses in the form of climate change, air pollution, and invasive pests. Detecting how intensification of these stresses will affect the trajectory of forests is a major scientific challenge that this paper addresses. https://science. sciencemag.org/content/349/6250/814/tab-pdf

Climate change and extreme weather events (2000). This assessment sponsored by the Worldwide Fund for Nature reviews scientific knowledge on climate change and its impacts regarding the weather, particularly weather extremes. It addresses the extent to which the human influence on the climate can be measured, the short- and long-term expectations and the potential impact on the future climate of measures to reduce net GHG emissions. http://awsassets.panda.org/downloads/xweather.pdf

\section{5) PESTS AND DISEASES}

Guide to the classical biological control of insect pests in planted and natural forests (2019). This FAO publication provides general theory and practical guidelines on the classical biological control, explains the "why" and "how" of classical biological control in forestry, and addresses the potential risks associated with such programmes. http://www.fao.org/3/ca3677en/ca3677en.pdf

Guide to implementation of phytosanitary standards in forestry (2011). This guide is intended to help reduce human-facilitated pest spread and its impacts. It provides easy-to-understandinformation on international standards for phytosanitary measures and the role of forest management practices in implementing phytosanitary standards and facilitating safe trade. www.fao.org/forestry/ foresthealthguide/en/

Climate change impacts on forest health (2008). This paper reviews the current state of knowledge on the effects of climate change on forest pests and their implications for forest health protection and management. Because of the relatively limited research that has been dedicated specifically to forest pests, information on non-forest pests is also included to enable a better understanding of the potential impacts of climate change on forest health. http://www.fao.org/forestry/15905-odc804ee7d97e6 56f06507bdcecddc721.pdf 


\section{6) WILDFIRES}

Fire management voluntary guidelines: principles and strategic actions (2006). These voluntary guidelines set out a framework of priority principles that will aid the formulation of policy, legal, regulatory and other enabling conditions and strategic actions for more holistic approaches to fire management. They have been tailored primarily for land-use policy-makers, planners and managers in fire management, including states, the private sector and NGOs. The guidelines cover the positive and negative social, cultural, environmental and economic impacts of natural and planned fires in forests, woodlands, rangelands, grasslands and agricultural and rural/urban landscapes. The scope includes early warning, prevention, preparedness (international, national, subnational and community), safe and effective initial attack on fire incidents, and landscape restoration in the wake of wildfire. http://www.fao.org/3/j9255e/j9255eoo.htm

World Bank Policy Note: Managing Wildfires in a Changing Climate (2020). This Policy Note aims to lay out the key policy messages and recommendations for mitigating and adapting to the increasing impacts of wildfires around the world under a changing climate and takes stock of factors that contribute to extreme wildfires, including climate change, land-use change, and demographic shifts. It recommends policy actions that can be taken to improve wildfire prevention and management depending on national circumstances. The biggest shift from the current reactive approach, which often relies on emergency response and fire suppression, is increased investment in prevention. Governments can help prevent extreme wildfires through measures such as improved land-use planning, eliminating perverse incentives for using fire to change land use, and clarifying land tenure rights. Other actions include implementing existing fire management techniques such as integrated fire management and fire danger rating, improving fire monitoring and early detection and strengthening stakeholder involvement in fire management planning.

Wildland fire management: handbook for trainers (2010). This handbook supports the implementation of the Voluntary Guidelines for Fire Management, targeting field trainers and instructors. Together with the Voluntary Guidelines, the handbook forms the basis for a programme of institutionstrengthening and capacity-building in fire management, particularly in developing countries. www.fao.org/docrep/012/i1363e/i1363eoo.htm

Forest Fires - Sparking firesmart policies in the EU (2018). An analysis of the knowledge, methodologies and technologies produced in the last two decades opens up new perspectives for forest fire risk management in the face of climate and environmental changes, social and cultural trends and growth dynamics. Based on the findings of this review, key recommendations are proposed for a more extensive dialogue between the key actors to improve forest fire risk management in Europe. https://ec.europa.eu/info/sites/info/files/181116 booklet-forest-fire-hd.pdf

Forest fire danger extremes in Europeunder climate change: variability and uncertainty (2017). Forests cover over a third of the total land area of Europe. In recent years, large forest fires have repeatedly affected Europe, in particular the Mediterranean countries. Fire danger is influenced by weather in the short term, and by climate when considering longer time intervals. In this work, the emphasis is on the direct influence on fire danger of weather and climate. https://publications.jrc.ec.europa.eu/repository/ bitstream/JRC108974/jrc108974_final.pdf

Climate change, carbon sequestration and forest fire protection in the Canadian boreal zone (2011). This report reviews the potential influence of climate change on fire regimes in boreal forests and associated peatlands and the implications for managing fires in those ecosystems. It also discusses the role of boreal forest and peatland fires in cycling carbon through both the release of carbon (in the form of GHGs) in combustion, and the subsequent uptake of carbon in post-fire vegetation renewal. http://www.climateontario.ca/MNR_Publications/ stdprod_088316.pdf

Assessment of forest fire risks and innovative strategies for fire prevention (2010). This publication presents the outcomes of the Workshop on the Assessment of Forest Fire Risks and Innovative Strategies for Fire Prevention, which was held on 4-6 May 2010 in Greece. It reviews the current national forest fire prevention systems in European countries and identifies innovative strategies, best practices and possible policy instruments in relation to forest fire prevention in Europe. https://www.foresteurope. org/documentos/FOREST_EUROPE_Forest_Fires_ Report.pdf 


\section{7) MANGROVES}

Can mangroves keep pace with contemporary sea level rise? A global data review (2016). This publication systematically reviews published studies of surfaceelevation change(SEC) and surfaceaccretion rate (SAR) from globally distributed monitoring sites using meta-analysis, and compare them with the Intergovernmental Panel on Climate Change Fifth Assessment Report (IPCC AR5) SLR scenarios. https://www.cifor.org/library/5775/

Mangroves for coastal defence. Guidelines for coastal managers \& policy makers (2014). This practical guidebook summarises the findings of the reviews and provides practical management recommendations to coastal zone managers and policymakers. It helps the reader to assess the risk context in a target area, to define hazard-specific mangrove management interventions and to incorporate these in risk reduction strategies, climate change adaptation protocols and broader coastal development planning. Case studies provide practical examples of mangrove management approaches and references to background information. Practical tools for risk assessment and mangrove management are provided throughout the book.

https://www.nature.org/media/oceansandcoasts/ mangroves-for-coastal-defence.pdf

Practical measures to tackle climate change: coastal forest buffer zones and shoreline change in Zanzibar, Tanzania (2009). This report of the United Nations Educational, Scientific and Cultural Organization presents the results of analyses of change (over 50 years) to coastal forests and practical actions to mitigate the unwanted effects of the change. http://www.globalislands.net/userfiles/ Tanzania-11.pdf

Managing mangroves for resilience to climate change (2006). This paper provides an overview of mangrove ecosystems, the benefits of mangroves to people, and the human and global threats that compromise mangrove ecosystems. It describes the impacts of climate change on mangroves and outlines tools and strategies that enhance mangrove resilience. https://portals.iucn.org/ library/sites/library/files/documents/2006-041.pdf

\section{8) INDIGENOUS COMMUNITIES LIVELIHOODS}

Local communities' and indigenous peoples' rights to forests in Central Africa: from hope to challenges (2013). This paper reviews the various rights of local communities and indigenous peoples over forest resources in Central Africa. In 2010, the Council of Ministers of the Commission des Forêts d'Afrique Centrale (COMIFAC) adopted the Subregional Guidelines on the Participation of Local Communities and Indigenous Peoples and NGOs in Sustainable Forest Management in Central Africa. A survey of this subregional legal instrument highlights a genuine commitment by states to consolidate the benefits and the emerging rights that can improve the living conditions of vulnerable communities and strengthen the subregional regime of sustainable forest management. However, the effectiveness of the subregional guidelines hinges on the administrative acts and practical measures of member states to incorporate this instrument into their domestic legal systems and to enforce it. http://www.cifor.org/publications/pdf_files/ articles/AAssembe-Mvondo1301.pdf

Understanding community-based REDD+: a manual for indigenous communities (2011). This manual prepared by the International Work Group for Indigenous Affairs and Asia Indigenous Peoples Pact is based on and seeks to promote in a holistic way an approach to REDD+ that respects and promotes the rights of indigenous peoples, as provided for in the United Nations Declaration on the Rights of Indigenous Peoples, the social and cultural systems of indigenous peoples and their values and practices, and the environment. ht tp s: / / a i p pnet.org / w p - content / uploads/2020/02/21.-A-Manual-for-IndigenousCommunities-20120117174234.pdf

A guide to learning about livelihood impacts of REDD+ projects (2010). This guide provides an overview of research methods which map causal chains of REDD+ projects, and gathers valuable evidence about how REDD+ interventions affect social welfare in forest regions. https://www.profor. info/sites/profor.info/files/CIFOR-learningREDD.pdf 


\section{9) GENDER}

ITTO policy guidelines on gender equality and the empowerment of women (2018). ITTO is committed to gender mainstreaming and enhancing gender equality outcomes across its policy and project work. ITTO's policy guidelines on gender equality and empowering women (GEEW) institutionalize this commitment. The Policy Guidelines serve as a framework for gender integration and mainstreaming in ITTO policies, plans, programmes, projects, activities and internal functioning and are intended to enhance the impact and effectiveness of the Organization's operations in all areas and at all levels.

https://www.itto.int/direct/topics/topics_pdf_ download/topics_id=6107\&no=1\&disp=inline

Gender and Forests: Climate Change, Tenure, Value Chains and Emerging Issues (2016). This enlightening book brings together the work of gender and forestry specialists from various backgrounds and fields of research and action to analyse global gender conditions as related to forests. Using a variety of methods and approaches, they build on a spectrum of theoretical perspectives to bring depth and breadth to the relevant issues and address timely and under-studied themes. http://www.cifor.org/ publications/pdf_files/Books/BColfer1701.pdf

Gender in Agroforestry: Special Issue (2015). This is a special issue of International Forestry Review on Gender in Agroforestry. A complete list of articles is found here: https://www.cifor.org/library/5736/

The gender box: A framework for analysing gender roles in forest management (2012). Recognising widespread uncertainty about how to address gender within the forestry world (from researchers, as well as natural resource, development and conservation practitioners), this paper strives to provide targeted guidance. It divides gender methods into three main approaches, based on the availability of resources. http://www.cifor.org/publications/pdf_files/ OccPapers/OP-82.pdf

\section{0) ECOSYSTEM SERVICES}

Valuing forest ecosystem services: A training manual for planners and project developers (2019). This manual released by FAO is intended as a training tool for officers and field practitioners working in environmental and forest agencies and other relevant areas of government. It focuses on forests and other tree-based ecosystems in Bangladesh but the concepts, methods and approaches described herein can be applied to a broad range of situations. The target audience of the manual comprises those people who must consider the environmental costs and benefits of development projects but who necessarily lack a strong background in environmental economics. The aim is to build a robust knowledge of ecosystem services and their economic valuation through a stepwise approach. The manual explains the underlying concepts, provides definitions, sets out the principles of financial mathematics and economic valuation, and provides examples and exercises.

http://www.fao.org/3/ca2886en/CA2886EN.pdf

Forests and Water - Valuation and payments for forest ecosystem services (2018). The objectives of this study conducted by FAO and UNECE are to further improve understanding about the ways in which payments for ecosystem services schemes can be applied to forests, in particular focusing on forest's hydrological functions for the mutual benefit of both humans and the environment. In addition, the study covers advances and challenges facing these schemes and provides practical guidance for policymakers and practitioners. This study contains the most comprehensive currently available database of case studies on water-related payment for forest ecosystem services schemes in the UNECE region. https://www.unece.org/fileadmin/DAM/timber/ publications/sp-44-forests-water-web.pdf

Forest Ecosystem Services (2018). Background analytical study prepared for the thirteenth session of the United Nations Forum on Forests. https://www. un.org/esa/forests/wp-content/uploads/2018/05/ UNFF13_BkgdStudy_ForestsEcoServices.pdf

Payments for forest environmental services in sub-Saharan Africa: A practical guide (2016). The long-term objective of this FAO publication is to augment financial resources for sustainable forest management by increasing the recognition and appreciation of the benefits of trees, forests and forestry. As such, this publication elaborates on various strategies for mobilizing investments for conserving and increasing the economic, social and environmental values of forests while enhancing benefits for African communities. By sharing success stories, the publication 
demonstrates how appropriate economic incentives can enable the transfer of financial resources from the beneficiaries of environmental services to those who provide them. It also seeks to empower national governments to play catalytic roles in ensuring that the full range of economic values of forests is reflected in the marketplace. http://www.fao.org/3/a-i5578e.pdf

Payments for Forest Ecosystem Services: SWOT Analysis and Possibilities for Implementation (2016). The aim of this report is to present an overview of PES implementation in forest ecosystems in Europe. A SWOT analysis is presented based on the analysis of first, policy drivers related with PES at the EU level, second literature review, and finally a comparison of best practices in PES. Best practices from European countries are shown in the case studies of established and functional PES schemes. https://publications.jrc.ec.europa.eu/repository/ bitstream/JRC103176/lb-na-28128-en-n.pdf

How Forest Management affects Ecosystem Services, including Timber Production and Economic Return: Synergies and Trade-Offs (2012). In light of limited attempts to illustrate and evaluate quantitatively the relationship between forest goods and services, this publication uses virtual but realistic datasets to quantify, for multiple services, the effects of five forest management alternatives that form an intensity gradient. https://www.jstor.org/stable/pdf/26269223

\section{1) WATER}

WaPOR: The FAO portal on Water Productivity through Open access of Remotely sensed derived data (WaPOR) monitors and reports on agriculture water productivity over Africa and the Near East. It is a vital new tool to address water scarcity and adapt to changing weather patterns. www.fao.org/in-action/ remote-sensing-for-water-productivity/wapor\#/ home

Forest and Water on a Changing Planet: Vulnerability, Adaptation and Governance Opportunities. A Global Assessment Report (2018). This comprehensive report presents the outcomes of the 6th scientific assessment undertaken in the framework of the Global Forest Expert Panels initiative (GFEP). The Global Forest Expert Panel on Forests and Water co-chaired by Irena F. Creed and Meine van Noordwijk prepared a scientific synthesis report and accompanying policy brief launched at the 2018 UN High-level Political Forum on Sustainable Development. More than 50 scientists from 20 countries contributed to this major assessment of the forests-water-climate-people link. The primary global policy context for this assessment is shaped by the 17 Sustainable Development Goals (SDGs). Water is central to all 17 SDGs and forests are inseparably tied to water. The report reflects the importance of integrated action towards ensuring access to water for all and sustaining life on land and highlights the important linkages between water and forests. https://www.iufro.org/fileadmin/material/ publications/iufro-series/ws38/ws38.pdf

Forest management and the impact on water resources: a review of 13 countries (2017). This UNESCO publication provides country-based summaries of the current state of knowledge on the relationship between forest management and water resources. Chapters were submitted by scientists from 13 countries experiencing the impacts of forest management on water. The publication seeks to identify similarities and differences in historical forest management, climate, vegetation types and socio-economic conditions that drive the use and management of forests. The core contents of this report aim to clarify how cooperation and conflict around forests and water resources are increasing worldwide. Future research should focus on how to solve current and future conflicts, taking into account local climates. https://unesdoc.unesco.org/ark:/48223/pfooo0247902

Water, climate change and forests: watershed stewardship for a changing climate (2010). This report describes adaptation opportunities associated with forest management, specifically in the context of water and aquatic ecosystems. The first two sections describe the importance of forests to water resources in the United States of America and summarize observed and projected effects of climate change on the hydrologic cycle and forested watersheds. www.fs.fed.us/pnw/pubs/pnw_gtr812.pdf

Forests and water (2008). This FAO publication explains the role of forests in the hydrological cycle, with a particular focus on critical "red flag" forest situations such as mountainous or steep terrain, river and coastal areas and swamp ecosystems. It also addresses the protection of municipal water supplies and emerging systems of payments for watershed services. The publication highlights the need for holistic management 
in complex watershed ecosystems, taking into account interactions among water, forest and other land uses, as well as socio-economic factors. http://www.fao.org/forestry/43810-05bc28890480b 481d4310a3c5fe8a1003.pdf

The new generation of watershed management programmes and projects (2006). This FAO publication has been prepared primarily for fieldlevel watershed management practitioners and local decision-makers involved in watershed management at the district or municipality level. It provides information on the new generation of watershed management using examples from France, Italy, Kenya, Nepal and Peru.

www.fao.org/docrep/009/a0644e/a0644e0o.htm

\section{2) BIODIVERSITY}

Wildlife in a changing climate (2012). This FAO publication analyses and presents how climate change affects or will likely affect wild animals and their habitats. Although climate change has already been observed and monitored over several decades, there are few long-term studies on how the phenomenon is affecting wildlife. There is growing evidence, however, that climate change significantly exacerbates other major human-induced pressures, such as encroachment, deforestation, forest degradation, land-use change, pollution and the overexploitation of wildlife resources. Case studies are presented that describe some of the body of evidence in some instances and provide projections of likely scenarios in others. www.fao. org/forestry/30143-obb7fb87ece780936a2f55130c8 7caf46.pdf

Climate change and forest genetic resources: state of knowledge, risks and opportunities (2011). This FAO paper reviews and examines the impacts of climate change on genetic resources of organisms that are important for human well-being, and the potential role of these resources in mitigating and adapting to climate change. It focuses on forest genetic resources in the context of trees in natural forests, plantations and agroforestry systems. The paper consists of a review of the current state of knowledge and the identification of gaps and priorities for action. www.fao.org/docrep/meeting/023/mb696e.pdf
Climate change and African forest and wildlife resources (2011). This book prepared by the African Forest Forum systematically presents climate change in the context of African forests, trees and wildlife resources. It includes information on the broader aspects of climate change and variability, an overview of climate change on African wildlife resources, and socio-economic and policy considerations for talking about climate change issues within the forest sector. http://afforum.org/ sites/default/files/English/English_o.pdf

Do European agroforestry systems enhance biodiversity and ecosystem services? A metaanalysis (2016). An analysis of the effects of agroforestry on biodiversity and ecosystem services which shows that Agroforestry has an overall positive, but this is a context dependent effect. https://www.sciencedirect.com/science/article/pii/ S0167880916303097

REDD+ and biodiversity (2011). This document has been prepared by the Secretariat of the Convention on Biological Diversity (CBD) with a view to providing technical and scientific information on designing and implementing REDD+ activities in a way that does not run counter to the objectives of the CBD and supports the implementation of the programme of work on forest biodiversity. More specifically, the document aims to outline: the potential benefits of REDD+ for biodiversity and indigenous and local communities; the importance of biodiversity and indigenous and local community co-benefits for the long-term success of REDD+; possible risks of REDD+ for biodiversity and indigenous and local communities with a view to contributing to the development or improvement of appropriate policy recommendations; the ways in which the CBD can contribute to the success of REDD+; and the potential ways in which REDD+ can contribute to the objectives of the CBD.

wwW.cbd.int/doc/publications/cbd-ts-59-en.pdf

Sustainable forest management, biodiversity and livelihoods: a good practice guide (2009). This publication by the CBD Secretariat addresses the linkages between forestry, biodiversity and development/poverty reduction. The summaries and examples show how biodiversity and sustainable economic development can go hand in hand. www.cbd.int/development/doc/cbd-good-practiceguide-forestry-booklet-web-en.pdf 
Mountain biodiversity and climate change (2009). This publication of the International Center for Integrated Mountain Development reviews the impacts of climate change on mountain ecosystems and the consequences for the rest of the world. It discusses the present situation and approaches towards a common future strategy for mountain biodiversity conservation. http://lib.icimod.org/ record/7973/files/attachment_613.pdf

Forest resilience, biodiversity, and climate change: a synthesis of the biodiversity/ resilience/stability relationship in forest ecosystems (2009). This paper by the CBD Secretariat reviews the concepts of ecosystem resilience, resistance and stability in forests and their relationship to biodiversity, with particular reference to climate change. https://www. cbd.int/doc/publications/cbd-ts-43-en.pdf

ITTO/IUCN guidelines for the conservation and sustainable use of biodiversity in tropical timber production forests (2009). These guidelines were prepared by ITTO and the International Union for Conservation of Nature and distinguish two levels of intervention. At one level, the guidelines set out those general approaches to forest management that will have wide application in ensuring that biodiversity values are maintained and should be adopted universally. At the other level, they review practical experience and provide advice that managers and decision-makers might draw on in designing locally applicable guidelines, codes of practice, regulations and silvicultural practices. https://www.itto.int/ direct/topics/topics_pdf_download/topics_ id $=1918 \&$ no $=0 \&$ disp $=$ inline

Connecting biodiversity and climate change mitigation and adaptation: report of the second ad hoc technical expert group on biodiversity and climate change (2009). This CBD document examines the observed and projected impacts of climate change on biodiversity, the links between biodiversity and climate change adaptation and mitigation, the links between biodiversity and climate change mitigation with a particular focus on land-use activities and reducing emissions from deforestation and forest degradation, and provides information on techniques for valuing biodiversity. It highlights that applying these techniques can quantify costs and benefits, opportunities and challenges and thus improve decision-making on climate change related activities.

www.cbd.int/doc/publications/cbd-ts-41-en.pdf
Climate change and forest genetic diversity: implications for sustainable forest management in Europe (2007). The publication reviews current understanding of how forest trees will cope with and adapt to climate change, and discusses the implications for SFM in Europe. www.euforgen.org/ fileadmin/bioversity/publications/pdfs/1216.pdf

Ecological monitoring of forestry management in the humid tropics: a guide for forestry operators and certifiers with emphasis on high conservation value forests (2004). This publication provides guidance to the global effort on the sustainable management of high conservation value forests (HCVF) using valid criteria for production and conservation. The general objective is to provide operators and certifiers of tropical forests with methodological procedures that are practical and relevant to the ecological monitoring of certified forestry activities in HCVF (following Forest Stewardship Council protocols and standards).

https://www.yumpu.com/en / document/ read/21765940/ecological-monitoring-of-forestrymanagement-in-the-humid-tropics-

\section{3) FOOD AND NUTRITION SECURITY}

Testing the Various Pathways Linking Forest Cover to Dietary Diversity in Tropical Landscapes (2019). A diverse diet is important to address micronutrient deficiencies and other forms of malnutrition, one of the greatest challenges of today's food systems. In tropical countries, several studies have found a positive association between forest cover and dietary diversity, although the actual mechanisms of this has yet to be identified and quantified. Three complementary pathways are explored in this article which may link forests to diets: a direct pathway (e.g., consumption of forest food), an income pathway (income from forest products used to purchase food from markets), and an agroecological pathway (forests and trees sustaining farm production).

https://www.cifor.org/library/7441/

Forest pattern, not just amount, influences dietary quality in five African countries (2019). This article links linked forest metrics and food consumption data across five African countries. https://www.sciencedirect.com/science/article/pii/ S2211912419300021?via\%3Dihub 
Sustainable forestry for food security and nutrition: A report by the High-Level Panel of Experts on Food Security and Nutrition (2017). This report calls for a renewed understanding of sustainable forestry in order to fully integrate the different functions of forests and trees, from farm and landscape to global levels, as well as at different timescales, for enhanced food security and nutrition and sustainable development. This requires inclusive and integrative governance mechanisms at different scales that enable the full and effective participation of concerned stakeholders, particularly of forest-dependent indigenous peoples and local communities. http://www.fao.org/fileadmin/user upload/hlpe/hlpe_documents/HLPE_Reports/ HLPE-Report-11_EN.pdf

Forests and Food: Drivers of Forests and Treebased Systems for Food Security and Nutrition (2015). A review of scientific findings identifies twelve major drivers of food and nutrition security in the context of forests (i.e. population growth, urbanisation, governance shifts, climate change, commercialisation of agriculture, industrialisation of forest resources, gender imbalances, conflicts, formalisation of tenure rights, rising food prices and increasing per capita income).

https://www.cifor.org/library/5937

\section{4) FOREST MANAGEMENT}

UN Forest Instrument. Provides a framework for national actions and international cooperation to sustainably manage forests. https://www.un.org/esa/forests/wp-content/ uploads/2018/08/UN_Forest_Instrument.pdf

United Nations strategic plan for forests, 2017-2030. A tool to support countries' efforts at integrating forest ecosystem services into all aspects of national policymaking and planning.

https://www.un.org/esa/forests/wp-content/ uploads/2016/12/UNSPF_AdvUnedited.pdf

Sustainable Forest Management (SFM) Toolbox. It collates a large number of tools, case studies and other resources, organized in modules. It has been created to provide forest owners, managers and other stakeholders with easy access to those resources for the implementation of SFM. http://www.fao.org/sustainable-forestmanagement/toolbox/en/
The Program on Forests (PROFOR). A multi-donor partnership which provides knowledge, tools and in-depth analysis to facilitate forests contribution to poverty reduction, sustainable economic development and the protection of global and local environmental services.

https://www.profor.info/tools

Agtrials: The Global Agriculture Trial Repository and Database. An information portal developed by the CGIAR Research Program on Climate Change, Agriculture and Food Security (CCAFS) which provides access to a database that collects and analyses the performance of agricultural technologies under climate change in developing countries. It is intended to help further evaluate and improve agricultural production models under current and future climate conditions.

http://www.agtrials.org/

The FAO Guidelines on urban and peri-urban forestry (2016). These are intended to provide a reference framework for decision makers and planners to adequately plan, design and manage the forest and trees in and around their cities. The document includes a general overview of the role of urban and peri-urban forests towards a sustainable urban development, as well as specific chapters recommending policy and management actions to be taken to maximize their contribution in addressing both global and local challenges, including climate change. http://www.fao.org/3/a-i6210e.pdf

Voluntary guidelines for the sustainable management of natural tropical forests (2015). This publication is an update of ITTO's first policy guidance document on the management of natural tropical forests published in 1990. The new voluntary guidelines are supported with increased knowledge and the emergence of a wide range of new challenges and opportunities for tropical forest management. It is designed to serve as guidance for addressing the policy, legal, governance, institutional, ecological, social and economic issues that need to be taken into account in the planning, implementation and evaluation of SFM in natural tropical forests to ensure the sustainable provision of forest goods and environmental services. https://www.itto.int/direct/topics/topics_pdf_ download/topics_id=4330\&no=0\&disp=inline 
Guidelines on sustainable forest management in drylands of sub-Saharan Africa (2010). These guidelines produced by FAO are intended to guide forestry decision-makers and managers in prioritizing the issues and aspects that need to be addressed to improve forest planning and management in drylands and as a result contribute to the well-being of local populations and enhance their social, cultural, environmental and economic benefits. http://www.fao.org/3/i1628e/i1628eoo.pdf

Voluntary guidelines for the responsible management of planted forests (2006). These nonlegally binding FAO guidelines may be adopted and applied to planted forests in all ecogeographical zones and in countries, regions and landscapes at all stages of economic development. They are applicable to planted forests that fulfil productive functions for the provision of wood, fiber and non-wood forest products or protective functions for the provision of ecosystem and social services. They cover all aspects of planted forests, from policy development and planning to the technical considerations of planted forest management. The guidelines establish a framework to support dialogue in the formulation of policies, laws, regulations and strategic and management plans that, in turn, will help improve enabling conditions and enhance capacity and capability in planted forest management.

http://www.fao.org/3/j9256e/j9256eoo.pdf

The sustainable forestry handbook: a practical guidefor tropical forest managers on implementing new standards (2004). This handbook provides a clear and concise guide to the practicalities of implementing international standards for SFM. It is targeted at forest managers and explains in clear terms what the standards require forest managers to do and how they might go about implementing them. https://www.taylorfrancis.com/books/9781849773317

ITTO guidelines for the restoration, management and rehabilitation of degraded and secondary tropical forests (2002). These guidelines by ITTO highlight the increasing importance of degraded and secondary forests in tropical landscapes. They provide a set of principles and recommended actions to promote and encourage the management, restoration, rehabilitation and sustainable use of degraded and secondary forests as a component of sustainable social and economic development. https://www.itto.int/direct/topics/topics_pdf download/topics_id=1540000\&no=1\&disp=inline
FAO model code of forest harvesting practice (1996). The FAO model code is intended to promote harvesting practices that will improve standards of forest use, reduce environmental impacts, help ensure that forests are sustained for future generations and improve the economic and social contributions of forestry as a component of sustainable development. It examines harvesting planning, the implementation and control of harvesting operations, harvesting assessment, the communication of results to the planning team, and the development of a competent and properly motivated workforce. Information is also provided on the potential consequences that might be expected from a failure to implement these practices. www.fao.org/docrep/V6530E/V6530E0o.htm

Criteria and indicators for the sustainable management of tropical forests (2016). This publication is an update to ITTO's Criteria for the Measurement of Sustainable Tropical Forest Management which was produced to assist in monitoring and assessing the condition of natural tropical forests in the Organization's producer member countries and in identifying improvements needed in forest practices. https://www.itto.int/ direct/topics/topics_pdf_download/topics_ id=4872\&no=1\&disp=inline

\section{5) ADAPTATION}

NAP-Ag Knowledge Tank. This searchable database supports countries in highlighting key resources for adaptation planning and budgeting, especially in formulating and implementing National Adaptation Plans (NAP). It contains tools, methods, case studies and other knowledge materials on climate change adaptation in the agriculture sectors (crops, livestock, forestry, fisheries and aquaculture). This tool is targeted at national planners, development actors and decision makers. http://www.fao.org/inaction/naps/knowledge-tank/en/

Suitability of key Central American agroforestry species under future climates (2017). This atlas (de Souza et al, 2017) presents current and future suitability maps for 54 species that are commonly used as shade in agroforestry systems in Central America. The 54 tree species that were selected include 24 species of fruit trees, 24 timber trees and six species used to improve soil conditions. https://www.worldagroforestry.org/output/ suitability-key-central-american-agroforestryspecies-under-future-climates-atlas 
The Canadian Council of Forest Ministers (CCFM) Climate Change Adaptation series. The CCFM identified climate change as one of two priority issues for Canada's forest sector. Ministers responsible for forest management were asked to collaborate with the federal government on adaptation in forestry through the CCFM's Climate Change Task Force. Phase 1 of this work, completed in 2010, involved a comprehensive assessment of the vulnerability of various tree species and identified management options for adaptation. Phase 2 has gone beyond the level of trees to look at climate change adaptation within forest ecosystems and the broader forest sector. Outputs from these phases are captured in the CCFM's Climate Change Adaptation series, which comprises several technical reports and review papers.

https://www.ccfm.org/english/coreproducts-cc.asp

MOTIVE: The project on models for adaptive forest management. MOTIVE investigates adaptive management strategies that address climate and land-use change. It also examines the impacts of these changes with respect to a broad range of forest goods and ecosystem services.

http://motive.pensoft.net/

Climate adapt: European climate adaptation platform (CLIMATE-ADAPT). This platform aims to support Europe in adapting to climate change, especially by providing access and information on expected climatic changes, the current and future vulnerability of regions and sectors, including forestry, national and transnational adaptation strategies, and potential adaptation options. https://climate-adapt.eea.europa.eu/

weADAPT climate change explorer. This is an online platform focused on adaptation (and the synergies between adaptation and mitigation) targeting practitioners, researchers and policy-makers and providing them with access to information and possibilities to share experiences and lessons learned. http://weadapt.org/

Recent development in agroforestry research and its role in climate change adaptation and mitigation (2016). This paper reviews the recent technological development of agroforestry model and its role in environmental services particularly in carbon sequestration.https://www.researchgate.net/profile/ Om_Prakash_Chaturvedi/publication/304879691 Recent_development_in_agroforestry_research_ and_its_role_in_climate_change_adaptation_ and_mitigation/links/577c9ff208aece6c2ofcd9a1/ Recent-development-in-agroforestry-researchand-its-role-in-climate-change-adaptation-andmitigation.pdf

Climate change impacts and adaptation in forest management: a review (2015). This paper conducts a literature review on climate change impacts on forests and adaptation options for forest management identified in the Web of Science database, focusing on papers and reports published between 1945 and 2013. It identifies key themes for researchers and for forest managers. https://link.springer.com/article/10.1007/ s13595-014-0446-5

Managing forests as complex adaptive systems: building resilience to the challenge of global change (2013). This book links the emerging concepts of complexity, complex adaptive systems and resilience to forest ecology and management. It explores how these concepts can be applied in various forest biomes with their differing ecological, economic and social settings and history. Individual chapters stress different elements of these concepts based on the specific setting and expertise of the authors. Regions and authors have been selected to cover a diversity of viewpoints and emphasis, from silviculture and natural forests to forest restoration, and from boreal to tropical forests.

www.routledge.com/books/details/9780415519779/

Climate risk adaptation by smallholder farmers: the roles of trees and agroforestry (2013). Drawing on global examples with a focus on African case studies, this paper demonstrates the versatile roles of trees and agroforestry in reducing smallholder's exposure to climate-related risks. https://www.sciencedirect.com/science/article/pii/ S1877343513001619?via\%3Dihub

Reviewing the science and implementation of climate change adaptation measures in European forestry (2011). This paper presents a comprehensive review of potential adaptation options in forestry in Europe based on three pillars: a review of the scientific literature, an analysis of current national response strategies, and an expert assessment based on a database compiled in the COST Action ECHOES (Expected Climate Change and Options for European Silviculture). The adaptation measures include responses to both risks and opportunities created by climate change and address all stages of forestry operations. Measures targeted to reduce vulnerability to climate change may either aim to 
reduce forest sensitivity to adverse climate change impacts or increase adaptive capacity to cope with the changing environmental conditions.

https://www.mdpi.com/1999-4907/2/4/961

Responding to climate change in national forests: a guidebook for developing adaptation options (2011). This guidebook is a summary of current knowledge on climate change adaptation taken from educational syntheses, specific tools, facilitated dialogues, workshops and case studies. It focuses specifically on topics and approaches that are relevant to and compatible with resource management in national forests and potentially on other federal lands. The guidebook is intended to assist the transition to climate-smart approaches in resource management. It is not intended to be a comprehensive account of all scientific and management efforts on climate change adaptation but rather a compilation of information and lessons learned that will inform adaptation planning and practice on national forests.

www.fs.fed.us/pnw/pubs/pnw_gtr855.pdf

European forestry in the face of climate change: EUSTAFOR guidelines (2010). The aim of this paper is to provide guidance to EUSTAFOR members on how forests can be managed to provide maximum benefits in terms of climate change mitigation and adaptation. The guidelines form a common framework of recommendations for EUSTAFOR members, focusing on the carbon balance. They come within the framework of the Pan European Operational-level Guidelines for SFM. The guidelines are voluntary and have been developed for state forests. They support synergies in implementing the United Nations Forum on Forests, the UNFCCC, the Convention on Biological Diversity, the United Nations Convention on Combating Desertification and other relevant forest-related international commitments. https://eustafor.eu/uploads/ EustaforClimateReport2010_2-1.pdf

Adaptation of forests to climate change: some estimates (2010). This paper focuses on the anticipated impacts of climate change on forests broadly and on industrial wood production in particular, and presents case studies from Brazil, South Africa and China. The aim is to identify likely damage and possible mitigating investments or activities. The results provide perspectives on and estimates and projections of the impacts of climate change on forests and forestry in various regions and countries. http://www.indiaenvironmentportal. org.in/files/Adaptation $\% 200 f \% 20$ Forests $\% 20 t 0 \% 20$ Climate\%20Change.pdf

Adaptation of forests and people to climate change: a global assessment report (2009). This report produced by the International Union of Forest Research Organizations assesses the interrelations among forest ecosystems, the services they provide, and climate change; the past and future impacts of climate change on forest ecosystems and the people that depend on these ecosystems; and the management and policy options for adaptation.

http://www.fao.org/forestry/17675-022721682d6ef9 e51076d5dc46577a9c9.pdf

Making forests fit for climate change: a global view of climate-change impacts on forests and people and options for adaptation (2009). This brief is based on a comprehensive assessment of scientific information about climate-change impacts and how forests and people can adapt to it. It also provides essential information for enhancing the adaptive capacity of both forests and people in the face of climate change. http://www.fao.org/forestry/17676ob7ffe470a8e78bfb572033703b751119.pdf

Impacts of climate change on European forests and options for adaptation (2008). This study compiles and summarizes knowledge about the observed and projected impacts of climate change on forests in Europe and reviews options for forests and forestry to adapt to climate change. https://ec.europa. eu/agriculture/sites/agriculture/files/externalstudies/2008/euro-forests/full_report_en.pdf

Adapting to climate variability and change: a guidance manual for development planning (2007). This manual was developed to assist project managers in understanding how climate change may affect their project outcomes and in identifying adaptation options to integrate into the design for more resilient projects.

http://pdf.usaid.gov/pdf_docs/PNADJ990.pdf 


\section{6) FORESTANDLANDSCAPERESTORATION}

Aguide to the restoration opportunities assessment methodology (ROAM) - Assessing forest landscape restoration opportunities at the national or subnational level (2014). The Restoration Opportunities Assessment Methodology (ROAM) described in this handbook provides a flexible and affordable framework for countries to rapidly identify and analyse forest landscape restoration (FLR) potential and locate specific areas of opportunity at a national or sub-national level. A ROAM application is generally undertaken by a small core assessment team through collaborative engagement with other experts and stakeholders. A national-level assessment typically requires 15-30 days of work by the assessment team spread over a two-to-three months period. https://portals.iucn.org/library/sites/library/files/ documents/2014-030.pdf

The global tree restoration potential (2019). The restoration of forested land at a global scale could help capture atmospheric carbon and mitigate climate change. This report uses direct measurements of forest cover to generate a model of forest restoration potential across the globe. Spatially explicit maps show how much additional tree cover could exist outside of existing forests and agricultural and urban land. https://science.sciencemag.org/ content/365/6448/76.abstract
A cost-benefit framework for analyzing forest landscape restoration decisions (2015). This report presents a cost-benefit framework for accounting for the ecosystem service and economic impacts of forest landscape restoration activities in a way that allows the results to be structured to inform multiple types of restoration decision-making that can help decision makers understand the trade-offs of different restoration scenarios. The results can be used to set prices for payment for ecosystem services, identify sources of restoration finance, identify low-cost/high-benefit pathways towards carbon sequestration, and identify priority landscapes for restoration based on return-on investment analysis. https://portals.iucn.org/library/sites/library/files/ documents/2015-018.pdf

Agroforestry for landscape restoration (2017). This FAO publication examines the potential of agroforestry systems to restore land productivity, conserve biodiversity, increase the resilience of agroecosystems, alleviate poverty and contribute to food security and nutrition, particularly in the context of climate change. http://www.fao.org/3/b-i7374e.pdf 


\title{
Annex 4. Sub-steps and methodologies to prioritize adaptation options
}

\author{
Adapted from (Brugère and De Young, (forthcoming)

\section{Prioritization process}

The process of prioritizing adaptation options that have been identified can take several forms. The prioritization process suggested here starts with a broad brushed evaluation of all preidentified adaptation options. Then, it moves on to a pre-selection of the "top $\mathrm{x}$ " most appropriate adaptation options according to their suitability, impact, livelihood and ecosystem benefits, affordability and the capacity to implement them. It concludes with a finer-grain analysis of each pre-selected option based on more specific criteria to determine what is to be chosen and retained.

\section{Sub-step 1: Broad-brush evaluation/scoping of} all pre-identified possible adaptation options.

Several approaches can be considered. Here we outline the SWOT (Strengths, Weaknesses, Opportunities, Threats), the SCORE (Strengths, Challenges, Options, Responses, Effectiveness) and problem structuring methods. Which to choose either individually or in combination, if any - is however left to the users of these supplementary guidelines. It also depends on whether the overall NAP process has itself adopted a method and which one.

A SWOT (Strengths, Weaknesses, Opportunities, Threats) analysis could be carried out to identify for each adaptation option, their strengths, weaknesses, opportunities as well as threats for the prevalent activities concerned. Whilst strengths and opportunities concern the adaptation option itself, opportunities and threats relate to the positive and negative factors affecting the feasibility and also the implementation of the adaptation option. If chosen, it is important that this analysis be as specific as possible, for example sub-divided based on the scale of each adaptation option and its spatial and temporal context.
This exercise is based on known information and experiences, not the generation of new information. What is unknown (information/ knowledge gaps) should be clearly marked as a weakness or as a threat, depending on the circumstances.

A related approach is the SCORE (Strengths, Challenges, Options, Responses, and Effectiveness). Like in the SWOT, inner and external influences are considered, however, SCORE goes a step further by adding both a time and strategic dimension to the analysis by taking into consideration the current potential (strengths and challenges) and future sustainability (options, responses and effectiveness criteria) of an adaptation option. Also, it is more suited than a SWOT to identifying potential gaps in resources where investments are needed. Here too, each possible adaptation option would need to be considered in turn, according to the five SCORE criteria ${ }^{10}$.

- Strengths / skills / support:

- What do we think are the strengths of this option?

- What skills and support (including resources) do we have to implement it? Which ones can we call on from others?

- Challenges / constraints / capabilities needed:

- What issues are we facing with the implementation of the adaptation itself and in relation to other, external, factors?

- What is likely to hold this option back, prevent any needed change?

- How will we resolve or work around these constraints?

- What new capabilities and support would we need? What would be needed to acquire them?

10 Adapted from Moore et al., 2014, and http://weblog.tetradian.com/2013/06/29/checking-the-score/. 
- Opportunities and risks:

- What risks are likely to emerge and opportunities are likely to be generated and should be seized in relation to the implementation of this adaptation option?

- Given the strengths and challenges identified, is this adaptation option suitable over time?

\section{- Responses / returns / rewards:}

- What are the probable or emergent consequences of action or inaction?

- What responses to the adaptation option can we expect from stakeholders (direct and indirect, at various scales)?

- What benefits are expected (weighted against risks)?

- Effectiveness / impact:

- How can we optimize the use of resources to implement this adaptation option?

- What benefits will it yield? To whom, what?

- How predictable and reliable in yielding positive impacts will it be over time?

- Will it create positive synergies with other forms of adaptation and development, and across wider social-ecological systems? Are there possible negative cross-scale impacts that we should be aware of?

Criteria of the SCORE approach are usually scored, allowing for most suitable options to stand out, based on the opportunities they present in terms of strengths and opportunities to overcome challenges. This scoring system is detailed under point (ii) Selection of appropriate actions, in the next section. Barbados has used the SCORE approach successfully in its scoping of options to green its economy (Moore et al., 2014).

For each pre-selected adaptation option, both the SWOT and the SCORE processes should highlight, albeit to slightly different depths, the following:

- What are the knowledge, capacity (individual and institutional) and financial gaps and constraints?

- Who are additional stakeholders to engage with?

- What are the potential barriers to planning, design and implementation of the adaptation actions?

- Which adaptation options appear to be the most feasible, both now and in the future?
Another type of approach to help initiate the prioritization of adaptation options is problem structuring methods (PSM). Climate change adaptation has been described as an unstructured or "wicked problem" (Incropera, 2015) because it involves multiple actors and multiple perspectives, reconciling incommensurable and/or conflicting interests, and accounting for important intangibles and key uncertainties - all of which raise complex governance questions (Termeer et al., 2013). Problem structuring methods can be more or less formal, ranging from brain storming, cognitive mapping and multi-criteria analysis to more advanced approaches such as the 'strategic choice approach' and 'strategic options development and analysis' developed specifically for problem structuring. Carried out in a group/ workshop setting, these methods make possible the joint exploration of a situation or issue and potential avenues to improve or solve it. The PSM methods (Yearworth, 2015):

1. are not mathematical, but structured and rigorous and based on qualitative, diagrammatic modeling;

2. allow for a range of distinctive views to be expressed/explored/accommodated and allow for multiple and conflicting objectives;

3. encourage active participation of stakeholders in the qualitative/visual modelling process, through facilitated workshops and cognitive accessibility;

4. can facilitate the negotiation of a joint agenda and ownership of the implications of action;

5. a significant uncertainty is to be expected and tolerated;

6. operate iteratively;

7. aim for exploration, learning, and commitment from stakeholders.

These methods constitute a form of collaborative strategy founded on stakeholder interactions through which adaption options for specific climate change threats can be discussed for evaluation and prioritization, while at the same time the inherent uncertainty and multiple benefits and constraints of each option are taken into account. Although diverging perspectives on the problems themselves and contextual external factors can put a strain on collaboration (Head et al., 2016), these methods can work across scales and help with "reframing problems, and building bridges in multi-level regional arrangements, as 
well as linking science, policy and community arenas in policy, planning and practice" (ibid, p.91), which is what one needs for an effective climate adaptation over the long term.

There are a large number of PSM applications in participatory forestry planning (Khadka et al., 2013). The visual and oral techniques upon which PSM rely (e.g. maps), which are aligned on participatory techniques and with the principles of participation, make them particularly amenable to low literacy contexts or engagement with groups of stakeholders of mixed status and abilities. While using PSM, power influences among the stakeholders involved should be kept in check as they may undermine collaborative efforts, particularly if adaptation options under consideration cut across institutional and geographical scales (Yearworth, 2015).

In addition to being useful while examining the multiple facets of potential adaptation options for their prioritization, PSM can also be useful for reviewing, checking and validating the characteristics of the climate impacts elicited in the initial steps of Element B with stakeholders involved in the prioritization of options and their ultimate choice for integration in the NAP. For example, some of the issues to be addressed are: who the stakeholders and affected parties are and their values, the levels of uncertainties, the key issues, influences from the external environment, constraints and opportunities for action, and the goals for adaptation. This validation process can pave the way for the implementation of multicriteria decision-making analyses (MCSA) (Belton and Stewart, 2010), which can be used to help evaluate the most appropriate adaptation options amongst the list of prioritized ones (see point (iii) "finer-grain" analysis).

\section{Sub-step 2: Weighing and scoring the most appropriate adaptation options.}

The process of interpreting and weighing out each option should be directed by stakeholders and tied to the overriding aims of the adaptation to be achieved in each system under consideration. Stakeholder consensus is required to agree on what constitutes the most appropriate options for each system (UNEP, 2012). Those options with the highest scores should be taken through to the next stage of prioritization. The stakeholders participating in the prioritization exercise should discuss and agree upon where the threshold lies between those options that 'make it' to stage (iii) and those that do not.

As described in the previous step, it is essential that primary stakeholders - local men and women depending directly and indirectly on forests and trees - be widely consulted during this process because they are at the frontline of climate change and will be the first involved and affected by the adaption options chosen.

All potential planned and autonomous adaptation options will have been elicited during the previous step. The idea here is to arrive at an evaluated and ranked list of the potential of each adaptation option, based on either assigned weights or scores to decrease vulnerability to climate change, before a finer grain analysis of the economic feasibility of each option is carried out (cf. sub-step 3 further).

Here we propose two slightly different approaches in support of prioritization and identification of the most promising adaptation options: one based on weighing out the important criteria and scoring adaptation options against these; the other based on scoring only, as a follow-up to the SCORE approach previously outlined. Given the importance of stakeholder participation in this process, both approaches should be carried out during a workshop

\section{Weighing and scoring.}

Weighing the importance begins with the choice of criteria (or indicators) and the weight to be assigned for evaluating the pre-identified adaptation options. This should be done by the stakeholders participating in the exercise and, moreover, context-specific; in Box A we suggest a number of such criteria. Although they are categorized in two broad groups of "impact" and "viability", the chosen criteria need to be aligned as precisely as possible with the chosen goals of adaptation previously determined.

When criteria are chosen, it is important to bear in mind that the selection made needs to possess the following characteristics (USAID, 2013; DCLG, 2009):

- Completeness: Have all important criteria been included?

- Redundancy: Are some criteria not necessary or redundant? 
- Operationality: Are the criteria measurable or defined?

- Mutually independent: Is the performance of one option against a criterion independent of the performance of the same option against a second criterion?

- Double counting: Are two criteria counting the same issue?

- Size: Are there too many criteria?

- Impacts occurring over time: Are timedifferentiated impacts adequately dealt with throughout the criteria?

Once the criteria for characterizing adaptation actions have been agreed upon, giving a score can be accomplished by asking stakeholders to individually allocate a fixed number of points (e.g. 100) across all chosen criteria to reflect their importance in general terms (not in relation to each potential adaptation option). The averages of allocated points constitute the weight, that is, the importance to be assigned. Standard deviations should also be considered and openly discussed to ensure that there is an overall consensus among stakeholders on the weights finally assigned. Alternatively, the allocation of the number of points can be completed jointly by all of the stakeholders in a facilitated plenary session.

\section{BOX A.}

Examples of generic criteria of importance against which possible adaptation options can be evaluated

\section{IMPACT}

- Timing/urgency for the adaptation action [which actions required when, consequences of delays on vulnerability, addressing short-, medium- and/ or long-term impacts, possible sequential implementation]

- Co-benefits/equity generated by the adaptation action in terms of e.g. emission reductions, and productivity and income increases [including who benefits and who loses, with gender, social and intergenerational equity considerations fully taken into account]

- Side-effects, either positive or negative [impacts on the delivery of ecosystem services, incl. biophysical processes, livelihoods; secondary and cross-sectoral impacts, trade-offs]

- Additional contributions and synergies [potential to address other issues than climate resilience, e.g. poverty reduction, wellbeing, strategic relevance to wider and long-term development goals]

\section{VIABILITY}

- Efficacy of the adaptation option [effective reduction of risks, taking into account uncertainty and different climate scenarios, fast and slow onset changes, prevention of irreversible damage]

- Flexibility and/or robustness of the adaptation action [possibility for adaptation action to evolve/remain fixed over time, if the system changes following adaptation, if impacts not initially anticipated occur and/or if external circumstances affect implementation]

- Social and political acceptance/legitimacy

- Barriers and capacity for implementation [dependence on other sectors to adapt and improve too (e.g. water management, tourism, legislation)]

NB: economic dimensions are addressed more specifically further, under sub-step 3. 
In order to evaluate each adaptation measure against each weighted criteria, stakeholders are subsequently given a matrix and asked to assign a value from 1 ("not at all") to 10 ("completely") that reflects the extent to which they believe each criteria is effectively addressed by each adaptation option. For example, "will adaptation option 1 enable a timely response to the identified threat $\mathrm{x}$ ?", "will adaptation option 1 have the capacity to generate co-benefits"? The scores (averaged if each participant has scored individually, or taken as such if this was done in plenary) of each adaptation option by criteria are then weighed against the criteria weights previously calculated. If deemed appropriate, the over-arching "impact" and "viability" criteria can be assigned an overall weight $50 \%$ each, but this can be discussed depending on the stakeholders' perceptions and the number of categories. The results are then multiplied by 100 to normalize the weighted scores to a maximum value of 100. Adaptation options can then be ranked by decreasing order of priority.

A number of Latin American countries used this approach to decide on their response strategies to climate change in the agricultural sector (World Bank, 2009).

\section{Scoring (SCORE approach follow-up)}

If the SCORE approach has been used earlier, each adaptation option evaluated can now be scored. However, scoring can also be carried out independently, for example, to broadly assess adaptation options in terms of their achievability. This approach helps to measure each option in terms of the "performance gap" it is representing (i.e. what is required to be filled for an adaptation action to fully achieve its objectives) and in terms of the importance of its combined effectiveness and potential to generate and seize opportunities. In this case, expert opinion may be used as an alternative to stakeholder consultation. Barbados has used it successfully in the scoping of options to green its economy (Moore et al., 2014).

Each of the challenges identified during the SCORE exercise, ensuring that they cover not only resources limitations but also what needs to change (e.g. capabilities, services), are first attributed a score based on a 1 (very low) to 10 (very high) points scale in relation to their frequency of occurrence or likelihood of impact. As outlined earlier, a number of other criteria could be used. The combination (i.e. multiplication) of these two (or more if more criteria are used) scores provides an overall value of the degree of the seriousness of the challenge. Thus, a challenge with a value close to 1 would mean that it is perceived as not being severe, while one with a score close to $10^{11}$ as extremely acute.

The second element of the gap analysis is to assign a score to where the adaptation option currently stands, i.e. its strengths in addressing each challenge, from 1 suggesting that it does not currently have what is required, to 10 that it completely does. Subtracting the challenge scores from the strength scores for each challenge gives an idea of the potential of the adaptation action in overcoming each listed challenge: the larger the negative value, the larger the amplitude of the 'performance gap' and efforts/investments that need to be deployed to fill it are.

As for challenges, each opportunity that the adaptation option presents can be scored on a 1-10 points scale according to its likelihood of occurrence and likelihood of effectiveness. The scores of occurrence and effectiveness are then multiplied to obtain a quantified indicator of importance (or attractiveness) for each opportunity, which offers the possibility to rank them (the higher the number, out of 100, the higher the importance).

\section{Sub-step 3: Finer-grained (economic) analysis and final decision on most appropriate options.}

The focus of this sub-step is on the economic, social and environmental feasibility, i.e. costs and benefits, of the adaptation options that have emerged as "top candidates" from the previous prioritizing steps.

Estimating the costs and benefits of each option is an integral yet potentially complicated aspect of the prioritization process, which is why it is dealt with separately here. In fact, it is important because it will ensure the visibility of adaptation options in the general NAP where these options will be standing alongside those made for other

11 After dividing the overall score by 10 to normalize the scores and make them comparable with those of the next steps. 
sectors. However, it is also important to bear in mind that the valuation of all their benefits, including for other sectors, may be difficult to fully capture in economic analyses and, as a result, adaptation options may appear more costly (at least in the short term) compared to those for other sectors.

While the previous prioritization steps (i) and (ii) may be carried out on a consultancy basis, for example, within the confines of a stakeholder workshop, this finer-grained economic analysis itself is likely to require more time and expertise. This expertise may be either in the cell overseeing the process to formulate and implement NAP or outsourced. Although likely to be more appropriately expert-driven, consultation with stakeholders involved in the earlier steps of the prioritization and/or the overall process will be necessary to seek their views and endorsement of the findings of this analysis.
There are several methods available for the evaluation of the costs of adaptation options. Their choice will be guided by the goals of adaptation and the number of possible adaptation options elicited earlier as well as data available.

Figure A provides a simplified decision tree as a guide on how to choose the most appropriate method.

The estimation of the costs and benefits of adaptation needs to account for issues of uncertainty, equity (distributional impacts) and valuation (baselines, types of valuation, discount rates and time horizons), which are particularly acute in the context of climate adaptation. Some of the methods highlighted below are more or less adapted to handle these issues, which, as a consequence, makes them more or less suited to the final appraisal of adaptation options (UNFCCC, 2011b; World Bank, 2010b).

\section{FIGURE A.}

\section{A (simplified) decision tree of possible approaches for assessing the costs and benefits of adaptation options}

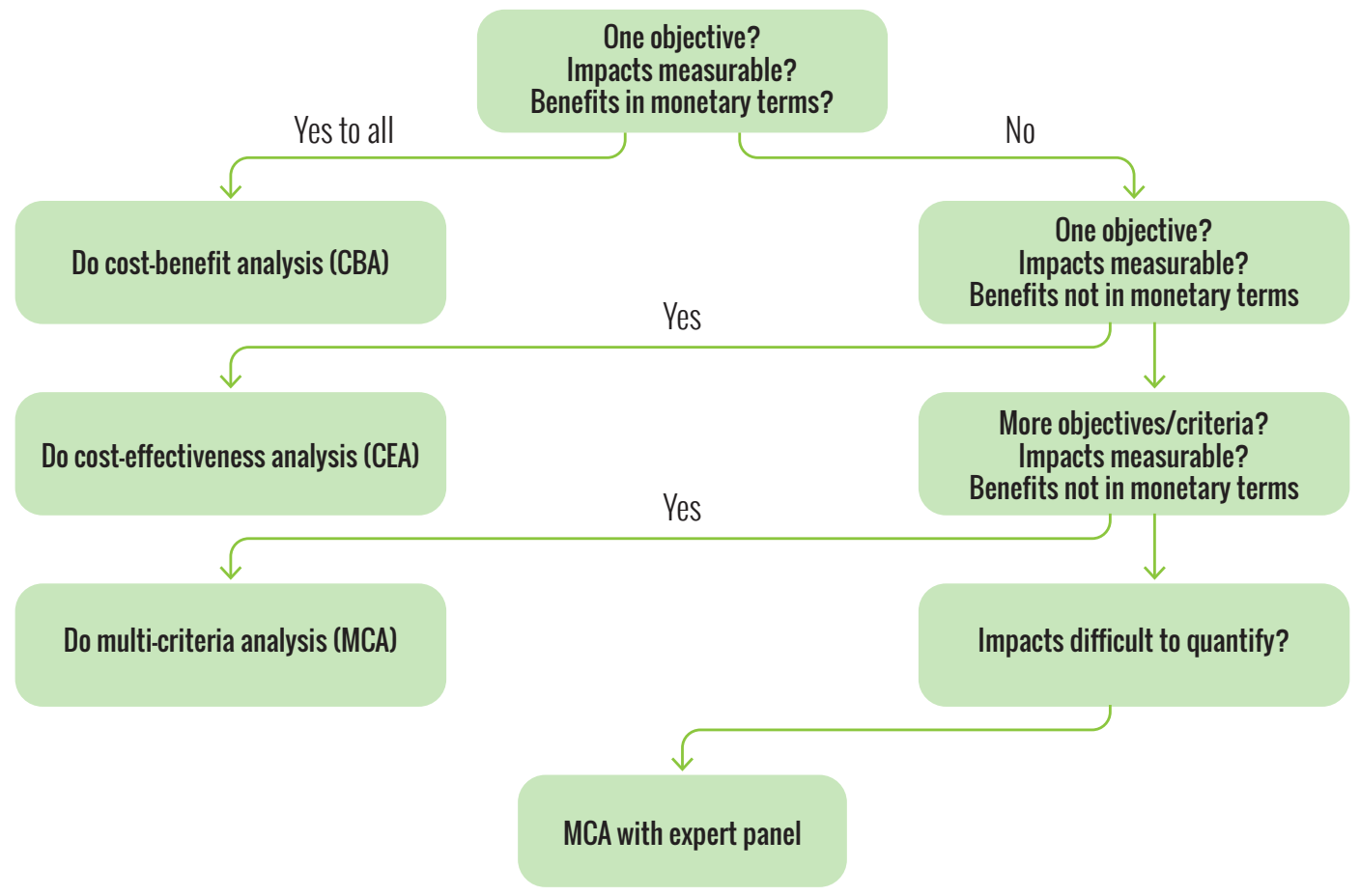


Cost-benefit analysis (CBA), cost-effectiveness analysis (CEA) and multi-criteria (decision) analysis (MCA or MCDA) are highlighted in Figure A. These are the three most commonly applied methods in support of the economic appraisal of adaption options in the agriculture sector. Table A summaries their purposes, as well as the pros and cons and data requirements. It also describes the analytical hierarchy process (AHP), a form of
MCA increasingly used in the context of climate change adaptation. This is however a field in constant evolution. Other approaches better able to handle uncertainty are now available: real options analysis, robust decision-making, portfolio analysis, iterative risk (adaptation) management. An overview of all these methods can be found in Watkiss and Hunt (2013 - open access).

\section{TABLE A}

\section{Summary features of key (economic) decision-support methods for choosing climate adaptation actions}

\begin{tabular}{|c|c|c|c|c|c|}
\hline METHOD (SUITE) & PURPOSE OF USE & STRENGTHS & LIMITATIONS & $\begin{array}{l}\text { DATA / INPUT } \\
\text { REQUIREMENTS }\end{array}$ & $\begin{array}{l}\text { RESOURCES AND } \\
\text { EXPERTISE }\end{array}$ \\
\hline $\begin{array}{l}\text { Cost-Benefit } \\
\text { Analysis (CBA) }\end{array}$ & $\begin{array}{l}\text { To value all costs } \\
\text { and benefits to } \\
\text { society of all } \\
\text { options, and } \\
\text { estimate the net } \\
\text { benefits/costs } \\
\text { of individual } \\
\text { interventions in } \\
\text { monetary terms. } \\
\text { Benefit metric: } \\
\text { Economic } \\
\text { (monetary). }\end{array}$ & $\begin{array}{l}\text { - Provides } \\
\text { direct analysis } \\
\text { of economic } \\
\text { benefits, } \\
\text { justification } \\
\text { for action, } \\
\text { and optimal } \\
\text { solutions. } \\
\text { - Well known and } \\
\text { widely applied. }\end{array}$ & $\begin{array}{l}\text { - Difficulty } \\
\text { of monetary } \\
\text { valuation for non- } \\
\text { market sectors } \\
\text { and non-technical } \\
\text { options. } \\
\text { - Uncertainty } \\
\text { usually limited } \\
\text { to probabilistic } \\
\text { risks. }\end{array}$ & $\begin{array}{l}\text { - Individual } \\
\text { scenario and } \\
\text { climate model } \\
\text { outputs. } \\
\text { - Baseline } \\
\text { damage costs } \\
\text { from scenario- } \\
\text { based impact } \\
\text { assessment. } \\
\text { Quantitative } \\
\text { adaptation } \\
\text { effectiveness. }\end{array}$ & Medium \\
\hline $\begin{array}{l}\text { Cost- } \\
\text { Effectiveness } \\
\text { Analysis (CEA) }\end{array}$ & $\begin{array}{l}\text { To compare } \\
\text { alternative options } \\
\text { for achieving } \\
\text { similar outputs } \\
\text { (or objectives) } \\
\text { in terms of } \\
\text { costs against } \\
\text { effectiveness. } \\
\text { Benefit metric: } \\
\text { Quantitative (but } \\
\text { not economic) }\end{array}$ & $\begin{array}{l}\text { - Benefits } \\
\text { expressed in } \\
\text { physical terms } \\
\text { (not monetary) } \\
\text { thus applicable } \\
\text { to non-market } \\
\text { sectors. } \\
\text { - Relatively } \\
\text { simple to apply } \\
\text { and easily } \\
\text { understandable } \\
\text { ranking and } \\
\text { outputs. } \\
\text { - Use of cost } \\
\text { curves can assess } \\
\text { policy targets } \\
\text { with least-cost } \\
\text { optimization. } \\
\text { - Often used for } \\
\text { mitigation, } \\
\text { thus widely } \\
\text { recognized and } \\
\text { with resonance } \\
\text { with policy } \\
\text { makers. }\end{array}$ & $\begin{array}{l}\text {-Benefits can } \\
\text { be difficult to } \\
\text { identify and } \\
\text { single metric does } \\
\text { not capture all } \\
\text { costs and benefits. } \\
\text { Less applicable to } \\
\text { cross-sectoral / } \\
\text { complex issues. } \\
\text { - Works best } \\
\text { with technical } \\
\text { options, and often } \\
\text { omits capacity } \\
\text { building and soft } \\
\text { measures. } \\
\text { - Sequential } \\
\text { nature of cost } \\
\text { curves ignores } \\
\text { inter-linkages } \\
\text { and potential for } \\
\text { portfolios. } \\
\text { - Does not lend } \\
\text { itself to the } \\
\text { consideration } \\
\text { of uncertainty, } \\
\text { as it works with } \\
\text { central tendency. }\end{array}$ & $\begin{array}{l}\text { - Scenario and } \\
\text { climate model } \\
\text { outputs and often } \\
\text { baseline damage } \\
\text { costs. } \\
\text { - Effectiveness } \\
\text { as reduction in } \\
\text { impacts (unit / } \\
\text { total). }\end{array}$ & Medium \\
\hline
\end{tabular}




\begin{tabular}{|c|c|c|c|c|c|}
\hline METHOD (SUITE) & PURPOSE OF USE & STRENGTHS & LIMITATIONS & $\begin{array}{l}\text { DATA / INPUT } \\
\text { REQUIREMENTS }\end{array}$ & $\begin{array}{l}\text { RESOURCES AND } \\
\text { EXPERTISE }\end{array}$ \\
\hline $\begin{array}{l}\text { Multi-criteria } \\
\text { Analysis (MCA) / } \\
\text { Multi-criteria } \\
\text { Decision Analysis } \\
\text { (MCDA) }\end{array}$ & $\begin{array}{l}\text { To systematically } \\
\text { assess and score } \\
\text { alternative options } \\
\text { against chosen } \\
\text { decision criteria. } \\
\text { Benefit metric: } \\
\text { Qualitative, } \\
\text { quantitative or } \\
\text { economic. }\end{array}$ & $\begin{array}{l}\text { - Combines } \\
\text { quantitative } \\
\text { and qualitative } \\
\text { data, and } \\
\text { monetary and } \\
\text { non-monetary } \\
\text { units, thus } \\
\text { applicable where } \\
\text { quantification is } \\
\text { challenging. } \\
\text { - Relatively simple } \\
\text { and transparent, } \\
\text { and relatively } \\
\text { low cost / time } \\
\text { requirement. } \\
\text { - Expert } \\
\text { judgement can } \\
\text { be used very } \\
\text { efficiently } \\
\text { and involves } \\
\text { stakeholders, } \\
\text { thus it can be } \\
\text { based on local } \\
\text { knowledge. }\end{array}$ & $\begin{array}{l}\text { - Results } \\
\text { need further } \\
\text { interpretation } \\
\text { and elaboration } \\
\text { in more detailed } \\
\text { studies. } \\
\text { - Different } \\
\text { experts may } \\
\text { have different } \\
\text { opinions, i.e. } \\
\text { subjectivity } \\
\text { involved. } \\
\text { - Stakeholders } \\
\text { may have lack } \\
\text { of knowledge } \\
\text { and can miss } \\
\text { important } \\
\text { options. } \\
\text { - Analysis of } \\
\text { uncertainty is } \\
\text { often qualitative } \\
\text { and subjective. }\end{array}$ & $\begin{array}{l}\text { - Qualitative or } \\
\text { quantitative } \\
\text { information on } \\
\text { climate change. } \\
\text { - Effectiveness } \\
\text { through } \\
\text { expert input } \\
\text { or stakeholder } \\
\text { consultation. }\end{array}$ & Low-Medium \\
\hline $\begin{array}{l}\text { Analytical } \\
\text { Hierarchy Process } \\
\text { (AHP) }\end{array}$ & $\begin{array}{l}\text { To derive priority } \\
\text { scales through } \\
\text { pair-wise } \\
\text { comparisons using } \\
\text { expert judgements. } \\
\text { Benefit metric: } \\
\text { Qualitative, } \\
\text { quantitative or } \\
\text { economic. }\end{array}$ & $\begin{array}{l}\text { - Can be applied } \\
\text { where elements } \\
\text { are difficult } \\
\text { to quantify or } \\
\text { not directly } \\
\text { comparable. } \\
\text { - Relatively } \\
\text { simple approach } \\
\text { and produces } \\
\text { simple rankings } \\
\text { that are easy to } \\
\text { communicate. } \\
\text { - Does not require } \\
\text { information } \\
\text { on economic } \\
\text { benefits, so wide } \\
\text { applicability. } \\
\text { - Can } \\
\text { accommodate } \\
\text { a wide range } \\
\text { of disciplines, } \\
\text { opinions and } \\
\text { groups of } \\
\text { people who do } \\
\text { not normally } \\
\text { interact. }\end{array}$ & $\begin{array}{l}\text { - Results change as } \\
\text { new options are } \\
\text { considered. } \\
\text { - Becomes } \\
\text { complicated if } \\
\text { lots of criteria } \\
\text { and options are } \\
\text { considered. } \\
\text { - Subjective scale } \\
\text { can lead to biases. } \\
\text { - Trans- } \\
\text { disciplinary } \\
\text { capacity } \\
\text { building can be } \\
\text { undermined at } \\
\text { the cost of the } \\
\text { expediency. } \\
\text { - Software } \\
\text { can conceal } \\
\text { conflicting value } \\
\text { Judgments. }\end{array}$ & $\begin{array}{l}\text { - Qualitative or } \\
\text { quantitative } \\
\text { information on } \\
\text { climate change. } \\
\text { - Effectiveness } \\
\text { through } \\
\text { expert input } \\
\text { or stakeholder } \\
\text { consultation. }\end{array}$ & Low-Medium \\
\hline
\end{tabular}


Because of the constraints in the economic valuation of the benefits of forests, multi-criteria (decision) analysis (MCA or MCDA) is likely to be the method of choice because it can serve to overcome issues of quantification and valuation in monetary terms. When applied at this stage of the process, an MCA would follow up on the scoring and weighing of options carried out previously (these earlier steps are effectively the first step of an MCA), using the criteria listed in Box A and the estimated costs and benefits - net or incremental - associated with each adaptation option, which may or may not be expressed in monetary terms.

The MCA involves scoring the performance of each adaptation option against each of the selected criteria, standardizing the scores obtained for the various criteria and assigning a weight to each criteria to reflect priorities, so as to include both economic and non-economic criteria in the prioritization process. As always, it is important to be very clear about the intended outcomes of each adaptation option and how it meets the stated adaptation goals.

The mixed quantitative-qualitative nature of MCA makes it more suited for stakeholder interactions, for example in the context of a workshop during which the weighing and scoring is carried out, then other approaches such as CBA. Another advantage of MCA is its ability to conduct sensitivity analyses with different scores or weights: What would happen if...? How would the options then compare? Iteratively adjusting scores or weights gives the opportunity to consider the "range of possibles" and thus to more explicitly account for different degrees of uncertainty in the decision-making process over the final choice of adaptation options.

In fact, MCA was the method of choice for least developed countries (LDCs) for ranking adaptation options in the preparation of their NAPAs (UNFCCC, 2011b), e.g. Rwanda (2006) and Ethiopia (2007).

De Bruin et al. (2009) have piloted the use of MCA in the evaluation of a range of possible climate adaptation actions in the Netherlands.

\section{Organizing and presenting information}

The results of the prioritization process should be presented in a way that is easily digestible and communicable, for example, in a tabular format with an overview of the ranking of options with other related information.

\section{Summary tables}

Summary tables can take many shapes. Ultimately, they will reflect the characteristics (or criteria) that have been emphasized or have resulted as important during the prioritization process. For example, Table B emphasizes estimated costs and benefits (these do not necessarily need to be monetized in the summary table, but can be estimated as high, medium, low). Another option would be to emphasize the actors responsible for implementation and the different timeframes for action. It can also illustrate the range of adaptation actions that have been considered and how 'onerous' each action would be (Garrett et al., 2015). 
TABLE B.

An example summary table of prioritized adaptation actions according to their benefits and costs.

\begin{tabular}{|c|c|c|c|c|c|c|c|c|c|c|c|c|c|c|}
\hline RANKED & & & & & FITS & & & & & & TS & & \multirow{2}{*}{\multicolumn{2}{|c|}{$\begin{array}{l}\text { IMPLEMENTATION } \\
\text { CAPACITY*** }\end{array}$}} \\
\hline $\begin{array}{l}\text { DECREASING } \\
\text { ORDER) }\end{array}$ & \multicolumn{2}{|c|}{$\begin{array}{l}\text { Macro- } \\
\text { economic }\end{array}$} & \multicolumn{2}{|c|}{$\begin{array}{l}\text { Livelihood- } \\
\text { micro- } \\
\text { economic }\end{array}$} & \multicolumn{2}{|c|}{ Ecosystem } & \multicolumn{2}{|c|}{$\begin{array}{l}\text { Other non- } \\
\text { market }\end{array}$} & \multicolumn{2}{|c|}{$\begin{array}{l}\text { Capital } \\
\text { costs* }\end{array}$} & \multicolumn{2}{|c|}{$\begin{array}{l}\text { Maintenance } \\
\text { costs** }\end{array}$} & & \\
\hline & ST & MT & ST & MT & ST & MT & $\mathrm{S}^{\prime}$ & $\mathrm{MT}$ & ST & MT & ST & MT & ST & MT \\
\hline A & & & & & & & & & & & & & & \\
\hline B & & & & & & & & & & & & & & \\
\hline C & & & & & & & & & & & & & & \\
\hline & & & & & & & & & & & & & & \\
\hline & & & & & & & & & & & & & & \\
\hline & & & & & & & & & & & & & & \\
\hline
\end{tabular}

Source: developed from UNEP, 2012

ST: short term, MT: medium term. $*$ = investment costs, $* *=$ operation costs. $* * *$ could be further divided according to whether it is individual (farmers, foresters) or institutional (local authorities, national government, extension services etc.) or according to the costs (e.g. training) that will need to be incurred to build capacity to the required levels.

Scoring: $0=$ nil, 1 = low, $2=$ medium, 3 = high. For capital and maintenance costs, the scoring should be inversed.

Another feasible way to organize and synthesize the information obtained so far, while supporting a final decision on which adaptation actions to take forward in the NAP, is graphically based on the criteria used in the prioritization process.
Both no-regret and low-regret options can be "winwin" options when they enhance adaptive capacity (i.e., they reduce climate vulnerability and exploit positive opportunities), while also contributing to the achievement of other social, environmental or economic outcomes. High-regret adaptation mainly involves decisions on large-scale planning (e.g., resettlement of a large population) and investments with high irreversibility (e.g., large infrastructure projects such as sea level walls). Given the considerable consequences at stake in large-scale planning decisions and the significant investment costs and long-life span of infrastructure, uncertainties in future climate projections must be carefully examined. The differentiation between no-regret, low-regret and high-regret adaptation is not universal but depends on local circumstances and the time horizon. Being aware of the level of regret is important because different levels of regret have different implications in the realms of climate information, timing of investment, planning horizon, project design, project risk and economic evaluation (World Bank, 2010a]. This also means that uncertainty is factored into the ranking of adaptation options. 


\section{References}

AC-LEG. 2016. An input to the discussions by the Adaptation Committee and the Least Developed Countries Expert Group at their meetings on their work in addressing the mandates contained in decision 1/CP.21, paragraphs 41 and 45. Desk Review by the Secretariat. Adaptation Committee Least Developed Countries Expert Group. (also available at https://unfccc.int/files/adaptation/groups_committees/adaptation_committee/application/pdf/ac-leg2_mandates. pdf).

Balikoowa, K., Nabanoga, G. \& Tumusiime, D.M. 2018. Gender stereotyping: Evidence from gender differentiated household vulnerability to climate change in Eastern Uganda. Cogent Environmental Science, 4(1): 1-15.

Bee, B.A. 2016. Power, perception and adaptation: exploring gender and social-environmental risk perception in northern Guanajuato, Mexico. Geoforum, 69: 71-80.

Bele, M.Y., Tiani, A.M., Somorin, O.A. \& Sonwa, D.J. 2013. Exploring vulnerability and adaptation to climate change of communities in the forest zone of Cameroon. Climatic Change, 119(3-4): 875-889.

Belton, V. \& Stewart, T. 2010. Problem structuring and multiple criteria decision analysis. In: M. Ehrgott, J. Rui Figueira and S. Greco (eds.) Trends in Multiple Criteria Decision Analysis. Springer, pp. 209-239.

Bogaert, J., Barima, Y.S.S,. Mongo, L.I.W., Bamba, I., Mama, A., Toyi, M. \& Lafortezza, R. 2011. Forest fragmentation: causes, ecological impacts and implications for landscape management. In C. Li, R. Lafortezza \& J. Chen, eds. Landscape ecology in forest management and conservation. Challenges and solutions for global change, pp. 273-296. Beijing, Higher Education Press, and Berlin/Heidelberg, Springer-Verlag.

Borja-Vega, C. \& de la Fuente, A. 2013. Municipal vulnerability to climate change and climate related events in Mexico. Washington DC, World Bank.

Brody, A., Demetriades, J. \& Esplen, E. 2008. Gender and climate change: mapping the linkages - A scoping study on knowledge and gaps. Brighton, UK, Institute of Development Studies.

CBD. 2014. Addressing Water in National Adaptation Plan. Water Supplement to the UNFCC NAP Technical Guidelines. (also available at https://wWW4.unfccc.int/sites/NAPC/Documents/Supplements/GWP_NAP_Water_Supplement_May2019.pdf).

CCFM. 2008. A vision for Canada's forests: 2008 and beyond. Canadian Council of Forest Ministers Climate Change Task Force.

CIFOR. 2011. Forests, Trees and Agroforestry: Livelihoods, Landscapes and Governance. CGIAR Research Programme on Forests, Trees and Agroforestry (FTA) Proposal. Bogor, Indonesia: CIFOR.

Climate Change Commission. 2011. The Philippines: National Climate Change Action Plan 2011-2028. Manila. (also available at http://extwprlegs1.fao.org/docs/pdf/phi152934.pdf).

Climate Investment Fund. 2016. PPCR Monitoring and Reporting Toolkit. Pilot Programme for Climate Resilience. (also available at https://www-cif.climateinvestmentfunds.org/sites/default/files/knowledge-documents/ppcr_ monitoring_and_reporting_toolkit_march_2016_revised.pdf).

Climate Outreach and Adaptation Scotland. 2017. Communicating climate change adaptation. A practical guide to valuesbased communication. Adaptation Scotland/Government of Scotland, Edinburgh. (also available at http://climateoutreach.org/resources/communicating-climate-change-adaptation-a-practical-guide-to-valuesbased-communication/).

Colls, A., Ash, N. \& Ikkala, N. 2009. Ecosystem-based Adaptation: a natural response to climate change. Gland, Switzerland: IUCN. (also available at https://www.iucn.org/content/ecosystem-based-adaptation-a-natural-response-climate-change).

Crumpler, K., Bloise, M., Meybeck, A., Salvatore, M. \& Bernoux, M. 2019. Linking nationally determined contributions and the sustainable development goals through agriculture: A methodological framework. Environment \& Natural Resources Management Working Paper No. 75, Rome, FAO. 40 pp. (also available at http://www.fao.org/3/ca5003en/ca5003en.pdf).

d'Annunzio, R., Gianvenuti, A., Henry, M. \& Thulstrup, A. 2016. Manual for assessing woodfuel supply and demand in displacement settings. Rome, FAO \& Office of the United Nations High Commissioner for Refugees (UNHCR).

Dasgupta, S., Hossain, M., Huq, M. \& Wheeler, D. 2014. Climate change, soil salinity, and the economics of high-yield rice production in coastal Bangladesh. World Bank Policy Research Working Paper No. 7140. Washington, DC, World Bank.

Dazé, A., Ambrose, K. \& Ehrhart, C. 2009. Climate vulnerability and capacity analysis handbook. CARE International. 
DCLG. 2009. Multi-criteria analysis: a manual. Department for Communities and Local Government, London. (also available at http://www.fao.org/3/ca5003en/ca5003en.pdf).

De Bruin, K., Dellink, R.B., Ruijs, A., Bolwidt, L., van Buuren, A., Graveland, J., de Groot, R.S., et al. 2009. Adapting to climate change in The Netherlands: an inventory of climate adaptation options and ranking of alternatives. Climatic Change, 95: 23-45. DOI 10.1007/s10584-009-9576-4. (also available at http://link.springer.com/article/10.1007/s10584-009-9576-4).

Djoudi, H. \& Brockhaus, M. 2011. Is adaptation to climate change gender neutral? Lessons from communities dependent on livestock and forests in northern Mali. International Forestry Review, 13(2): 123-135.

Edwards, J.E., Pearce, C., Ogden, A.E., \& Williamson, T.B. 2015. Climate change and sustainable forest management in Canada: a guidebook for assessing vulnerability and mainstreaming adaptation into decision making. Canadian Council of Forest Ministers, Climate Change Task Force. Ottawa.

Fisher, R.J., Srimongkontip, S. \& Veer, C. 1997. People and forests in Asia and the Pacific: situation and prospects. FAO/ RAPA Working Paper APFSOS/WP/27. Bangkok, FAO

FAO. 2006. Fire management Voluntary guidelines: Principles and strategic actions. Working Paper 17/E. Rome. (also available at http://www.fao.org/3/j9255e/j9255e00.pdf).

FAO. 2012. Mainstreaming Climate-Smart Agriculture into a Broader Landscape Approach. Rome. (also available at http://www.fao.org/3/ap402e/ap402e.pdf).

FAO. 2013. Climate change guidelines for forest managers. FAO Forestry Paper No. 172. Rome.

FAO. 2014. Climate-Smart Agriculture Sourcebook. Rome. (also available at http://www.fao.org/3/i3325e/i3325e.pdf).

FA0. 2016a. Climate change and food security: Risks and responses. Rome. (also available at http://www.fao.org/3/a-i5188e.pdf).

FAO. 2016b. The State of Food and Agriculture: Climate Change, Agriculture and Food Security. Rome. (also available at http://www.fao.org/3/a-i6030e.pdf).

FAO. 2017a. Intended nationally determined contributions: global analysis key findings. Rome. (also available at http://www.fao.org/3/a-i6573e.pdf).

FA0. 2017b. Sustainable woodfuel for food security A smart choice: green, renewable and affordable. Rome. (also available at http://www.fao.org/3/a-i7917e.pdf)

FA0. 2017c. Tracking adaptation in agricultural sectors. Rome. (also available at http://www.fao.org/3/a-i8145e.pdf).

FA0. 2018a. The State of the world's forests 2018. Forest pathways to sustainable development. Rome. (also available at http://www.fao.org/3/I9535EN/i9535en.pdf).

FAO. 2018b. Institutional capacity assessment approach for national adaptation planning in the agriculture sectors. Briefing note. (also available at http://www.fao.org/3/I8900EN/i8900en.pdf).

FAO. 2018c. Terms and Definitions FRA 2020. Forest Resources Assessment Working paper 188. Rome. (also available at http://www.fao.org/3/I8661EN/i8661en.pdf).

FAO. 2018d. Guidelines and Specifications FRA 2020. Forest Resources Assessment Working paper 189. Rome. (also available at http://www.fao.org/3/I8699EN/i8699en.pdf).

FAO. 2018e. Climate change for forest policy-makers - An approach for integrating climate change into national forest policy in support of sustainable forest management. Version 2.0. FAO Forestry Paper no.181. Rome, 68 pp. (also available at http:// www.fao.org/3/CA2309EN/ca2309en.PDF).

FAO. 2019. Regional Analysis of the Nationally Determined Contributions in Southern Europe, Eastern Europe and Central Asia Gaps and opportunities in the agriculture sectors. Rome. (also available at http://www.fao.org/3/CA2518EN/ca2518en.pdf)

FA0. 2020a. Adaptation in the agriculture sectors: leveraging co-benefits for mitigation and sustainable development. Rome. (also available at http://www.fao.org/3/ca9195en/ca9195en.pdf)

FAO. 2020b. Regional Analysis of the Nationally Determined Contributions in Asia. Rome. (also available at http://www.fao.org/3/ca7264en/CA7264EN.pdf)

FAO \& UNDP. 2018. Integrating Agriculture in National Adaptation Plans (NAP-Ag) Programme. Case study: the Philippines. Rome. (also available at http://www.fao.org/3/CA3024EN/ca3024en.pdf).

FAO \& UNDP. 2019. Enhancing adaptation planning for agricultural resilience in Viet Nam: Linkages between National Adaptation Plans (NAPs) and Nationally Determined Contributions (NDCs). Case Study. (also available at https://www.vn.undp.org/content/dam/vietnam/docs/Publications/2019_UNDP_NAPNDC\%20Case\%20Study.pdf). 
FAO \& UNDP. 2020a. Integrating Agriculture in National Adaptation Plans Case Study: Uganda. Rome (also available at http://www.fao.org/3/cb0576en/cb0576en.pdf)

FAO \& UNDP. 2020b. Assessing sustainable water conservation and agroforestry practices for climate change adaptation in Kenya: A cost-benefit analysis. Rome.

Forest Management Bureau, Philippines. 2016. Master Plan for Climate Resilient Forestry Development. (also available at https://forestry.denr.gov.ph/pdf/mp/PMPCRFD_2015_plus_Annexes.pdf).

Gaisberger, H., Kindt, R., Loo, J., Schmidt M., Bognounou, F., Da, S., Diallo, O.B., et al. 2017. Spatially explicit multithreat assessment of food tree species in Burkina Faso: a fine-scale approach. PLOS ONE, 12(9): e0184457.

Garrett, A., Buckley, P., Brown, S., \& Townhill, B. 2015. Climate change adaptation in UK seafood: Understanding and responding to climate change in the UK wild capture seafood industry. A joint Seafish/MCCIP summary. Seafish, Edinburgh. doi:10.14465/2015.sarps.001-016.

Gebrekirstos, A., Bräuning, A., Sass-Klassen, U. \& Mbow, C. 2014. Opportunities and applications of dendrochronology in Africa. Current Opinion in Environmental Sustainability, 6: 48-53.

GIZ \& IISD. 2014. Monitoring and evaluating adaptation at aggregated levels: A comparative analysis of ten Systems. Deutsche Gesellschaft für Internationale Zusammenarbeit (GIZ), Bonn. (also available at https://gc21.giz.de/ibt/var/app/wp342deP/1443/wp-content/uploads/filebase/me/me-guides-manuals-reports/ GIZ_2014-Comparative_analysis_of_national_adaptation_M\&E.pdf).

Global Commission on Adaptation. 2019. Adapt now: a global call for leadership on climate resilience. Global Center on Adaptation and World Resources Institute.

Gobierno de Chile. 2014. Plan Nacional de Adaptación al Cambio Climático - Elaborado en el marco del Plan de Acción Nacional de Cambio Climático. Chile. (also available at http://portal.mma.gob.cl/wp-content/uploads/2016/02/PlanNacional-Adaptacion-Cambio-Climatico-version-final.pdf).

Guariguata, M.R., Locatelli, B. \& Haupt, F. 2012. Adapting tropical production forests to global climate change: risk perceptions and actions. International Forestry Review, 14(1): 27-38.

GWP. 2019. Addressing Water in National Adaptation Plans. (also available at https://www4.unfccc.int/sites/NAPC/Documents/Supplements/GWP_NAP_Water_Supplement_May2019.pdf).

Hahn, M. \& Fröde, A. 2011. Climate proofing for development. Adapting to climate change, reducing risk. Deutsche Gesellschaft für Internationale Zusammenarbeit (GIZ) GmbH, Eschborn. (also available at http://www.preventionweb.net/files/globalplatform/entry_bg_paper giz2011climateproofing.pdf).

Head, B.W., Ross, H. \& Bellamy, J. 2016. Managing wicked natural resource problems: The collaborative challenge at regional scales in Australia. Landscape and Urban Planning, 154: 81-92.

HLPE. 2017. Sustainable forestry for food security and nutrition. A report by the High-Level Panel of Experts on Food Security and Nutrition of the Committee on World Food Security. Rome. (also available at http://www.fao.org/3/a-i7395e.pdf).

Holzschuh, A., Steffan-Dewenter, I. \& Tscharntke, T. 2010. How do landscape composition and configuration, organic farming and fallow strips affect the diversity of bees, wasps and their parasitoids? Journal of Animal Ecology, 79: 491-500.

Incropera, F.P. 2015. Climate Change: A Wicked Problem. Cambridge University Press, New York.

IPCC. 2001. McCarthy, J.J. Canziani, O.F, Leary, N.A., Dokken, D.J. \& White, K.S, eds. Climate Change 2001: Impacts, Adaptation, and Vulnerability. Contribution of Working Group II to the Third Assessment Report of the Intergovernmental Panel on Climate Change Cambridge, UK, Cambridge University Press.

IPCC. 2007. Parry, M.L., Canziani, O.F, Palutikof, J.P., van der Linden, P.J. \& Hansen, C.E., eds. Climate Change 2007: Impacts, adaptation and vulnerability. Contribution of Working Group II to the Fourth Assessment Report of the Intergovernmental Panel on Climate Change. Cambridge, UK, Cambridge University Press. (also available at https://www.ipcc.ch/site/assets/uploads/2018/03/ar4_wg2_full_report.pdf).

IPCC. 2014. Climate change 2014: Impacts, adaptation, and vulnerability. Intergovernmental Panel on Climate Change, Working Group II. (also available at http://www.ipcc.ch/report/ar5/wg2/).

IPCC. 2019. Special report on climate change and land. (also available at https://www.ipcc.ch/srccl/).

IUCN. 2009. No time to lose - make full use of nature-based solutions in the post-2012 climate change regime. Position paper on the Fifteenth session of the Conference of the Parties to the United Nations Framework Convention on Climate Change (COP 15). Gland: IUCN. (also available at

https://www.iucn.org/sites/dev/files/import/downloads/iucn_position_paper_unfccc_cop_15.pdf). 
Johnston, M., Williamson, T., Munson, A., Ogden, A., Moroni, M., Parsons, R., Price, D. \& Stadt, J. 2010. Climate change and forest management in Canada: impacts, adaptive capacity and adaptation options - A State of Knowledge report. Sustainable Forest Management Network, Edmonton, Alberta. 54 pp.

Juergenliemk-Avagyan, A., Wolf, J., Kohli, R., Garcia, C., Spairani, A., Teng, J., Terrefe, D. \& Hodes G. 2017. The role of the National Adaptation Plans (NAPs) in agriculture for achieving multiple Sustainable Development Goals and implementing the Paris Agreement. Proceedings of the International Conference on Sustainable Development. New York, USA.

Karttunen, K., Wolf, J., Garcia, C. \& Meybeck, A. 2017. Addressing Agriculture, Forestry and Fisheries in National Adaptation Plans - Supplementary Guidelines. Rome, FAO. (also available at http://www.fao.org/3/a-i6714e.pdf).

Katila, P., Pierce Colfer, C., De Jong, W., Galloway, G., Pacheco, P., \& Winkel, G., eds. (2019). Sustainable Development Goals: Their Impacts on Forests and People. Cambridge: Cambridge University Press. doi:10.1017/9781108765015

Khadka, C., Hujala, T., Worlfslehner, B. \& Vacik, H. 2013. Problem structuring in participatory forest planning. Forest Policy and Economics. 26: 1-11.

Koffi, C. K., Djoudi, H. \& Gautier, D. Landscape diversity and associated coping strategies during food shortage periods: evidence from the Sudano-Sahelian region of Burkina Faso. Regional Environmental Change 17, no. 5 (2017): 1369-1380.

Lambrou, Y. \& Piana, G. 2006. Gender: the missing component of the response to climate change. Rome, FAO.

LEG (Least Developed Countries Expert Group). 2012. National Adaptation Plans. Technical guidelines for the national adaptation plan process. UNFCCC Secretariat. Bonn. Germany. December 2012. (also available at http://www4.unfccc.int/nap/Guidelines/Pages/Technical-guidelines.aspx).

LEG (Least Developed Countries Expert Group). 2013. Development of a tool for monitoring, reviewing and assessing progress, effectiveness and gaps under the NAP process in LDCs: the PEG M\&E Tool. By Latasi, P., UNFCCC Adaptation Committee workshop on the M\&E of adaptation 9-11 September 2013, Nadi, Fiji. (slides). (also available at https://unfccc.int/files/adaptation/cancun_adaptation_framework/adaptation_committee/application/pdf/peg_ tool_latasi.pdf).

Lilles $\emptyset$, J. B. L., Graudal, L., Moestrup, S., Kjær, E.D., Kindt, R., Mbora, A., Dawson, I., et al. 2011. Innovation in input supply systems in smallholder agroforestry: seed sources, supply chains and support systems. Agroforest Syst (2011) 83:347-359 DOI 10.1007/s10457-011-9412-5

Lilles $\emptyset$, J.P.B., Harwood, C., Derero, A., Graudal, L., Roshetko, J. M., Kindt R., Moestrup S., et al. 2018. Why institutional environments for agroforestry seed systems matter. Dev Policy Rev. 2018; 36: 089-0112

Lim, B. \& Spanger-Siegfred, E. (eds). 2005. Adaptation Policy Framework for Climate Change. Developing Strategies, Policies and Measures. Cambridge, UK, Cambridge University Press (also available at www.preventionweb.net/publications/view/7995).

Locatelli, B., Kanninen, M., Brockhaus, M., Colfer, C.J.P., Murdiyarso, D. \& Santoso, H. 2008 Facing an uncertain future: How forests and people can adapt to climate change. Forest Perspectives No. 5. CIFOR, Bogor, Indonesia.

Locatelli B., Pavageau C., Pramova E., Di Gregorio M., 2015. Integrating climate change mitigation and adaptation in agriculture and forestry: Opportunities and trade-offs. WIREs Climate Change, 6(6): 585-598.

http://onlinelibrary.wiley.com/doi/10.1002/wcc.357/pdf

Locatelli B. 2016. Ecosystem services and climate change. M. Potschin, R., Haines-Young, R. Fish \& R.K. Turner (eds) Routledge Handbook of Ecosystem Services. Routledge, London and New York, pp.481-490. (also available at http://agents.cirad.fr/pjjimg/bruno.locatelli@cirad.fr/Locatelli_2016_Handbook_Ecosystem_Services_and_ Climate_Change_PostPrint.pdf).

Louman B., Meybeck A., Mulder G., Brady M., Fremy L., Savenije H., Gitz V. \& Trines E. 2020. Scaling of innovative finance for sustainable landscapes. FTA.

Lumosi, C. \& McGahey, D. 2016. Communicating climate change for adaptation: Challenges, successes and future priorities. Information Brief. Collaborative Adaptation Research Initiative in Africa and Asia (CARIAA). International Development Research Centre, Ottawa. (also available at https://www.weadapt.org/knowledge-base/assar/communicating-climate-change-for-adaptation).

Lundgren, B.O. \& Raintree, J.B. 1982. Sustained agroforestry. In Nestel, B. ed. Agricultural research for development: potentials and challenges in Asia, pp. 37-49. The Hague, ISNAR.

MAAIF. 2018. National Adaptation Plan for the Agricultural Sectors in Uganda. Kampala. (also available at https://www. agriculture.go.ug/wp-content/uploads/2019/09/National-Adaptation-Plan-for-the-Agriculture-Sector-1.pdf).

Mackay, A., Gallo, I., Husch, J. and Raksakulthai, V. 2015. Skills Assessment for National Adaptation Planning. How countries can identify the gap. United Nations Institute for Training and Research (UNITAR), Geneva. (also available at http://www.uncclearn.org/sites/default/files/inventory/nap16062015.pdf). 
MacKinnon, K., Sobrevila, C., Hickey, V. 2008. Biodiversity, climate change, and adaptation: nature-based solutions from the World Bank portfolio (English). Washington, DC: World Bank.

http://documents.worldbank.org/curated/en/149141468320661795/Biodiversity-climate-change-and-adaptationnature-based-solutions-from-the-World-Bank-portfolio.

Meybeck, A., Rose, S. \& Gitz, V. 2019. Climate change vulnerability assessment of forests and forest-dependent people - A framework methodology. FAO Forestry Paper No. 183. Rome, FAO.

McNaught, R., Warrick, O. \& Cooper, A. 2014. Communicating climate change for adaptation in rural communities: a Pacific study. Regional Environmental Change, 14:1491-1503.

Metzger, M.J. \& Schröter, D. 2006. Towards a spatially explicit and quantitative vulnerability assessment of environmental change in Europe. Regional Environmental Change, 6(4): 201-216.

Ministry of Livestock, Agriculture and Fisheries (MGAP). 2019. National Adaptation Plan for the Agriculture Sector (PNA-Agro). Uruguay.

Moore, W., Alleyne, F., Alleyne, Y., Blackman, K., Blenman, C., Carter, S., Cashman, A., et al. 2014. Barbados' Green Economy Scoping Study. Government of Barbados, University of West Indies - Cave Hill Campus, United Nations Environment Programme (UNEP). (also available at

http://www.greengrowthknowledge.org/resource/green-economy-scoping-study-synthesis-report-barbados).

Morin, X., Fahse, L., Jactel, H., Scherer-Lorenzen, M., García-Valdés, R. and Bugmann, H., 2018. Long-term response of forest productivity to climate change is mostly driven by change in tree species composition. Scientific reports, 8(1): 5627.

Newton, P., Miller, D. C., Ateenyi Byenkya, M. A., Agrawal A. 2016. Who are forest-dependent people? A taxonomy to aid livelihood and land use decision-making in forested regions. Land Use Policy 57: 388-395.

Ndlovu, E., 2013. Impact of tree species on maize productivity by smallholder farmers in Eastern Kenya. Unpublished Master Thesis, Jomo Kenyatta University of Agriculture and Technology, Juja, Kenya.

Nyoka, B. I., Roshetko, J., Jamnadass, R., Kalinganire, A., Lilles J. B. L., Beedy T., Cornelius J. 2014. Tree Seed and Seedling Supply Systems: A Review of the Asia, Africa and Latin America Models. Small-scale Forestry. DOI 10.1007/ s11842-014-9280-8

Obeng, E.A., Owusu-Sekyere, E., Dumenu, W.K., Nutakor, E.E., Samar, S.B. \& Opoku, E.A. 2011. Climate change and forest dependent livelihoods: vulnerabilities and impacts. Technical report, Government of Ghana Project.

Parkins, J.R. \& MacKendrick, N.A. 2007. Assessing community vulnerability: a study of the mountain pine beetle outbreak in British Columbia, Canada. Global Environmental Change 17(3): 460-471.

Porter, J.R., L. Xie, Challinor, A.J., Cochrane, K., Howden, S.M., Iqbal, M.M., Lobell, D.B. \& Travasso, M.I.. 2014. Food security and food production systems. In: Climate Change 2014: Impacts, Adaptation, and Vulnerability. Part A: Global and Sectoral Aspects. Contribution of Working Group II to the Fifth Assessment Report of the Intergovernmental Panel on Climate Change [Field, C.B., Barros, V.R., Dokken, D.J., Mach, K.J., Mastrandrea, M.D., Bilir, T.E., Chatterjee, M., et al., (eds.)]. Cambridge University Press, Cambridge, United Kingdom and New York, NY, USA, pp. 485-533.

Pramova, E., Locatelli, B., Brockhaus, M., Fohlmeister, S., 2012. Ecosystem services in the National Adaptation Programmes of Action. Climate Policy 12(4): 393-409. (also available at https://www.tandfonline.com/doi/pdf/10.1080/14693062.2011.647848).

Pramova, E., Locatelli, B., Djoudi, H., Somorin, O., 2012. Forests and trees for social adaptation to climate variability and change. WIREs Climate Change 3: 581-596. (also available at http://onlinelibrary.wiley.com/doi/10.1002/wcc.195/pdf).

Price-Kelly, H. 2016. Financing National Adaptation Plans (NAP): Options for implementation. Targeted Topics Forum Report 2. International Institute for Sustainable Development, Winnipeg. (also available at http://www.napglobalnetwork.org/wp-content/uploads/2016/05/TTF2-Report.pdf).

Price-Kelly, H. \& Hammill, A. 2016. sNAPhot: Domestic public finance for implementation of NAP. Overview Brief II. NAP Global Network Secretariat, International Institute for Sustainable Development, Winnipeg. (also available at http://napglobalnetwork.org/resource/snapshot-domestic-public-finance-implementation-naps/).

Pureswaran, Deepa S., Alain Roques, \& Andrea Battisti. Forest insects and climate change. Current Forestry Reports, 4, no. 2 (2018): 35-50.

Puri, J. (2018). Transformational Change - The Challenge of a Brave New World. Independent Evaluation Unit (IEU) Learning Paper No. 1, Green Climate Fund. Songdo, South Korea.

Ranjitkar, S., Sujakhu, N.M., Merz, J., Kindt, R., Xu, J., Matin, M.A., Ali, M. \& Zomer, R.J. 2016a. Suitability analysis and projected climate change impact on banana and coffee production zones in Nepal. PLOS One, 11(9): e0163916. 
Ranjitkar, S., Sujakhu, N.M., Lu, Y., Wang, Q., Wang, M., He, J., Mortimer, P.E., Xu, J., Kindt, R. \& Zomer, R.J. $2016 \mathrm{~b}$. Climate modelling for agroforestry species selection in Yunnan Province, China. Environmental Modelling \& Software, 75: 263-272.

Ranjitkar, S., Sujakhu, N.M., Merz, J., Kindt, R., Xu, J., Matin, M.A., Ali, M. \& Zomer, R.J. 2016a. Suitability analysis and projected climate change impact on banana and coffee production zones in Nepal. PLOS One, 11(9): e0163916.

Reid, H., Hou Jones, X., Porras, I., Hicks, C., Wicander S., Seddon, N., Kapos V., Rizvi A.R. \& Roe, D. 2019. Is Ecosystembased adaptation effective? Perceptions and lessons learned from 13 project sites. IIED Research Report. IIED, London. (also available at https://pubs.iied.org/17651IIED/).

Ricketts, T.H. 2004. Tropical forest fragments enhance pollinator activity in nearby coffee crops. Conservation Biology, 18(5): 1262-1271.

Ricketts, T.H., Regetz, J., Steffan-Dewenter, I., Cunningham, S.A., Kremen, C., Bogdanski, A., Gemmill-Herren, B., Greenleaf, S.S., Klein, A.M., Mayfield, M.M., Morandin, L.A., Ochieng, A. \& Viana B.F. 2008. Landscape effects on crop pollination services: are there general patterns? Ecology Letters, 11: 499-515.

Rodenberg, B. 2009. Climate change adaptation from a gender perspective: a cross-cutting analysis of development-policy instruments. Discussion Paper 24/2009. Bonn, Germany, German Development Institute (DIE).

Roques, A. et al. 2015. Climate Warming and Past and Present Distribution of the Processionary Moths (Thaumetopoea spp.) in Europe, Asia Minor and North Africa. In: Roques A. (eds) Processionary Moths and Climate Change: An Update. Springer, Dordrecht

Scienseed. 2016. Communicating climate change and biodiversity to policy makers. A guide by Scienseed SL for the Bern Convention (Council of Europe). (also available at https://rm.coe.int/168064e897).

Shackleton C. \& Shackleton, S. 2004. The importance of non-timber forest products in rural livelihood security and as safety nets: a review of evidence from South Africa. South African Journal of Science, 100, November/December 2004.

Southern Voices on Adaptation, 2018. NAP progress in participation and transparency, assessment by SV-Adapt partner networks in Vietnam, Cambodia, Nepal, Sri Lanka, Kenya, and Malawi. (also available at

http://unfccc.int/files/adaptation/workstreams/national_adaptation_plans/application/pdf/participation_and_ transparency_by_svadapt.pdf).

Spearman, M. \& McGray, H. 2011. Making adaptation count. Concepts and options for monitoring and evaluation of climate change adaptation. GIZ and World Resources Institute (WRI), Washington D.C. (also available at http://www.wri.org/publication/making-adaptation-count).

Stevens-Rumann, Camille S., Kemp, Kerry B., Higuera, Philip E., Harvey, Brian J., Rother Monica T., Donato, Daniel C., Morgan, P., \& Veblen. T.T. Evidence for declining forest resilience to wildfires under climate change. Ecology Letters 21, no. 2 (2018): 243-252.

Strohmaier, R., Rioux, J., Seggel, A., Meybeck, A., Bernoux, M., Salvatore, M., Miranda, J. \& Agostini, A. 2016. The Agriculture sectors in the Intended Nationally Determined Contributions: Analysis. Environment and Natural Resources Management Working Paper No. 62. Rome, FAO. (also available at http://www.fao.org/3/a-i5687e.pdf).

Sunderland, T., Achdiawan, R., Angelsen, A., Babigumira, R., Ickowitz, A., Paumgarten, F., Reyes-Garcia, V. \& Shively, G. 2014. Challenging perceptions about men, women, and forest product use: a global comparative study. World Development, (64, Suppl. 1): 56-66.

Termeer, C., Dewulf, A. \& Breeman, G. 2013. Governance of wicked climate adaptation problems. In: J. Knieling and W.L. Filho (eds.) Climate Change Governance. Climate Change Management, DOI: 10.1007/978-3-642-29831-8_3, Springer-Verlag, Berlin.

UNEP. 2012. Ecosystem-based adaptation guidance. Moving from principles to practice. Working Document: April 2012. Geneva. (also available at http://www.unep.org/).

United Nations Forum on Forests (UNFF) \& Collaborative Partnership on Forests (CPF). 2018. Draft of Global Core Sets. (also available at http://www.cpfweb.org/96344/en/).

UNFCCC. 2011a. Ecosystem-based approaches to adaptation: compilation of information. Note by the secretariat. Subsidiary Body for Scientific and Technological Advice, Thirty-fifth session, Durban, 28 November to 3 December 2011, FCCC/SBSTA/2011/INF.8. (also available at www.unfccc.int/resource/docs/2011/sbsta/eng/info8.pdf).

UNFCCC. 2011b. Assessing the costs and benefits of adaptation options: An overview of approaches. UNFCCC Secretariat, Bonn. (also available at http://unfccc.int/files/adaptation/nairobi_work_programme/knowledge_resources_and_ publications/application/pdf/2011_nwp_costs_benefits_adaptation.pdf).

UNFCCC, 2015. Synthesis report on the aggregate effect of the intended nationally determined contributions. Note by the secretariat. FCCC/CP/2015/7, 30 October 2015. (also available at https://unfccc.int/resource/docs/2015/cop21/eng/07.pdf). 
UNFCCC, 2017. The 31st meeting of the Least Developed Countries Expert Group Report by the secretariat. FCCC/ $\mathrm{SBI} / 2017 / 6$.

UNFCCC, 2018. Progress, experience, best practices, lessons learned, gaps, needs and support provided and received in the process to formulate and implement national adaptation plans. Synthesis report by the secretariat. FCCC/SBI/2018/INF.1

UNISDR (United Nations International Strategy for Disaster Reduction). 2009. UNISDR terminology on disaster risk reduction. Geneva (also available at www.unisdr.org/we/inform/terminology).

USAID, 2013. Analysing climate change adaptation options using multi-criteria analysis. African and Latin American Resilience to Climate Change (ARCC). US Agency for International Development, Washington, D.C. (also available at http://www.iee.usp.br/sites/default/files/Analyzing_climate_change_adaptation_options_using_multi-criteria_ analysis_2013_0.pdf).

UNDP. 2018. Viet Nam's Climate Risk Index. http://eng.climaterisk.org.vn/

UN-Water. 2014. International Decade for Action 'Water for Life, 2005-2015'.

van Breugel, P., Friis, I., Demissew, S., Lilles $\emptyset$, J.-P.B. \& Kindt, R. 2016. Current and future fire regimes and their influence on natural vegetation in Ethiopia. Ecosystems, 19(2): 369-386.

Viggh, A., Leagnavar, P. and Bours, D. 2015. Good practice study on principles for indicator development, selection, and use in climate change adaptation monitoring and evaluation. Climate-Eval. GEF Independent Office of Evaluation, GEF, Geneva. (also available at https://www.climate-eval.org/sites/default/files/studies/Good-Practice-Study.pdf).

Vira, B., Wildburger, C. \& Mansourian, S., eds. 2015. Forests, trees and landscapes for food security and nutrition. IUFRO World Series, 33.

Watkiss, P. and Hunt, A. 2013. Method overview: Decision support methods for adaptation. Briefing Note 1. Summary of Methods and Case Study Examples from the MEDIATION Project. Funded by the EC's 7FWP. (also available at https:// mediamanager.sei.org/documents/Publications/sei-mediation-briefing1-method-overview.pdf).

World Bank. 2009. Building Response Strategies to Climate Change in Agricultural Systems in Latin America. The World Bank, Washington D.C. (also available at https://openknowledge.worldbank.org/handle/10986/12473).

World Bank. 2010a. Mainstreaming adaptation to climate change in agriculture and natural resources management projects. Guidance Note 6. The World Bank, Washington D.C.

World Bank. 2010b. Economic evaluation of climate change adaptation projects. Approaches for the agricultural sector and beyond. World Bank, Washington, D.C. (also available at https://www.preventionweb.net/files/14726_DevCC1Adaptation1.pdf).

WRI. 2018. Connecting the Dots: Elements for a Joined-Up Implementation of the 2030 Agenda and Paris Agreement

Yearworth, M. 2015. Sustainability as a "super wicked" problem; opportunities and limits for engineering methodology. In Proceedings of the 7th International Conference on Sustainable Development on Building and Environment (SuDBE). SuDBE. University of Bristol, UK. 


\section{ADDRESSINGFORESTRY ANDAGROFORESTRY, INNATIONALADAPTATIONPLANS}

\section{[ Supplementary guidelines ]}

This publication Addressing Forestry and Agroforestry in National Adaptation Plans: supplementary guidelines provides technical guidance on the integration of forests, agroforestry and trees in the formulation and implementation of NAPs. It aims to inform policy makers and government officers responsible for NAP planning and processes, as well as forestry stakeholders and other interested actors, on the needs of forestry and agroforestry for adaptation and their potential to support the adaptation of other sectors, subsectors and activities. 